Portland State University

PDXScholar

Spring 7-23-2013

\title{
An Archaeology of Capitalism: Exploring Ideology through Ceramics from the Fort Vancouver and Village Sites
}

Dana Lynn Holschuh

Portland State University

Follow this and additional works at: https://pdxscholar.library.pdx.edu/open_access_etds

Part of the Other History Commons, Other Political Science Commons, and the Social and Cultural Anthropology Commons

Let us know how access to this document benefits you.

\section{Recommended Citation}

Holschuh, Dana Lynn, "An Archaeology of Capitalism: Exploring Ideology through Ceramics from the Fort Vancouver and Village Sites" (2013). Dissertations and Theses. Paper 982.

https://doi.org/10.15760/etd.982

This Thesis is brought to you for free and open access. It has been accepted for inclusion in Dissertations and Theses by an authorized administrator of PDXScholar. Please contact us if we can make this document more accessible: pdxscholar@pdx.edu. 
An Archaeology of Capitalism: Exploring Ideology through Ceramics from the Fort

Vancouver and Village Sites

by

Dana Lynn Holschuh

A thesis submitted in partial fulfillment of the

requirements for the degree of

\author{
Master of Arts \\ in \\ Anthropology
}

Thesis Committee:

Michele R. Gamburd, Chair

Douglas C. Wilson

Kenneth M. Ames

Portland State University

2013 


\begin{abstract}
The Hudson's Bay Company (HBC), a mercantile venture that was founded by royal charter in 1670, conceived, constructed and ran Fort Vancouver as its economic center in the Pacific Northwest, a colonial outpost at the edge of the company's holdings in North America. Research into the history of the HBC revealed that the company was motivated by mercantile interests, and that Fort Vancouver operated under feudal land policies while steadily adopting a hierarchical structure.
\end{abstract}

Following the work of Marxist archaeologist Mark Leone whose work in Annapolis, Maryland explored the effects of capitalist ideology on archaeological assemblages of ceramics, this study sought to locate the material signatures of ideologies in the ceramic assemblages recovered from the Fort and its adjacent multi-ethnic Village sites. In Annapolis, matching sets of ceramics were used as a material indicator of the successful penetration of capitalist ideals of segmentation, division and standardization that accompanied the carefully cultivated ideology of individualism, into working class households.

Following this model, this study analyzed six assemblages for the presence of matched sets of ceramic tablewares using the diversity measures of richness and evenness. The results of this analysis for five assemblages from households in the Village were then compared to those expected for a model assemblage that was inferred to represent the ultimate model of participation in and dissemination of the same ideals of segmentation and division: that recovered from the Chief Factor's House within the fort. 
Documentary research confirmed that ideology was used to indoctrinate workers into the unique relations of production at Fort Vancouver however it was an ideology of paternal allegiance to the company rather than one of possessive individualism, as in Annapolis. At Fort Vancouver the notion of individuality was subtly downplayed in favor of one that addressed the company's responsibility to its workers and encouraged them to view its hierarchy, which was reinforced spatially, socially and economically, as natural. Analysis of the archaeological assemblages revealed that it is unlikely that the Village assemblages are comprised of complete sets of matching ceramicwares. The lack of these sets is likely the result of the multivalent nature of the economic system at the fort and its distinct ideology of paternalism, as well as the diverse backgrounds and outlooks of the Village occupants themselves, who appear to have purchased and used these European ceramics in unique ways. 


\section{Acknowledgements}

To my committee: Thank you for helping me design and implement this project, for all the instructive feedback and for always challenging me to always take things a step further. I have been truly inspired by and feel lucky to have worked with you all.

To my professors at Portland State University: Thank you for giving me the tools to conduct this research, and the inspiration to follow it through to completion.

To Connie Cash: Thank you for everything you have done to help me get here!

To my boss, Alex Gall: You have seen me through every step of the way, from studying GRE vocabulary in our excavation units to the final days of editing. Thank you for your patience, encouragement and flexibility throughout this process.

To all my friends and mentors at Fort Vancouver National Historic Site: I am grateful for all the advice, support and kindness I have received from you all. I feel truly lucky to have received so many opportunities to work and to learn as a part of this remarkable community and place.

To my fellow students at PSU: Thank you for challenging me to become a better archaeologist, for all the late nights, all the theory arguments, all the words of encouragement, and all the humor and empathy.

To Kristen, Annie and Angie: Thank you for being my Portland family and getting me through these years.

To my family: Thank you for your love and encouragement, and for always believing in me, even when I didn't believe in myself. 


\section{Table of Contents}

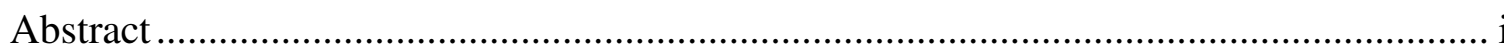

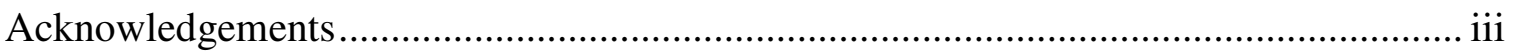

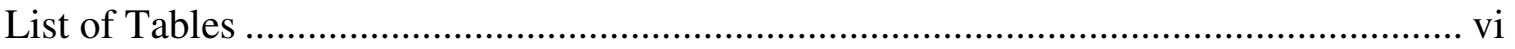

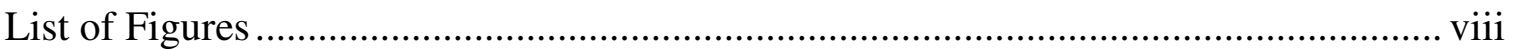

CHAPTER I: INTRODUCTION .........................................................................

CHAPTER II: HISTORICAL CONTEXT .................................................................

Establishment and Early Growth of the Hudson's Bay Company....................................5

Competition in the North American Fur Trade............................................................8

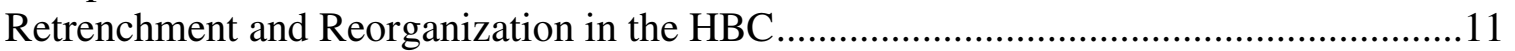

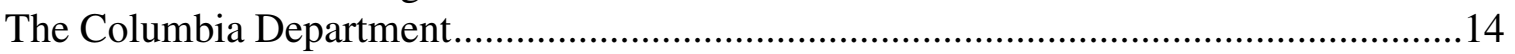

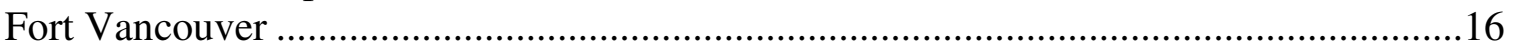

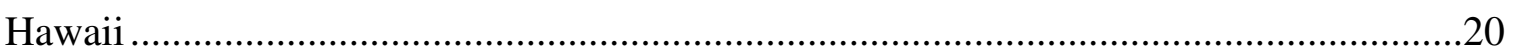

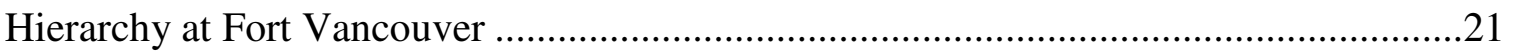

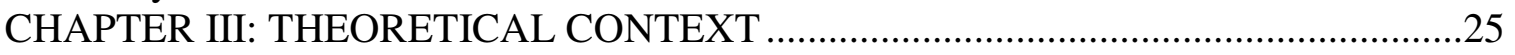

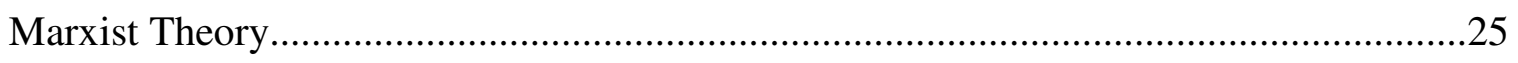

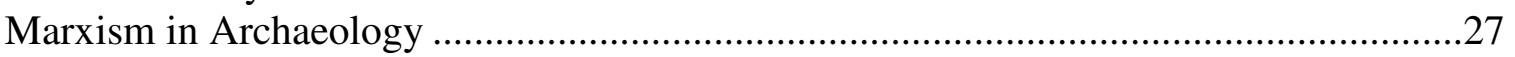

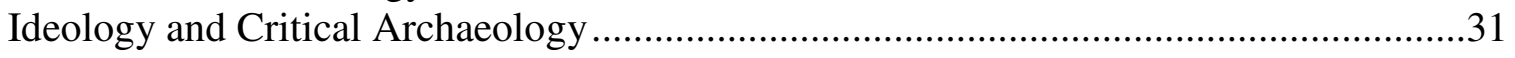

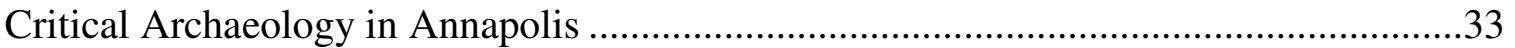

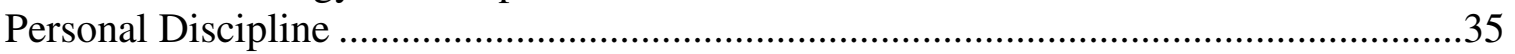

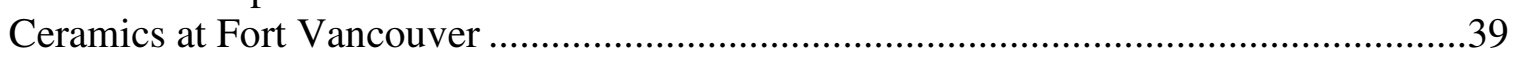

CHAPTER IV: MATERIALS AND METHODS .......................................................43

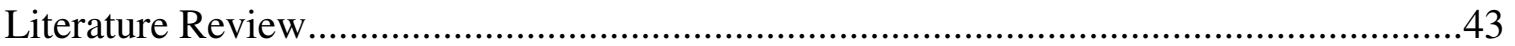

Measures of Archaeological Diversity: Richness and Evenness .....................................44

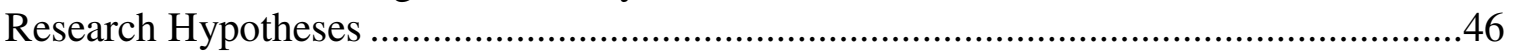

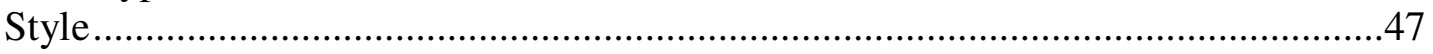

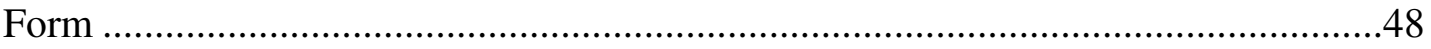

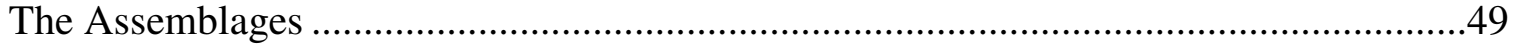

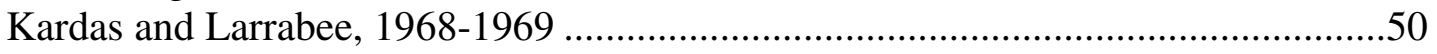

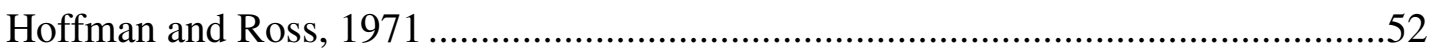

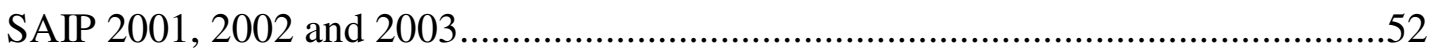

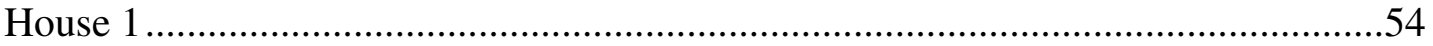

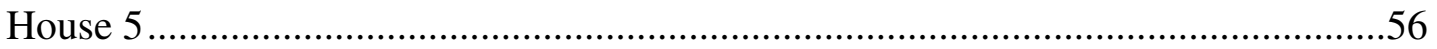

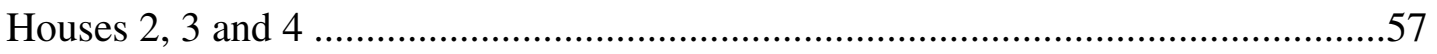

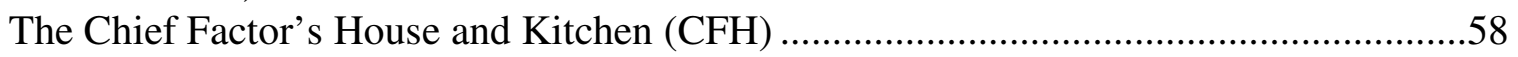

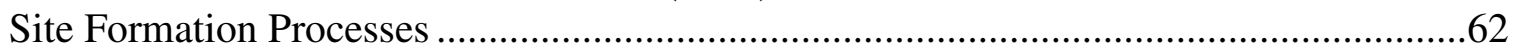

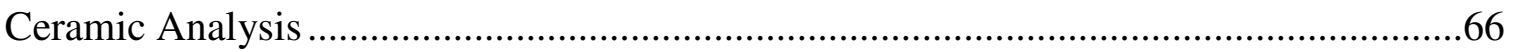

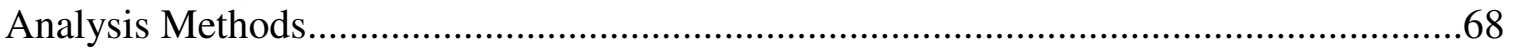

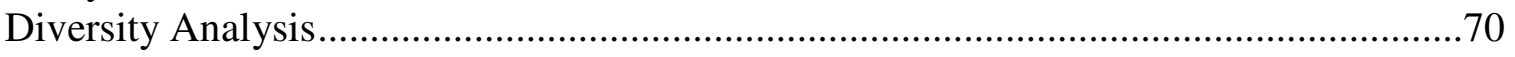

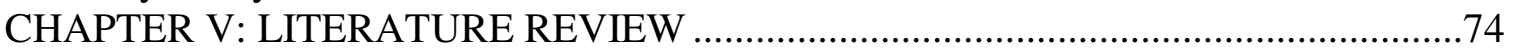




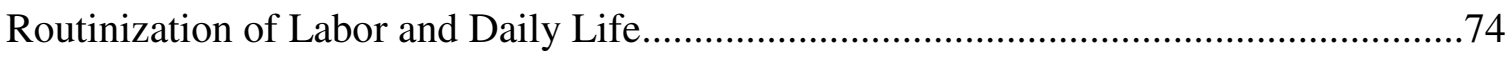

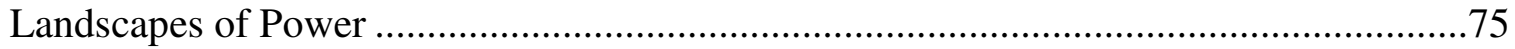

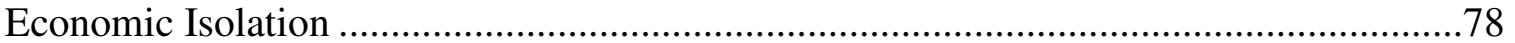

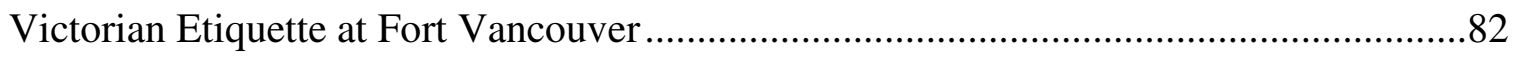

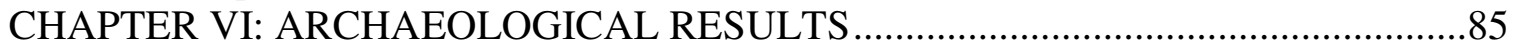

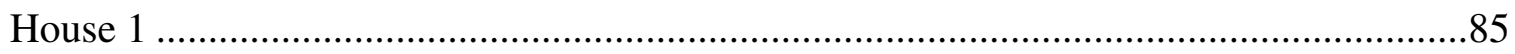

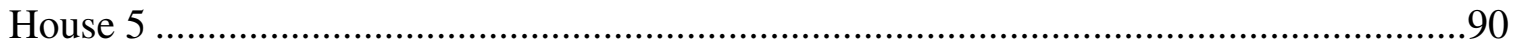

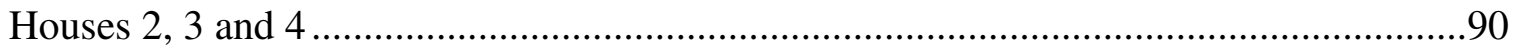

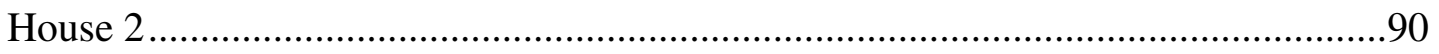

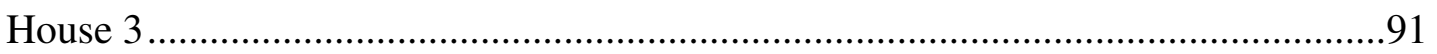

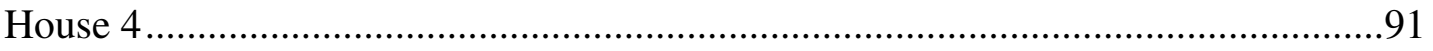

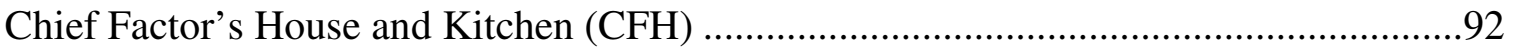

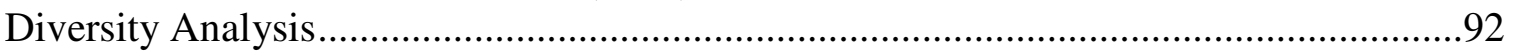

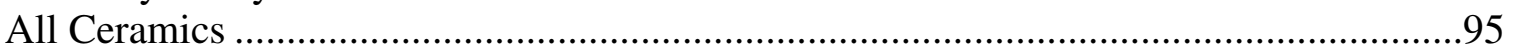

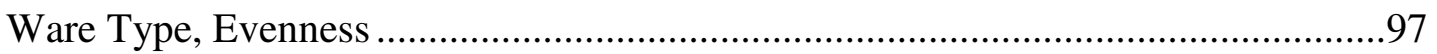

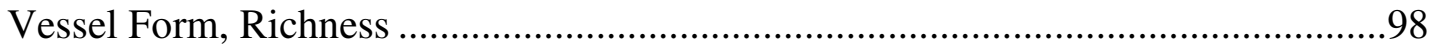

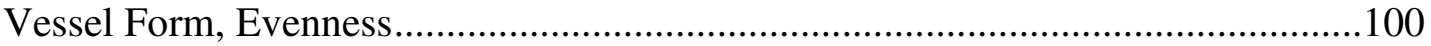

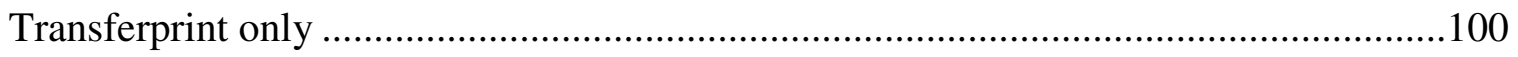

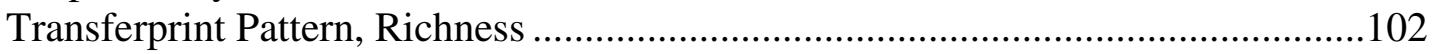

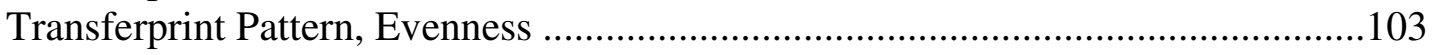

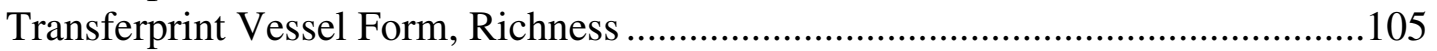

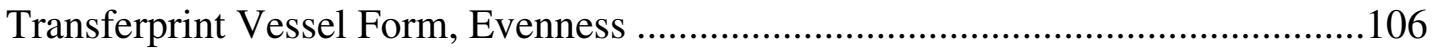

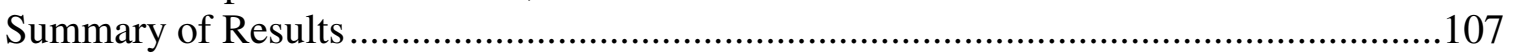

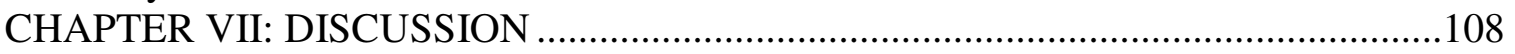

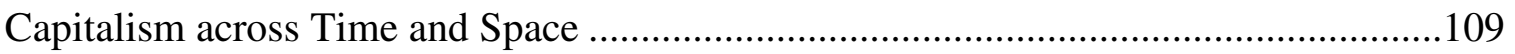

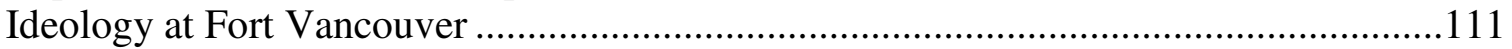

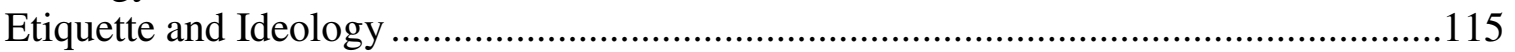

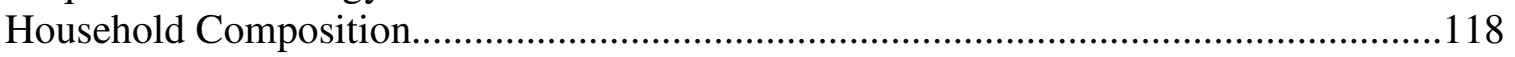

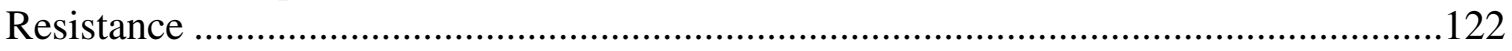

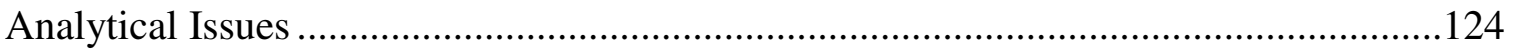

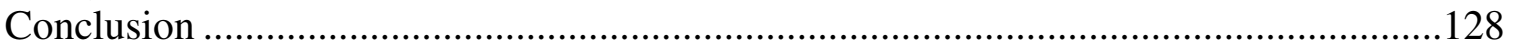

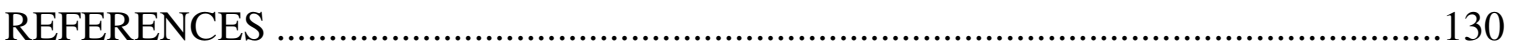




\section{List of Tables}

TABLE 1

SHERD COUNTS AND MINIMUM NUMBER OF VESSEL (MNV) COUNTS FOR

EACH OF THE VILLAGE ASSEMBLAGES AND THE CFH.

TABLE 2

GENERALIZED PAY SCALE OF FORT VANCOUVER/HBC EMPLOYEES, CA. 1829-1860, BY COMPANY CLASS AND JOB RANK (HBCA B.223/D/162; MORRISON

1999; CROMWELL 2006: 126)

TABLE 3

PERCENT INCREASE IN THE COST OF GOODS AT FORT VANCOUVER, BASED

UPON SOCIAL CLASS AND ETHNICITY, CA.1829-1860 (CROMWELL 2006: 128) ... 81

TABLE 4

WARE TYPES IN ASSEMBALGES FROM HOUSES 1-5 (VILLAGE) AND THE CFH

(FORT)

TABLE 5

VESSEL FORMS IN ASSEMBLAGES FROM HOUSES 1-5 (VILLAGE) AND THE

CFH (FORT)

TABLE 6

TRANSFERPRINT PATTERNS INDENTIFIED IN ASSEMBLAGES FROM HOUSES 1-5 (VILLAGE) AND THE CFH (FORT), CONTINUED ON THE FOLLOWING PAGE

TABLE 7

RICHNESS VALUES FOR WARE TYPE OF VILLAGE HOUSES 95

TABLE 8

EVENNESS VALUES FOR WARE TYPE.

TABLE 9

RICHNESS VALUES FOR VESSEL FORM . 98

TABLE 10

EVENNESS VALUES FOR VESSEL FORM 100

TABLE 11

RICHNESS VALUES FOR TRANFERPRINT PATTERN. 102 
TABLE 12

EVENNESS VALUES FOR TRANSFERPRINT PATTERN ……………………….... 103

TABLE 13

RICHNESS VALUES FOR TRANSFERPRINT VESSEL FORM................................ 105

TABLE 14

EVENNESS VALUES FOR TRANSFERPRINT VESSEL FORM................................. 105 


\section{List of Figures}

FIGURE 1. PROJECT AREA LOCATION MAP SHOWING FORT VANCOUVER NHS, THE NPSADMINISTERED PORTION OF THE VILLAGE, AND THE ENCOMPASSING VANCOUVER NATIONAL Historic ReSERVE (MulLALEy 2011).

FIGURE 2. HOLDINGS OF THE HUDSON'S BAY COMPANY, INCLUDING THE COLUMBIA DEPARTMENT AND ForT VANCOUVER (CENTER FOR THE STUDY OF THE PACIFIC NORTHWEST, UNIVERSITY OF WASHINGTON)

FIGURE 3. HYPOTHESIZED ORGANIZATIONAL HIERARCHY FOR THE HBC BETWEEN CA. 1825-1860 (Following BALLANTYNE 1972; RICH 1959; Ross 1976 AND CROMWELL 2006)

FIGURE 4. AERIAL PHOTOMAP OF THE WESTERN EXTENT OF THE VILLAGE SITE, SHOWING HOUSES 1-5 EXCAVATIONS (WYNIA 2013)

FIGURE 5. AERIAL PHOTOMAP SHOWING THE HOUSE 1, 2 AND 3 EXCAVATIONS (WYNIA 2013) 55

FIGURE 6. AERIAL PHOTOMAP SHOWING THE HOUSE 5 EXCAVATIONS (WYNIA 2013)... 57

FIGURE 7. AERIAL PHOTOMAP SHOWING THE HOUSE 4 EXCAVATIONS (WYNIA 2013) .... 58

FIGURE 8. CHIEF FACTOR'S HOUSE AND KITCHEN EXCAVATION UNITS; CERAMICS RECOVERED FROM THE UNITS IN RED WERE PREVIOUSLY ANALYZED BY DR. CROMWELL AND ARE USED IN THE CURRENT ANALYSIS (HOFFMAN AND ROSS 1972; AUTHOR 2013)... 61

FIGURE 9. PLAN VIEW SHOWING THE LOCATION OF EARLY 20TH CENTURY U.S. ARMY BUILDINGS AT

FIGURE 10. EXAMPLES OF SPODE CERAMICS REPRESENTING VARIOUS PATTERNS AND VESSEL FORMS, RECOVERED ARCHAEOLOGICALLY FROM EXCAVATIONS AT FORT VANCOUVER NATIONAL Historic Site (NPS STOCK IMAGE)

FIGURE 11. SCATTER PLOT OF THE RICHNESS VALUES FOR WARE TYPE MAPPED ONTO THOSE EXPECTED FOR THE CFH

FIGURE 12. SCATTER PLOT OF EVENNESS VALUES FOR WARE TYPE, MAPPED ONTO THOSE EXPECTED FOR THE CFH

FIGURE 13. SCATTER PLOT OF RICHNESS VALUES FOR VESSEL FORM, MAPPED ONTO THOSE 
FIGURE 14. SCATTER PLOT OF EVENNESS VALUES FOR VESSEL FORM, MAPPED ONTO THOSE

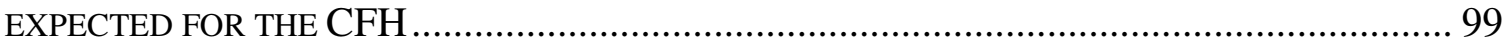

FIGURE 15. SCATTER PLOT OF RICHNESS VALUES FOR TRANSFERPRINT PATTERN, MAPPED ONTO THOSE EXPECTED FOR THE CFH …................................................................ 101

FIGURE 16. SCATTER PLOT OF EVENNESS VALUES FOR TRANSFERPRINT PATTERN, MAPPED

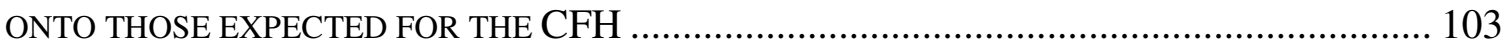

FIGURE17. SCATTER PLOT OF RICHNESS VALUES FOR TRANSFERPRINT VESSEL FORM,

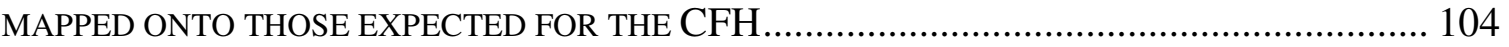

FIGURE 18. SCATTER PLOT OF EVENNESS VALUES FOR TRANSFERPRINT VESSEL FORM, MAPPED ONTO THOSE EXPECTED FOR THE CFH...................................................... 106 


\section{CHAPTER I: INTRODUCTION}

The discipline of historical archaeology has become increasingly concerned with the archaeology of capitalism. There are many variations of capitalism, which differ in their institutional makeup and economic policies, but all capitalist modes of production are structured upon the accumulation of capital and the production of goods and services for profit. Marxist archaeology is specifically interested in the ways that material culture is used in the production and reproduction of reality in capitalist sites. Scholars around the world have used Marxist archaeology as an analytical framework to explore the role of material culture in the production and reproduction of reality in capitalist systems, in order to perpetuate the system. This includes mechanisms of control such as the dissemination of ideology, which prevents workers from seeing their true position at the bottom of the hierarchy. Ideology, in the sense used here, refers to a distortion of thought that obscured the inequalities inherent in capitalism and promoted the acceptance and active replication of concepts such as etiquette, segmentation and division, as will be explored below.

In the mid-nineteenth century Fort Vancouver was a strategic outpost of corporate capitalism: conceived, constructed and run as the economic center of the Hudson Bay Company's (HBC) business on the Northwestern frontier of North America. The situation at Fort Vancouver was more complicated than simple capitalism however. The HBC was driven by mercantile and colonial politics, it assumed a feudal position in land holding policies, and ultimately adopted the structure of a corporate capitalist entity. Established 
as both a supply depot for the company's operations in North America, and a strategic British foothold in the Northwest, the fort and its adjacent workers' Village offered appealing locations for the examination of capitalist ideologies, and the ways they were manifested in the archaeological record.

One of the most important loci of Marxist archaeology in North America is Annapolis, Maryland where Marxist archaeologists, including Mark Leone undertook a comprehensive exploration of capitalist ideology in the colonial city, using various avenues of exploration including landscape design and city planning, printed materials and ceramic tablewares (Leone 2005). This project built on his work, seeking many of the same archaeological signatures of ideology in the material record from Fort Vancouver and the Village. The material record of both the Fort and Village sites are dominated by English manufactured goods, particularly ceramicwares. It was the intention of this thesis to translate Leone's methods of Marxist archaeological interpretation of ceramics in Annapolis to those from the Fort and Village sites.

There were many goals of this project, the most fundamental of which was to provide a more fully documented past for the inhabitants of the Village site by exploring the ways in which their realities were shaped by capitalism. Historical documents can be incomplete, inaccurate, and biased, especially for the inhabitants of the Village, who were largely illiterate and left no written record. Archaeological investigation based on the material remains of these people, rather than accounts of others, is a valuable tool for gaining an understanding of the lives of the working class who are generally missing 
from the historical record. In addition, this study sought to add the analysis of two previously unanalyzed ceramic assemblages (Houses 1 and 5) to the already prodigious amount of archaeological information gleaned from the Village site. Finally, this study sought to locate the ideology that sustained capitalism at Fort Vancouver, and to gauge the degree to which this ideology affected the material reality of the Village and Fort inhabitants.

This thesis presents the theoretical framework and analytical methods used to accomplish these goals. It begins with an examination of the history of the Hudson's Bay Company and the policies that guided it during its establishment and expansion in the $17^{\text {th }}$ and $18^{\text {th }}$ centuries. It then provides the theoretical context for the current study, including a discussion of the model developed in Annapolis, on which this work is based. Next it presents the methodologies that shaped the scope and extent of the project. These methods include both documentary research into the capitalist policies and ideologies at work at Fort Vancouver, and the analysis of ceramic assemblages recovered from various loci within the Village, as well as their comparison with ceramics from the Chief Factor's House and Kitchen site. 


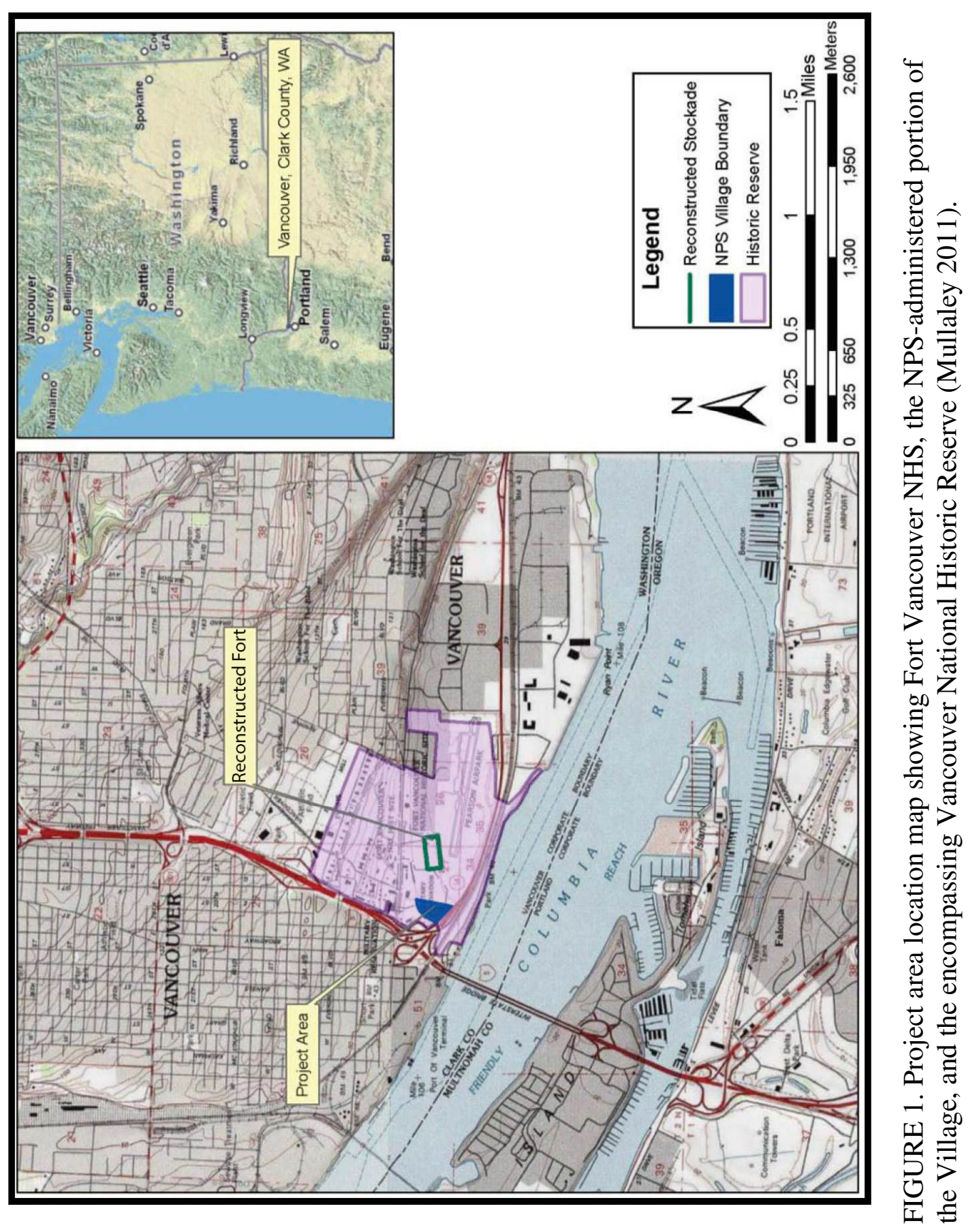




\section{CHAPTER II: HISTORICAL CONTEXT}

This chapter is concerned with the history and motivations of the Hudson's Bay Company (HBC) from its inception through the mid-19 $9^{\text {th }}$ century. It presents a review of the literature relating to the history of the Company and its role in the North American land-based fur trade, focusing specifically on the economic and political motivations behind the Company's establishment of Fort Vancouver and the organization of labor and social hierarchy there. The HBC was established as a mercantile enterprise, which extracted raw materials in the form of beaver pelts from North America in order to feed demand for felted beaver fur hats on the markets of England and Europe. Over its history the company's mode of production evolved into a mix of mercantile and corporate capitalism with vestiges of the feudal system that supported its inception. The company's unique brand of capitalism fueled colonial expansion as it established forts increasingly further afield, resulting in a mixed economic system at Fort Vancouver that combined

different aspects of various modes of productions. Fort Vancouver in the mid- $19^{\text {th }}$ century represented a unique, frontier branch of the global system of capitalism in which the HBC operated, and incorporated some of the relations of feudal land holding, the political dynamics of colonialism, and the differential class structure common of both mercantile and corporate capitalism.

\section{Establishment and Early Growth of the Hudson's Bay Company}

The Hudson's Bay Company came into being during a period of dramatic economic development when joint-stock and chartered trading companies first appeared 
in Europe (Bryce 1968; Carlos and Nicholas 1988). While royally chartered companies had been an accepted trading structure for more than a century, it was during the 16th and 17th centuries that their form became more rigid, including monopoly privileges as well as imperial powers under the blessing of the Crown (Mackay 1938: 37). The founding of the Hudson's Bay Company was instigated by Pierre Espirit Radisson and Medard Chouart, the Sieur de Grosseillers (Bryce 1968), two French adventurers who recognized the advantage of exploiting the luxurious furs available in North America to feed high demand on European markets. Furs, especially beaver pelts, were felted and made into large hats, fashionable as status symbols in 17th-century England (Schenk 1932; Bryce 1968; Morrison 1999). Radisson and Groseillers eventually attracted the interest of Prince Rupert, the cousin of King Charles, as well as a handful of other financial backers, eager to profit from furs in British North America (Schenk 1932; Bryce 1968; Morrison 1999).

King Charles granted the company a royal charter on May 2nd, 1670, establishing the company as both a profitable trading enterprise, and as a means to gain a political foothold for Britain in North America by
“...the Discovery of a new Passage into the South Sea, and for the finding some Trade for Furs, Minerals, and other considerable Commodities....by means whereof there may probably arise very great Advantage to Us and Our Kingdom" (sic, HBCA 1670).

Finding a passage through the continent to the Pacific would effectively open the Oriental markets to the fur trade and create a vast British territory across the northern hemisphere, which could be translated into diplomatic power as the HBC pushed further inland, making England a world entrepôt (Mackay 1938; Carlos and Nicholas 1990: 853). The 
charter also outlined the foundation of what would become the executive hierarchy of the HBC, establishing Prince Rupert as its first Governor, and granting him complete control and authority over all decisions made by the company both in England and North America. Below the Governor was the London Committee; made up of a Deputy Governor, Secretary and board members who were also shareholders, the London Committee was responsible for creating and implementing policy throughout the HBC's holdings.

The royal charter granted the company monopoly privileges to the North American fur trade, free from British competition within all the land surrounding Hudson's Bay and all of its tributaries, the full extent and financial promise of which were not yet fully understood (Schenk 1932: 2; Williams 1970). In North America, control over company affairs was vested in a Governor-in-Chief, to whom the head agents or "factors" of each of the company's business establishment, or "factory" reported. The newly formed company established a few factories around Hudson's Bay, each of which was managed by a Chief Factor who carried out trade with Native Americans, who brought furs to the fort annually to barter for manufactured goods such as knives, kettles, beads and blankets (Williams 1970). The Chief Factor also managed the day-to-day operations and oversaw the workers, or Servants at these factories (Mackay 1938: 47; Bryce 1968; Carlos and Nicholas 1988).

Throughout its early years, the company operated as an extractive mercantile enterprise, bartering with Native Americans for the peltry and other goods they provided 
that were then processed and bundled at the factories and sent to meet the market demand for these products in England. Control over its workforce was a central concern for the company, which always hired a proportion of its employees on long-term contracts that tied them to it in a master-servant relationship. The company never ceased to believe that men from pre-industrial societies were the most desirable as Servants because they were accustomed to subordination (Burley 1997).

The HBC sent large returns to their shareholders in London throughout the 1700s, however by the late $18^{\text {th }}$ century competition and overhunting of beaver populations forced the company to expand into the interior, eventually establishing a chain of forts along the river network surrounding Hudson's Bay. Early traders attempted to create a market and demand for many products that were plentiful in North America, speculating on any product that might make a profit, including bed feathers, whale fins, goose quills, deer horns, fish and whale oil and walrus tusks (Mackay 1938; Hammond 1993).

\section{Competition in the North American Fur Trade}

The long history of the HBC's rivalry for control of the North American fur trade demonstrates the Company's commitment to profit maximization and imperial maneuvering. For most of its history, the North American fur trade industry had two distinct branches: the HBC controlled the branch operating from London through Hudson's Bay, while the French controlled the St. Lawrence Basin, operating out of Montreal until 1764, when it was operated by a decreasing number of British and Scottish firms (Carlos 1981). The HBC's operations spanned two continents, resulting in a 
tremendous time lag between the issuance of orders in England or in Europe and the appearance of commodities from afar; turnaround time could take as long as eighteen months or two and a half years. This distance complicated the Company's internal structure, and created problems of control that opened the door to almost continuous competition from rival French and later American fur-traders (Williams 1970; Carlos and Nicholas 1990).

The HBC faced its most persistent competition from the Northwest Company. French-Canadian fur traders, or "pedlars", backed by Montreal merchants or their own capitol, had been taking canoes to buy furs from Natives in the west for years. During the American Revolutionary War, a group of Montreal pedlars banded together and, under the name of The Northwest Company, they established a base on Lake Superior in the early $19^{\text {th }}$ century, from which they brought in supplies and carried out furs by canoe, saving the long trek to the company's headquarters in Montreal (Morrison 1999). The Northwest Company (NWC) became the main rival of the Hudson's Bay Company throughout the 18th and 19th centuries, and from 1804 to 1821 the Hudson's Bay Company and the NWC existed as a duopoly in the North American fur trade. Not only were these two companies the sole buyers of furs, operating in the same North American market area, they were also the most important sellers of furs on the British market (Carlos and Hoffman 1986: 968).

Differences between the NWC and the Hudson's Bay Company stemmed largely from their corporate structures. While both were joint-stock companies, the HBC 
operated in a strict top-down hierarchy, and the NWC was a partnership with each partner, whether wealthy Montreal merchants or "wintering partners," who went out to trade with the Indians, fully liable for the debts of the whole (Carlos 1981; Carlos and Hoffman 1986; Morrison 1999). Wintering partners were shareholders who were on profit-sharing rather than wage contracts. Thus, they were individually motivated to further the company's profits (Carlos and Hoffman 1986: 970). In comparison, the Hudson's Bay Company had a more rigid, formal structure in which policy was directed by a remote, overseas committee (Carlos 1981). The Northwest Company also enjoyed the advantages of a North American-based headquarters in Montreal and the expertise of their highly experienced field personnel, the Nor'westers who were intimately familiar with frontier North America. Additionally, the NWC sent their partners out into the wilderness to trade instead of relying on the Natives to travel to stationary forts or factories like the HBC. The Northwest Company offered aggressive competition to the HBC, establishing posts increasingly further west.

Competition in the Northwest came from many sources. Four nations were vying for control of the fur trade on the Northwest Coast, including Russia, Spain, Britain and America (Morrison 1999). Of particular importance to the history of the HBC and Fort Vancouver is the Pacific Fur Company, a subsidiary of the American Fur Company, founded by John Jacob Astor in 1808. The Pacific Fur Company operated in the Pacific Northwest out of Fort Astoria, a trade outpost and regional distribution center established by Astor at the mouth of the Columbia River in 1811 (Hussey 1957; Cromwell 2006). 
There were other factors affecting the HBC's accumulation of profits; by the beginning of the 19th century, European market behavior was causing a steady decline in profits from the fur trade. Beaver hats had been replaced by silk, and the Napoleonic wars cut the numbers of furs exported from Great Britain to Europe (Carlos 1981). Thus, by the 1809-1810 annual round, the HBC was facing its worst financial crisis to date. The rigidity of the company worked against it, as it was subject to war-induced price inflation on goods while the Northwest Company, with their ability to change their prices to suit demand, did not face as great a crisis. In order to ensure profit maximization, and the retention of its political position in North America, the HBC undertook a complete reorganization of its management and trading methods, known as retrenchment (Carlos 1981).

\section{Retrenchment and Reorganization in the $\mathrm{HBC}$}

The aim of retrenchment was to save the company by increasing its market share and forcing the Northwest Company to accept a change in market share distribution (Carlos and Hoffman 1986: 980). Retrenchment introduced a new orderliness to the HBC's organization and its records, and clarified the distinction between officers and servants by solidifying the Company's executive hierarchy (Carlos 1981; Burley 1997). At its highest levels the $\mathrm{HBC}$ remained as it had under the charter. Central control was vested in a Governor, a Deputy Governor, and the Honorable Committee in London (Hussey 1957: 11). The HBC's highest North American officers were the Commissioned Officers or Gentlemen, including the Chief Factors and Chief Traders for each post, all of 
whom were now placed on a profit-sharing scheme (Carlos 1981; Burley 1997; Morrison 1999).

Whereas prior to the retrenchment system, each factory operated on its own, after retrenchment, the HBC's holdings were divided into the Northern and Southern Departments. Each factory was assigned an accountant to make accurate reports of company business holdings each year and by 1811 new accounting systems had been put into place and all Chief Factors and district masters were required to keep journals, with maps and sketches, describing the state of their districts and their trade (Carlos and Hoffman 1986; Burley 1997). This policy had the dual result of extending the company's chain of command from London onto the ground in North America, linking each individual outpost to the superintendent and then to the committee, while at the same time offering the managerial class a more thorough and businesslike knowledge of company operations (Carlos 1981; Burley 1997). The new policies demanded an Officer class, mainly comprised of clerks, who could keep the books of account and write all letters, reports and journals required at various posts as part of the Gentlemen class. Neart the top of the North American hierarchy, clerks and apprentice clerks were paid salaries rather than shares in company profits, and saw some room for advancement in the company's ranks (Brown 1943; Burley 1997: 48). The creation of this middle class sharpened the distinction between Officers and Servants within the HBC's ranks by requiring of the former, skills that the latter rarely possessed and increasing the distance between the Committee and the Servants (Burley 1997). 
Servants of the company, including engagés, interpreters, guides, and various tradesmen and laborers including carpenters, blacksmiths, coopers, tinsmiths, millwrights, ship's carpenters and gunsmiths were relegated even further to the bottom of the hierarchy following the interposition of this middle class of clerks (Brown 1943; Hussey 1957; Cromwell 2006). Those that were classed as Servants carried out the heaviest tasks, work that no Gentleman would be required to do, and were expected to do as they were told (Burley 1997). The Servant class had its own organizational hierarchy based on wage, ethnicity and occupation, which will be discussed in greater detail below in Chapter V.

The strengthening of the HBC's internal hierarchy readied the company for a period of ruthless competition and bargaining with the Northwest Company, which had effectively taken control of the fur trade in the far west after purchasing Fort Astoria (renamed Fort George) from the Pacific Fur Company in 1813 (Williams 1970; Carlos 1981; Carlos and Hoffman 1986; Mackie 1997; Morrison 1999; Cromwell 2006: 104). The HBC moved into the western extremes of its territory in order to maintain some control of the limits of their charter-granted lands, to compete directly with Northwest Company traders and to profit from this previously under-exploited region.

After a prolonged period of increasingly competitive negotiations, papers were signed uniting the Northwest Company with the Hudson's Bay Company on March 26th, 1821 (Morrison 1999). The agreement specified that each company would provide an equal share of capital and that trade was to be carried on under the name and charter of 
the HBC. The new company was a financial survivor of the competitive era: British, well-capitalized, and holding a 'vast command of capital' (Carlos and Hoffman 1986; Mackie 1997: 30). It represented a powerful combination of the old HBC name, charter and monopoly privileges along with the experienced field personnel of the Northwest Company.

\section{The Columbia Department}

After the merger, the HBC partitioned British America into departments, including the Columbia Department which consisted of the valley of the Columbia River, and after 1825: the Canadian Pacific slope called New Caledonia (Mackay 1938: 159). George Simpson, the epitome of the new type of officer at the top of the HBC hierarchy, was appointed Governor of the Columbia Department (Hussey 1957). Recruited from outside, and promoted over the heads of older, experienced men, Simpson characterized the HBC's ideals, dedicating his career to eradicating inefficiency within the company in order to better maximize profit and maintain a British presence in the North American fur trade and beyond (Burley 1997). The history of the Columbia Department under the governance of George Simpson illustrates the company's commitment to profit making and maintaining its imperial holdings (Hussey 1957; Burley 1997).

At the time of its acquisition the Columbia Department was not profitable as a locus of fur trade, but was used by the HBC as a strategic holding, maintained through a policy of active competition and over-hunting in order to discourage opponents drawn to the fur-rich New Caledonia Department to the north (Galbraith 1957). The Columbia 
Department was an important political foothold in the battle between Spain, England, Russia and America, all of whom were vying for control of the Columbia River, the largest entryway to the Pacific on the Northwest Coast between San Francisco Bay, under Spanish (and later Mexican) control in the mid- $19^{\text {th }}$ century, and Puget Sound, in disputed territory (Morrison 1999). Simpson contended that without securing the Columbia, the HBC would be "forced to abandon their trade in some parts and probably to relinquish it on the west side of the Rocky Mountains altogether" (Galbraith 1957: 185).

The treaty of 1818 between the U.S. and Britain had established joint occupancy of the area between California and Russian America, leaving sovereignty undefined and settlement open to citizens of both states. The boundary between the U.S. and Canada was in dispute with the British favoring the Columbia River, and the Americans the 54th parallel. Either line would give the U.S. the south bank of the Columbia, where Fort George, now a HBC post after the merger, was located (Schenk 1932; Morrison 1999). By establishing a post on the north side of the Columbia, the HBC ensured both a British presence on the river and control over the land to its north once a boundary settlement was reached. Finally, in addition to its importance as a fur trade outpost and political holding, Simpson's correspondence with London after the merger shows his belief that the Columbia might be made to support itself, and greatly reduce the costs of importing goods to support the company (Hussey 1957: 15). The vision of a fur trade that was more self-sustaining inspired the establishment of Fort Vancouver in its current location. 


\section{Fort Vancouver}

In 1825 the HBC shifted its headquarters from Fort George to Fort Vancouver, which under the control of Chief Factor John McLoughlin, eventually grew to become the economic focus of the company's presence in the Northwest. Establishing this post on the north bank of the Columbia offered the HBC opportunities "to protect New Caledonia's fur trade, to maintain a British mercantile presence on the northern Pacific coast, to keep the Russians well to the north, to confront American traders in the southern interior and on the Northwest Coast, and to find new exports to Pacific markets" (Mackie 1997: 39). With the establishment of Fort Vancouver the tide of commerce moved away from coastal Fort George and the diminishing fur and Indian trades, and toward permanent and stable agricultural development (Schenk 1932; Hammond 1993). The move was motivated by the desire to decrease reliance on costly imports and the choice of location was influenced by the good soil and a long growing season on the Columbia, important to the cultivation of crops and livestock (Gailbraith 1957). In addition to financial incentive for the move, Fort Vancouver's location offered political advantages as well. It provided opportunities “to protect New Caledonia's fur trade, to maintain a British mercantile presence on the northern Pacific coast, to keep the Russians well to the north, to confront American traders in the southern interior and on the Northwest Coast, and to find new exports to Pacific markets" (Mackie 1997: 39). Unlike previous forts in the area, Fort Vancouver was specifically planned to become a permanent, selfsupporting settlement of the fur trade, and it developed into an agricultural center which 
produced its own beef, pork, mutton, cereals, fruits, and vegetables as well as supplies for Company vessels and other posts (Kardas 1971: 4).

The original Fort Vancouver was built in a defensible position on a bluff above the Columbia, but after the river failed to flood, and the Natives proved they were not hostile, the first of the company's many farms in the Northwest was established at Fort Vancouver's current location at Bellevue point (Schenk 1932; Hussey 1957; Morrison 1999). The HBC applied its commercial strategies to the local resources, labor supplies and available markets the Columbia offered with impressive results. Because it possessed the only adequate supplies of seed and farm animals, the HBC controlled the economic life of the Oregon country through its post at Fort Vancouver for many years, eventually developing a substantial provision trade in agricultural produce from farms along the Lower Columbia, which provided beef and pork as well as staple crops such as corn, oats, peas, potatoes, rice and wheat (Hussey 1957; Mackie 1997).

The fort operated under a mixed economy, with a feudal system of land holding and a capitalist labor structure. Marx defined feudalism as the economic system that came before the rise of capitalism, wherein the power of the ruling class rested on their control of arable land, leading to a class society based upon the exploitation of the peasants who farm these lands (Bloch 1961: 100). This was certainly the situation at Fort Vancouver, as the Hudson's Bay Company and their committee in London controlled the lands on which crops were grown and other resources were cultivated and harvested. However, in addition to this demi-feudalist system of land holding, the workers at the fort were 
engaged in the sale of their labor to the company to produce capital for export, while earning a wage, rations and the right to live in the Village.

By the mid-1800s, Fort Vancouver had become the basis for many industries in the Northwest, including lumber, salmon processing, and brewing (Hussey 1957; McKie 1981). It was both a self-sufficient supply depot for the vast Columbia Department, with upwards of 1200 acres under cultivation, and the center of social and cultural life in the Oregon Territory, housing the first school, library, theater and some of the earliest churches in the northwest (Hussey 1957; McKie 1981). At Fort Vancouver the HBC applied its commercial strategies to the local resources, labor supplies and available markets in order to take advantage of the possibility of bringing other articles as well as peltries to a profitable market on the Pacific (Mackie 1997: xx). 


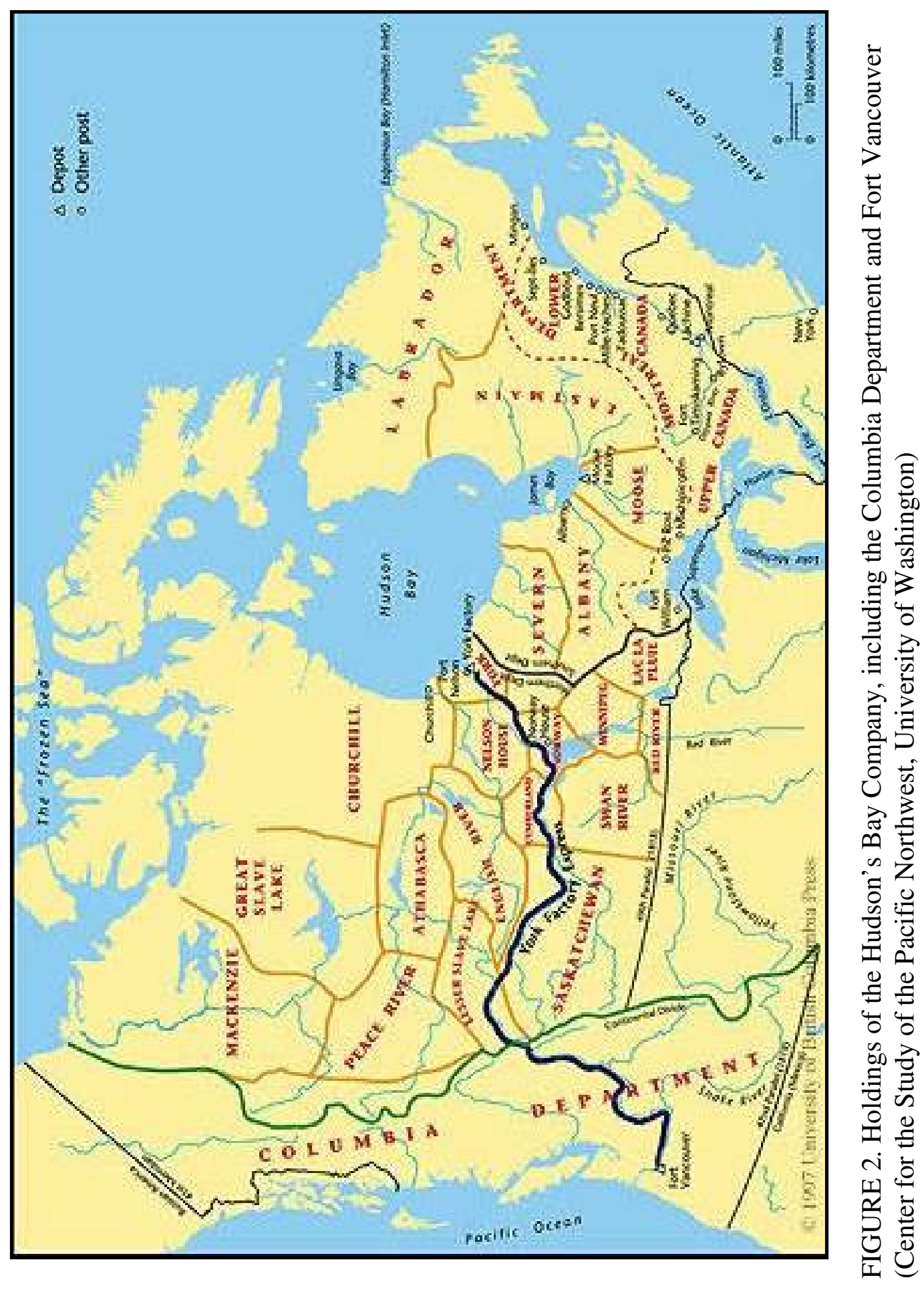




\section{Hawaii}

Access to the lucrative Asian market was a major incentive for establishing a post on the Columbia, however Simpson had to abandon the goal of marketing Columbia Department furs in China after being blocked by the East India Company, which had its own charter-backed monopoly, and allowed the HBC to sell skins in Asia but not transport goods back to North America in exchange (Morrison 1999). Simpson and McLoughlin looked for other avenues for company profit through the export market, eventually appointing an HBC agent in the Sandwich (Hawaiian) Islands in 1828. An HBC agency was established on Oahu in 1833 (Morrison 1999; Barman and Watson 2006). The Hawaiian market effectively took the place of Canton in the company's transPacific ambitions and by 1843, sales of salmon, lumber, and other goods at Oahu and other Pacific markets, including Yerba Buena (San Francisco) contributed materially to departmental profit (Galbraith 1957; Mackie 1997).

In addition to the market benefits of the Sandwich Islands, Hawaii became an important and valuable source of labor for the company in the Northwest. Eventually about one third of the labor force at Fort Vancouver consisted of native men from the Sandwich Islands, called Kanakas after the traditional Hawaiian word for person (Burley 1997; Barman and Watson 2006; Cromwell 2006). Historical and ethnographic sources reveal only that the Hawaiians were young men who signed up as general laborers in Honolulu and were transported to posts on the Columbia River (Kardas 1971: 104). Historic accounts variously refer to Hawaiians in the Northwest as Kanakas, Owyhees or 
Sandwich Islanders (Schenk 1932; Kardas 1971; Morrison 1999; Cromwell 2006), who came to occupy an important position in the Fort Vancouver hierarchy of labor, which is discussed in detail below.

\section{Hierarchy at Fort Vancouver}

Historical documents indicate that in this period, the $\mathrm{HBC}$ as a colonial system in the Northwest, ranked their employees in a strict hierarchical socioeconomic structure (Lightfoot 2006). This hierarchy reinforced the system of mercantile and corporate capitalism that was fostered at the fort. Although subtle gradations ran from the Governor down to the apprentice laborer, the service was fundamentally divided like an army into Officers, or Gentlemen; and workers, or Servants (Hussey 1957; Ross 1976; Goldring 1979). The Officers lived within the fort and took their meals at the Chief Factor's table, while the Servants lived entirely within the Village. Complicating the company's structure was the considerable ethnic diversity present in the workforce at Fort Vancouver, the result of generations of diverse fur traders intermarrying with women from many North American tribes as they crossed the continent. The colonial settlement at Fort Vancouver grew into a stratified, multi-ethnic community highly influenced by hierarchy and ethnicity (Lightfoot 2006). 


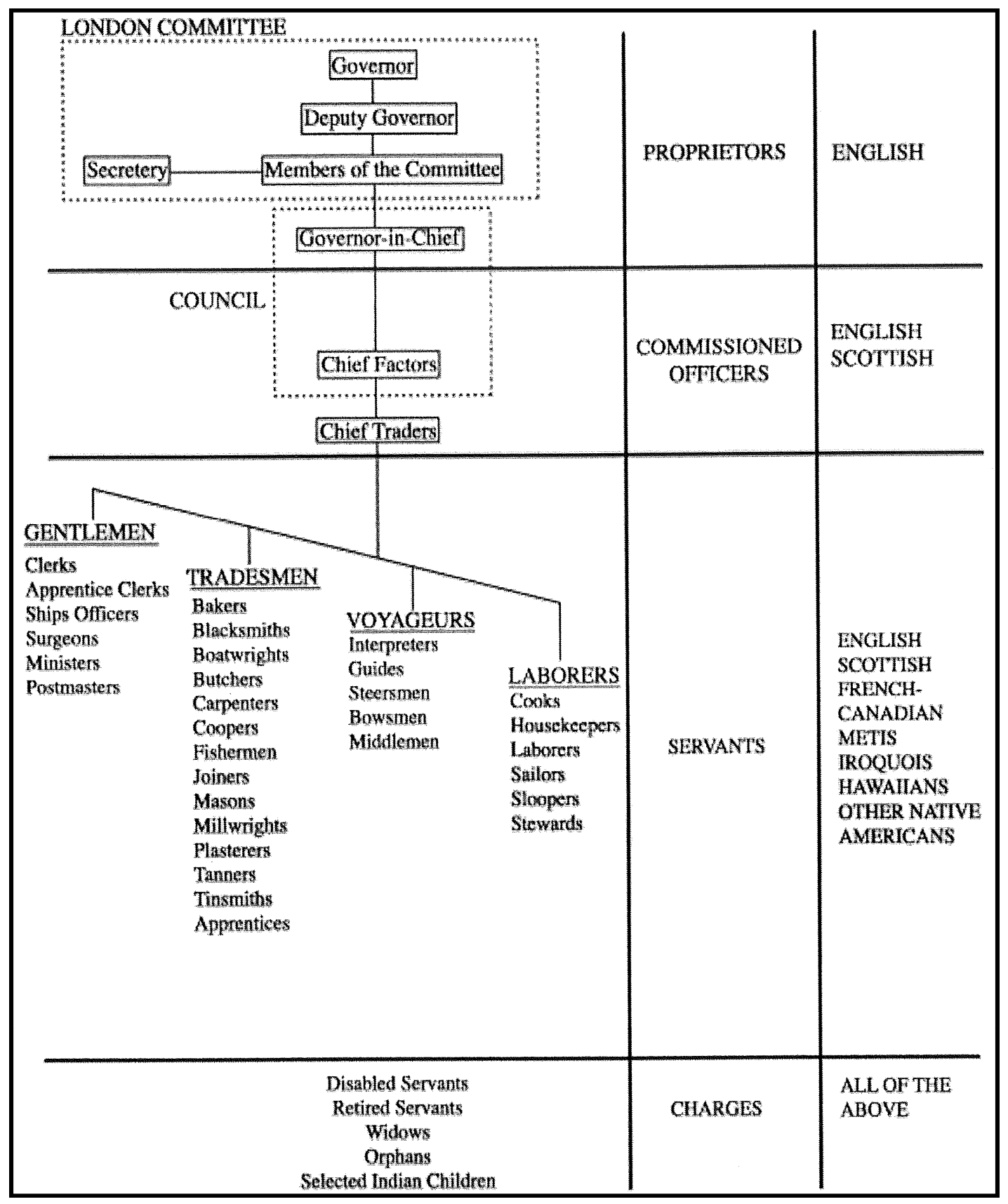

FIGURE 3. Hypothesized Organizational Hierarchy for the HBC between ca. 1825-1860 (Following Ballantyne 1972; Rich 1959; Ross 1976 and Cromwell 2006) 
Lester Ross presents one model for this ethnically diverse company structure as a hierarchical pyramid specific to Fort Vancouver, which describes four socioeconomic classes: Proprietors, Commissioned Officers, Servants and Charges, each with its associated majority ethnic composition (Ross 1975: 15) (Figure 3). At Fort Vancouver the class distinctions outlined in the company charter and strengthened during the retrenchment and reorganization of the company in the early 1800 s were sharpened. The Gentlemen class, made up of the Chief Factor, John McLoughlin, together with Fort Vancouver's English, French-Canadian or Scottish clerks, apprentice clerks, ships officers, surgeons, ministers and postmasters were expected to be gentlemen by definition, possessing the requisite education to be socially as well as administratively superior to the servants whose labor they commanded (Goldring 1979: 132; Barman and Watson 2006: 62). This upper class lived within the walls of the stockade and dined in the Gentlemen's dining hall inside the Chief Factor's House (Ross 1975; Cromwell 2006).

The Servant class was primarily comprised of Iroquois, Hawaiians, members of local Native American tribes and Metis, or individuals of mixed European and Indian ancestry (Ens 1996). Charges were of mixed ethnicity, and consisted largely of disabled and retired Servants, as well as Indian children, orphans and widows (Ross 1975; Cromwell 2006). True to its profit-maximizing structure, the HBC favored workers whom they thought could be controlled easily, who would readily adapt to being in a 
position of subordination, would work hard and produce the maximum amount of work expected of them.

The preference for Hawaiian and local Native American laborers was primarily due to the belief that because strict dichotomies existed between upper and lower class peoples in the societies of both the people of the Columbia River and the Hawaiian Islands, they would transition and adhere easily to the fur trade society, as cultivated by the HBC (Kardas 1971; Barman and Watson 2006). Documentary sources indicate that Kanakas were especially highly favored because they had no established relationships with local Indian groups, and would neither run away to Indian relatives nor cause war with traditional enemies (Kardas 1971; Barman and Watson 2006).

The vulnerability of Hawaiian laborers in the Northwest increased company control over them, as they were both foreign to the region and entirely dependent on their employers for return passage to the Sandwich Islands (Kardas 1971). Indeed the HBC fostered this notion of dependence, as will be discussed in Chapter V. 


\section{CHAPTER III: THEORETICAL CONTEXT}

The documentary record shows that Fort Vancouver was a strategic link in the system of global capitalism, founded by the $\mathrm{HBC}$ as a colonial settlement at the edge of its holdings in order to sustain and expand their operations abroad. Any examination of the material culture from this locale therefore cannot be divorced from an examination of the various modes of production and the social and economic relations in such an environment.

\section{Marxist Theory}

Marxist archaeology developed from the writings of political activist Karl Marx (1818-1893), who wrote critical analyses of society and analyzed various modes of production, or the ways that productive property is owned and controlled, combined with the corresponding social relations between individuals based on their connection with the process of production (1867). While Marx wrote about many distinct modes of production and their combinations, he devoted much attention to capitalism, perhaps most famously in Capital: Critique of Political Economy (1867), wherein he claimed that the exploitation of labor is the motivating force of capitalist society. By producing capital rather than commodities (goods and services), workers in capitalist societies continually reproduce the economic conditions by which they labor and solidify their place in the exploitative system (Marx 1867). Classical Marxist theory is derived from Marx’s examination of how social inequality was created and maintained by capitalists who withdrew from production and relied on the exploitation of labor, sold by contract 
between the capitalists and the working classes, in order to sustain their position at the top of the hierarchy. The opposition this created between the classes drove the development of class-based societies in general, and of capitalist society in particular (Marx and Engels 1848; Patterson 2003).

Marxist theory studies society holistically in order to examine the systematic interdependence of all aspects of social life, including material culture (Trigger 1993: 163). Society in classical Marxist scholarship is comprised of two elements: the economic foundation or base and the superstructure, which includes the culture, institutions, political power structure, roles, ritual and state. The base consists of the whole of productive relationships, including both the forces of production, comprised of all forms of technology, human and non-human resources and scientific knowledge, and the relations of production, which signify specific patterns in the ownership and control of the forces of production and hence different forms of access to the products themselves (McGuire 1992; Trigger 1993: 332).

There was no escaping the relations of production which, in Marx's view, defined capitalism as an economic system and played a major role in shaping the superstructure, the system of meaning through which specific groups of human beings comprehend themselves and the world in which they live (Trigger 1993). As Marx wrote:

In the social production of their existence, men inevitably enter into definite relations, which are independent of their will, namely relations of production appropriate to a definite stage in development of their material forces of production. The totality of these relations of production constitutes the economic structure of society, the real 
foundation, on which arises a legal and political superstructure and to which correspond definite forms of social consciousness. The mode of production of material life conditions the general process of social, political, and intellectual life (Marx 1867: 20).

Using a dialectical method to examine the contradictions in this economic system, Marx observed that the human labor power employed by the capitalist to transform raw materials into commodities is the only commodity that could create extra value (Patterson 2003). According to Marx, capitalism creates classes of people united by their relationship to the means of production and to labor power. Capitalists are those members of the dominant classes who own the means of production, raw materials, tools, factories, machines etc., but need to hire workers to produce objects. Workers, not owning the means of productions, had to sell their ability to work to the capitalists in return for a wage (Paynter 1988: 412; Trigger 1993: 169). The concept of class is an inherently antagonistic one, and capitalism creates an exploitative relationship between the capitalists and the direct producers; members of the capitalist class seek to maximize the rate of exploitation of the labor of subordinate classes in order to reach their goal of maximizing profits and maintaining their position (McGuire 2006). The ways in which class affected members of the Fort Vancouver economic hierarchy will be explored in Chapter V.

\section{Marxism in Archaeology}

The logical relevance of Marxism to archaeology becomes obvious when one considers that Marx and Engels were materialists who believed that through the labor 
process, social relations, culture, ideas and meaning are objectified; that is, take a material role in the process of the production and reproduction of real life (McGuire 2006). Through a process known as objectification the object becomes something people apply labor to; and is transformed into material culture. In effect, human labor is solidified in material culture so that these objects serve as indicators of the social conditions under which that labor is carried out (McGuire 1992). A Marxist analysis therefore allows an examination of material culture through the lens of a society's social relations, which mirror the relations of production. A Marxist framework in historical archaeology regards material culture as a product of social, conscious labor, and as part of the material conditions of the world that structure that labor (Paynter 1988; McGuire 2006). Marxist archaeologists view material culture as actively involved in creating and maintaining social relations, and the application of Marxist theory to archaeology has developed greatly throughout the more than 100 years since Marx's death. Marxist archaeologists see material things as products and expressions of social relations as well as part of the structure of those relations that are the conditions for their existence (McGuire 1992: 95).

In the 1930s and 40s Australian archaeologist V. Gordon Childe was the first western archaeologist to use Marxist theory in his work. Childe juxtaposed the findings of archaeologists and functionalist sociologists with the socio-historical perspectives forged by Marx, Engels and their successors, combining what had up until this time been 
distinct discourses (Patterson 2003). He espoused the primacy of the base in relationship to superstructure, stating that

Marx....asserted that the mode of production in the long run determines the ideological superstructure. Here "mode of production' means the means of production together with the property relations that permit their full utilization, and 'ideological superstructure' includes social, religious, legal, and aesthetic institutions, beliefs and conventions (Childe 1946: 250).

Childe studied the ways in which forces that shaped development were manifested in various settings, noting that material culture reflects and participates in the social relations that produce it and that archaeologists are therefore able to study these social relations by studying material culture (Childe 1944:1).

By the middle of the 20th century archaeology was dominated by the study of typology, chronology, diffusion and migration instead of social philosophy (McGuire 1992). During the 1950s and 60s, cultural evolutionism gained prominence followed by the rise of processualism, within which the concept of culture primarily signified the different ways diverse groups adapted to their environmental settings (Binford 1962; Trigger 2006). Marxist archaeologists carried this further, maintaining that to understand any culture one must begin with the ways in which that culture sustains life.

The first wave of Marxist archaeologists appeared in British archaeology in the 1970s and followed French structural Marxism, emphasizing the structures and the circulation of goods within a society (McGuire 1993). Of particular importance were the writings of Louis Althusser, who believed that the form any particular society takes does not arise from the traditional Marxist concept of an economic base, but rather from a 
hierarchy of structures that interact with one another but remain distinct (Althusser 1971; McGuire 1992, 2006). Following this view of society, this first cohort of scholars sought to make Marxism more scientific with structuralism, emphasizing the inherent contradictions between different levels or types of structure, each with its own mode of human labor. As part of this approach, structural Marxists employed the concept of ideology and stressed its importance to mediating these contradictions. Ideology was "a set of beliefs needed to adapt or to socialize people into a society" (Althusser 1971: 153). The work of these structural Marxists brought considerations of ideology to the forefront of British archaeology.

In the 1980s, a second cohort of Marxist archaeologists formed around ideas from anthropological political economy, which grew out of the work of North-American anthropologists (Leacock 1972; Diamond 1974; Nash 1979; Leacock 1981; Wolf 1982, 2001). These scholars rejected many of the fundamental concepts of Marx, including the notion that the mode of production and the superstructure were discrete levels of society that could be studied autonomously. They studied these concepts as different facets of the same societal whole, which could not exist without the other (McGuire 2006: 133). It was the relationship between the mode of production and the superstructure that shaped society. One of the key aspects of this relational view of archaeology is that class exploitation entailed relationships to other forms of exploitation based in social dimensions such as gender and race (Paynter 1988). These archaeologists returned to a relational concept of class to define the social world in terms of the ambiguities, tensions 
or contradictions within the social relations of society and not objects. The relational concentration in this strain of Marxist archaeology developed into an increased awareness of archaeology's place in the modern world.

This study uses a version of structural Marxism put forth by historic archaeologist Mark Leone to examine the seemingly objective structures shaping society at Fort Vancouver and the ways in which their reinforcement ensured the ongoing viability of the capitalist mode of production there. Leone's definition of ideology acts as an entry point for the examination of material culture from the Fort Vancouver and Village sites.

\section{Ideology and Critical Archaeology}

Marx's theory of capitalism currently represents a major school of thought in Anglo-American historical archaeology as historical archaeology in North America has increasingly become an archaeology of capitalism (McGuire 2006). A mix of critical archaeology and anthropological political economy characterizes the most common approach among Marxist historical archaeologists today. Critical archaeology attempts to explore and adapt Marx's insights to the understanding of events and circumstances of life that Marx did not know (Leone et al 1987: 283). It refers specifically to the study of ideology, the forms it took in daily life and the ways it is manifested in the material record. Ideology is studied as an active part of all human practice. Artifacts cannot be divided up according to economic, social or ideological criteria; all practice and the technology employed to implement that practice was mediated through ideology with 
each item taking its meaning from the whole set of material conditions, social practices and belief systems (Pearson 1984: 60).

Leone defined ideology as the notions about explicit belief in the sacred or secular sense, or the givens of life held unawares (Leone 1982: 742). Stated more emphatically, ideology is a distortion of thought (false consciousness) that actively conceals social contradictions both within and between the base and superstructure and naturalizes exploitation within stratified or class societies in order to maintain the status quo and avoid serious resistance, violence or revolution (Leone 2005; McGuire 2006: 128). It is the projection of a particular class interest, which distinguishes it from more totalizing concepts of societal status quo such as hegemony, which describes the entirety of the lived social process (Williams 1977: 108). Ideology, as thought that serves class interests, is actively created and maintained by those in power to obscure the realities of inequality and exploitation and to ensure the continuation of the capitalist system.

The ideology of capitalism implies that most people live in a world of many negotiated meanings, where work produces profit for someone else (Leone 1999). The position of a ruling class might be legitimated by misrepresenting the inequalities between surplus-producing and the surplus-consuming groups or by representing the interests of the elite as universal for the whole society (Pearson 1984: 61). As Leone explains, "Marx created the idea of ideology, not to reconstruct any part of the past, but to understand why workers failed to see their true economic and political condition" (Leone 1982: 750). Beginning with Leone and his colleagues, critical archaeology was 
built from structural Marxism and the critical theory of the Frankfurt school (McGuire 2006: 133). Underlying critical archaeology is the assumption that ideology is dominant, both because it is the beliefs of the dominant class and because it will dominate subordinate classes and is used as a political control, to prevent subordinates from seeing the realities of their exploitation.

Critical theory uses ideology in many senses: as the givens of everyday life, unnoticed, taken for granted, and activated and reproduced in use. It is used to describe inequality and mask or rationalize exploitation by naturalizing it, acting within a stratified or class society to produce inequality without serious resistance, violence or revolution (Leone et al. 1987). The work of critical archaeologists emphasizes meaning as expressed in ideology and a number of their studies have examined the ways in which material culture serves to maintain ideology through landscape design and through the mundane objects of everyday life (Leone 1977, 1981, 1982; McGuire 1988; Shackel 1994). Critical archaeologists view material culture as actively involved in creating social relationships, and use the notion of ideology to describe symbolic systems deployed through material culture, in order to negotiate power relations (DeCunzo and Ernstein 2006).

\section{Critical Archaeology in Annapolis}

In the Archaeology in Annapolis project, Leone and others used critical archaeology to examine how during the colonial period the plan, architecture, landscape and material culture of the city established and reinforced the dominant ideology in Annapolis at the time, which Leone defined as individualism, equality and social contract 
(Shackel 1993, 1994; Leone 2005). They sought to reveal through both documentary and archaeological analyses the ways in which the historic district had been manipulated to reinforce modern capitalist ideologies, how these ideologies were sustained, and how they obscured the contradictions and social inequalities of the hegemonic structures of Annapolis (Leone 2005: 132). Archaeological analysis in Annapolis centered on areas where the ideology of individualism was sustained: specifically through the design and layout of the city's landscape and in the diversity and distribution of household ceramicwares.

The ideology behind landscape design and layout is a common theme in historical archaeology (Leone 1984; McGuire 1988; Shackel 1994; Monks 1997; Leone 2005; DeCunzo and Ernstein 2006; Nelson 2007). Leone's analysis of the Paca house garden provides a powerful example of the contradictions and conflicts masked behind an artifice of symmetry and function and how these contradictions can be revealed archaeologically (Leone 1984; 2005). Paca, a wealthy landowner and signer of the Declaration of Independence, lived in Annapolis and his formal garden used the rules of perspective to create optical illusions that made the wilderness appear further away and the garden seem larger than it actually was, resulting in an increased perception of the level of power at his command (Leone 2005; Dorset 2012). The contradictions of Paca's own life as both a slave holder and a signer of the Declaration of Independence are mirrored in the layout of his garden, which is constructed to distance the house from the wilderness (McGuire 2006). The ideology of independence and harmony, in both cases 
overwhelmed the reality of the encroaching unruly wilderness and by extension, the reality of slave labor (Leone 1984, 1987, 1988, 2005; Leone et al. 1989; Leone at al. 2005). The layout of the garden functioned to present the way that the dominant class sought to represent reality for outside observers, including the working class.

Ideology functioned to maintain the illusion of smooth functioning in an unequal society by naturalizing conditions and keeping the working class in their subordinate position. This was accomplished in a myriad of ways, including through material culture, which played an important role in the disciplining of workers (Paynter 1988: 413). The concept of ideological distortion in capitalist societies is of primary interest in the present study, which explores the ways in which the inherent conflict and contradiction between the classes and between the base and the superstructure were masked or naturalized (Leone, Potter and Shackel 1987: 287).

\section{Personal Discipline}

Leone and other Marxist archaeologists working in Annapolis built on the work of James Deetz (1977), exploring the ways that the routines of daily life and, most relevant to the current study, the organization of tablewares, indoctrinated workers and held them in the relationships of capitalism. They applied Marxist analysis to material items such as ceramicwares and toothbrushes to explore the production and maintenance of the culture of capitalism, that is, a culture of labor exploitation that relied on effective discipline of the working classes. The growth of mercantile capitalism is associated with the standardization of life's domains on the one hand, and the increasing interchangeability 
of things, acts and persons on the other (Leone et al 1987: 288). The culture of capitalism is one of predictability and routine, which was marked by the standardization of life and the routinization of labor along with many aspects of modern society. The increasing division of time and labor actively reinforced social positions, created the laborers of the new industrial era, and was mirrored in the increasing segmentation or division of material culture such as tablewares, into multiple smaller components (Shackel 1993).

Deetz focused on shifts in cognitive patterns and behavior, and the ways that the shift to a more segmented reality could be documented through examination of the stylistic shifts in the material culture, including design of houses, grave markers and ceramic tablewares. With regards to ceramics, Deetz argued that table setting became modular after the beginning of the $18^{\text {th }}$ century in New England, where central dishes for stews eaten primarily by hand were replaced by sets of equal-looking dishes, with sets of forks, individual chairs and mugs or glasses Deetz 1977; Leone 2005). The way that food was separated into portions and courses as sets of tableware were adopted to accommodate these shifts in dining was indicative of the recognition that each person was an individual, and therefore entitled to separate, hierarchically ordered private spaces, the appearance of which accompanied the rise of personal discipline pertaining to sleeping, eating and cooking as well as personal elimination and garbage disposal (Deetz 1977; Shackel 1993).

The notion of personal discipline comes from Foucault, who discussed the ways in which discipline and social control became increasingly important during the 
Enlightenment in order to standardize and control behavior through the use of structures such as space and time (Foucault 1979). The wealthy reaffirmed their place in the hierarchy by dismembering the communal values of medieval society and using a new form of social discipline and material culture to create social differences between them and the lower classes (Shackel 1994). Leone analyzes culture change in the 18th century as a product of the penetration of Enlightenment ideas of merchant capitalism, acknowledging that these ideas affected people differently, depending on their class (Shackel 1993; Leone 2005).

One of the central concepts of Foucault's analysis of modern society is the notion of surveillance. Leone (2005) included Foucault's description of Bentham's panopticon and surveillance in his discussion of personal discipline as it related to Annapolis. Foucault located the power to police peoples' behavior in structures such as schools, prisons and hospitals, as well as within the population itself, as the citizens quickly learned to inspect themselves and each other (Foucault 1979). In Annapolis, the concept of self-inspection was integral to the creation and improvement of social worth as the citizens learned new technologies such as gardening, writing or eating (Leone 2005: 97). An important element of the work in Annapolis is its examination of etiquette and the role it played in these technologies of personal discipline, enforcing the segmentation that was crucial to the creation and maintenance of a capitalist workforce.

Leone and the archaeologists in Annapolis argued that this same segmentation and standardization in ceramic use appeared in Annapolis along with an etiquette 
associated with the accumulation of profit. Greater diversity of plate sizes and growing functional diversity of ceramics in an assemblage were interpreted by Paul Shackel to be an indication of the increasing segmentation which helped reinforce a new standardized way of eating (Shackel 1993). Leone argued that eating was a discipline observed widely as a marker of individualism, or a person's capacity to self-inspect, signaling readiness to learn rules, observe portions, be punctual, accept being observed by others and be subject to working for wages (Leone 2005: 57). A set containing one dish per person and a variety of dish sizes for different courses in the meal (e.g.: butter dishes, dessert dishes, meat dishes etc.) indicated a new etiquette that reinforced a segmenting trend and in turn disciplined people's behavior both at, and away from the table. Many of these patterns of segmentation accompanied the transition to capitalism and the corresponding ideology of individualism in Annapolis, where new social relations based on a modern discipline, a behavior that was regular, predictable and replicable manifested itself in a new code of manners and material culture (Shackel 1994).

The new modern discipline was indicated in part by the new etiquette and material culture used in the process of eating, such as sets of plates, knives and forkswhich are formal and segmenting items (Shackel 1994). The etiquette of work life, which extended to eating, health and hygiene in Annapolis contributed to the creation of citizens by routinizing daily life, including dining and all the rules surrounding what, where, how and with whom one ate (Shackel 1993; Leone 2005). Leone and Shackel viewed the increasing number of dish sizes and wares observed in the archaeological assemblages 
from house in Annapolis as a reflection of a new etiquette, and an increasing segmentation at the table that served both as training ground for the new order and as reinforcement for it (Leone et al 1987: 288; Shackel 1993: 30; Leone 2005: 161). The success of capitalism at generating wage workers and those who pay interest willingly depended upon individuals who were interchangeable (Leone 1999: 211). The current study followed this model, seeking the presence of matched sets of individual place settings in the ceramic assemblages recovered from households from Fort Vancouver and Kanaka Village.

\section{Ceramics at Fort Vancouver}

The archaeological record for ceramics is one of the most complete and informative available to historical archaeologists. Ceramics are widely used, easily breakable, not recyclable, and do not decompose. Therefore changes in the use of dishes and crockery, and in their styles, are well documented, although interpretations of these changes vary (Leone 1999: 195).

Sherds of English ceramicwares are the most ubiquitous artifact type recovered from archaeological excavations at Fort Vancouver; it is not uncommon for ceramic sherds to represent upwards of $25 \%$ of archaeological assemblages recovered from within both the Fort and the Village (Caywood 1954; Larrabee and Kardas 1969; Hoffman and Ross 1972a, 1972b, 1973a, 1973b, 1973c, 1974a, 1974b, 1974c, 1975; Chance and Chance 1976; Ross 1976; Thomas and Hibbs 1984; Cromwell 2002; Gembala et al. 2004). In comparison to their pervasiveness, however, relatively little analytical work has been performed on the ceramics recovered from these sites. Until 2006, analysis of 
ceramics was largely limited to inventories, and analysis of ceramics from the Village centered on the presence or absence of viable ethnic markers (Larrabee and Kardas 1969; Kardas 1971). These analyses revealed that there is almost no archaeological evidence of non-European residents, although they comprised the majority of the population (Kardas 1971: 411). Later work by Cromwell revealed that the historically documented disparities in wealth, power and privilege were minimally observable archaeologically and that the total vessel count for each household and the occurrence of matching sets of ceramics was independent of the socio-economic class of the household (Cromwell 2006).

Cromwell used a consumer choice perspective to compare ceramicwares recovered from the Village to those recovered from within the stockade. Consumer choice and consumer behavior models have assumed an important role in historical archaeology, focusing on the consumer choices of autonomous individuals as symbolically meaningful actions (Wurst and McGuire 1999: 192). Cromwell's model was predicated on the idea that differences in the table and toiletwares recovered from the archaeological remains of discreet households would reflect differences in the habits of the people who acquired, used and discarded these objects. Cromwell hypothesized that assemblages from commissioned Officer and Gentlemen-class households (within the stockade) would demonstrate larger quantity and higher quality of material possessions, and a higher level of functional variety and a lower level of decorative variety than those from Servant households in the Village (Cromwell 2006: 33). He explored the availability, prices and taxation of these goods, to the various classes, and measured their 
worth through the use of both Miller's $(1980,1991)$ index and a Fort-Vancouver specific index. Using price fixing lists from the Staffordshire potteries, which set prices for specific ceramic vessel types based on decoration type and vessel form, Miller (1980, 1991) showed that the cost of undecorated creamware was consistently the lowest of any ceramic type and could therefore be used as the basis of the index system. By assigning index values to specific ware and vessel types, Miller was able to form comparative values that are useful from one year to another. Cromwell (2006) created a similar index based on the historic inventories of the prices of ceramics sold at the Fort Vancouver Sale Shop. His results revealed that the worth of the ceramics within the Servant class households is comparable to those from within the fort, and despite many differences between the Village residents and those of the fort, material culture from the Village was not easily distinguished from that recovered from the fort site.

Cromwell's data showed that transferprint white earthenware vessels are present in each household, whether they were occupied by the richest Officers, or the poorest Servants (Cromwell 2006: 266). This undermines the assertion that socio-economic status is the only factor affecting the accumulation of ceramics within the sites under study, and may indicate a weakness in the ability of consumer choice models to take into account the social relationships that both restrict these choices and make them possible. Consumerism goes beyond simple acquisition to denote the complex cultural relationships between humans and consumer goods, including how material goods confer social identity or status, the role of fashion and demand in spurring changes in 
manufacture and the ways in which people construct their own meanings for objects produced by themselves and others (Barker and Majewski 2006: 225).

The limitations of a consumer choice framework for the exploration of social processes stems from its failure to take into account the realities of the environment in which the consumption was taking place. The use of consumer choice models can be misleading as, in some ways the notion of "choice" actually trivializes human action. All individuals are not equivalent and all choices are not similar; because individuals are social beings, social position both restricts choices and makes choices possible (Wurst and McGuire 1999). This was especially the case at Fort Vancouver, where all classes were immersed in the same ideological reality, while the individuals and households from the Village were also economically, socially and spatially distinct from those within the fort.

This study is a reanalysis of the ceramic assemblages used by Cromwell from Fort Vancouver and those from the Village (together with two previously unanalyzed assemblages presented here for the first time), using a Marxist approach in order to address the social processes in which Fort Vancouver was immersed. It is patterned after the work of the Annapolis archaeologists, using ceramics, and seeks to translate the model of Leone's work to the Pacific Northwest, looking specifically the presence of matching sets of ceramics as an indicator of the degree to which the Village households were subject to, and actively adopting the ideologies of capitalism that were in play at Fort Vancouver. 


\section{CHAPTER IV: MATERIALS AND METHODS}

This chapter is a discussion of the assemblages and methodologies used to explore the influence of ideology on ceramics recovered from Fort Vancouver and the Village. It begins with an explanation of the hypotheses behind the archaeological analysis, and describes the assemblages used for analysis, including the excavation methods and post depositional processes that influenced their composition, before discussing the specific ways these assemblages were manipulated in order to gauge the presence of matched sets.

Cromwell (2006) touched upon the phenomenon of matched sets in the Village, stating that "all of the household assemblages displayed multiple matching sets of differing patterns" (Cromwell 2006: 287). This study builds on Cromwell's analyses by specifically examining the presence or absence of matched sets in order to gauge the effects of ideology and place the ceramics from the Village into a larger historical and theoretical context. This study uses the data from four previously analyzed assemblages recovered from Houses 2-4, and the Chief Factor's House and Kitchen site, all of which were analyzed by Dr. Cromwell in 2006. It also incorporates data from two previously unanalyzed assemblages from the Village, Houses 1 and 5, analyzed and reported here for the first time.

\section{Literature Review}

In order to offer a contextual interpretation of the archaeological analysis in Chapter VI, this study includes a review of literature concerning the particular modes of production and the ideologies in play at the fort, and the ways in which these ideologies 
were manifested in the daily lives of those who lived and worked there. There has been a large amount of scholarship on the corporate policies of the Hudson's Bay Company and its status as a capitalist entity (Wilkes 1856; Shenk 1932; MacKay 1938; Galbraith 1951; Rich 1959; Bryce 1968; Williams 1970; Goldring 1979, 1980; Carlos 1981; Carlos and Hoffman 1986; Carlos and Nicholas 1988, 1990; Hammond 1993; Burley 1997; Mackie 1997; Hamilton 2000). This literature review focused on reviewing secondary sources and critiques pertaining to Fort Vancouver, however some primary sources including letters and accounts from Chief Factor John McLoughlin, Governor George Simpson, and various visitors to Fort Vancouver, as well as corporate documents in the Hudson's Bay Company Archives (HBCA) provided additional information. The results of this research are presented in Chapter V.

\section{Measures of Archaeological Diversity: Richness and Evenness}

The archaeological analysis in the current study concerns locating evidence of matched sets of ceramics. A matched set of ceramics is made up of many identical place settings, and as such it is expected to be comprised of many vessel forms, and rendered in a single decorative pattern. The archaeological analysis for the current study sought to recognize the presence of matched sets through the diversity measures of richness and evenness.

Richness and evenness are measures of an assemblage's diversity as it relates to categories or divisions within that assemblage. According to Kintigh (1989: 26), richness is a measure of the number of classes present in a particular assemblage. This could refer 
to any nominal measurement such as colors or sizes; in the current study it refers to either stylistic decoration (i.e.: a ware type such as transferprint or a specific transferprint pattern, such as "Lily"), or functional type (i.e.: a specific vessel form, such as "soup plate").While richness measures the number of categories present, evenness measures the distribution of artifacts across these classes. For the purpose of this study, evenness is measured on a scale from 0 to 1; an assemblage with an evenness value approaching 1 is more even than one with an evenness value approaching 0 (Kintigh 1989). A value of 1 indicates a completely evenly distributed assemblage (i.e.: all classes have the same number of artifacts), and a value of 0 indicates a completely uneven assemblage (i.e.: almost all the artifacts belong to a single class).

It was expected, given the definition of a matched set, above, that such a set would be low in both richness and evenness values for style, as the vessels would be rendered in only a few patterns (highly uneven, evenness=close to 0 ). The opposite was expected for vessel form, as a matched set would contain many vessel forms, and would be fairly evenly distributed over those forms, as a typical set consists of several matching place settings as well as some serving vessels. Therefore, it was expected that a matched set would be high in both richness and evenness of form: the vessels would represent many categories of form. The same set would likely be evenly distributed over those categories (evenness approaching 1). For this study, it was expected that matched sets would be present in the ceramic assemblages from the Village, and that therefore the 
assemblages would display low richness and evenness values for style, and high richness and evenness values for form.

This study compared the appearance of matched sets from the Village, as measured through the above diversity measures, to a model assemblage, which was expected to display the attributes of an ideal assemblage of matched sets, as described above. The model assemblage was that recovered from the excavation of the Chief Factor's House and Kitchen (CFH), as analyzed by Cromwell (2006). Documentary evidence indicates that ceramicwares on the Chief Factor's table were comprised of matching sets of Spode/Copeland ceramic dishes that were specifically ordered for use at the Chief Factor's table. The HBC has a well-documented history of importing these ceramicwares to their outposts. The firm of Spode/Copeland first began supplying ceramics to the HBC in 1836, under the name Copeland and Garrett, eventually becoming the sole ceramic provider to the $\mathrm{HBC}$ in 1837 they retained a monopoly in supply until 1847.

\section{Research Hypotheses}

As discussed above, documentary evidence reveals that life at both Fort Vancouver and in the Village were affected by the ideologies of capitalism. Following the work of Marxist archaeologists in Annapolis, this study maintains that capitalist ideologies would be evident in the material culture recovered from the Village, and more specifically, that the influence of ideologies at Fort Vancouver would be to some extent indicated by the presence of matched sets in the ceramic assemblages recovered from 
workers' households. The presence of matched sets is measured through two variables: style and form. The expectations for each variable, as measured through the diversity indicators of richness and evenness, are given below.

\section{Style}

Style refers to the decorative style of each ceramic piece (i.e.: stoneware, yellowware, transferprint, and more specifically, distinct transferprint patterns such as Lily, Italian and Seasons). Stylistically it was expected that the presence of matched sets of ceramics would be indicated by a low level of richness as a matched set is comprised of many pieces that all adhere to one decorative style. It is therefore hypothesized that the presence of matching sets in the assemblages from the Village houses would be indicated by richness values roughly equal to or below the mean richness value for the model assemblage from the $\mathrm{CFH}$ :

$\mathrm{H}_{\mathrm{O}}$ (style): the richness values of Village household assemblages will be higher than that of the model assemblage (Village houses did not contain matching sets)

$\mathrm{H}_{\mathrm{A}}$ (style): the richness values of Village household assemblages will be equal to or below that of the model assemblage (Village houses did contain matching sets)

It was expected that the presence of matched sets would be demonstrated by a correspondingly low value for evenness of style, as the distribution of vessels across the various categories present would be skewed toward the decorative style defined for the set(s) (i.e.: Lily pattern etc.). It was therefore hypothesized that the evenness values for 
the Village assemblages would be roughly equal to or below the mean evenness value for the $\mathrm{CFH}$ :

$\mathrm{H}_{\mathrm{O}}$ (style): the evenness values of Village household assemblages will be higher than that of the model assemblage (Village houses did not contain matching sets)

$\mathrm{H}_{\mathrm{A}}$ (style): the evenness values of Village household assemblages will be equal to or below that of the model assemblage (Village houses did contain matching sets)

\section{Form}

Form refers to the functional significance of each vessel (i.e.: plate, serving platter, teacup etc.). It was expected that the presence of matched sets would be indicated by a high richness value for form, as these sets consist of many different vessel forms, reflecting an increased functional diversity. It was therefore hypothesized that the richness values for the Village assemblages would be roughly equal to or above the mean richness value for the model assemblage from the $\mathrm{CFH}$ :

$\mathrm{H}_{\mathrm{O}}$ (form): the richness values of Village household assemblages will be below that of the model assemblage (Village houses did not contain matching sets)

$\mathrm{H}_{\mathrm{A}}$ (form): the richness values of Village household assemblages will be equal to or above that of the model assemblage (Village houses did contain matching sets)

Along with a high richness value for vessel form, it was expected that matched sets would display a correspondingly high evenness value, as the presence of matched sets would be relatively evenly distributed across the high number of functional categories present in the assemblage, as a set is comprised of several matching place settings. It was therefore hypothesized that the evenness values for the Village 
assemblages would be roughly equal to or above the mean richness value for the model assemblage from the $\mathrm{CFH}$ :

$\mathrm{H}_{\mathrm{O}}$ (form): the evenness values of Village household assemblages will be below that of the model assemblage (Village houses did not contain matching sets)

$\mathrm{H}_{\mathrm{A}}$ (form): the evenness values of Village household assemblages will be equal to or above that of the model assemblage (Village houses did contain matching sets)

\section{The Assemblages}

The current study includes the original analysis of two mid- $19^{\text {th }}$ century ceramic assemblages recovered from excavations of two households within Kanaka Village (House 1 and House 5), as well as a reexamination of data from Village Houses 2, 3 and 4, and the CFH within the stockade (Cromwell 2006). The materials used in this study were all recovered during three periods of archaeological excavations undertaken within the Village and Fort Vancouver.

The earliest excavations occurred during preliminary testing and excavation undertaken by Edward Larrabee and Susan Kardas in 1968. This first year of testing within the Village yielded the majority of the House 1 assemblage, while subsequent testing the following year (1969) recovered the majority of the House 2, 3 and 4 assemblages. The second period of excavation is comprised of the 1971 field season, during which Jake Hoffman and Lester Ross performed a full data recovery of the Chief Factor's House and Kitchen buildings. The third period of excavation consisted of three consecutive archaeological field schools administered by the National Park Service 
within the Village site in 2001, 2002 and 2003. The three phases of excavation all utilized different field methods, as described below.

\section{Kardas and Larrabee, 1968-1969}

The majority of the House 1-4 assemblages are the result of two seasons of excavation in the Village by Susan Kardas and Edward Larrabee, who conducted preliminary testing in order to locate the remains of the Village site and to assess the extent and information potential of these remains (Larrabee and Kardas 1968).

Excavation began using exploratory trenches to locate the remains of Village houses, hypothesized to be concentrations of artifacts. Once these concentrations were encountered, excavation proceeded using hand trowels. Larrabee and Kardas note that screening through 1/4-in. mesh was attempted only in areas of high artifact concentration, and that it was ultimately abandoned after it "proved impractical" (Larrabee and Kardas 1968). Units measured 3-ft. to a side, with balks left to separate the units. After the removal of the sod, any overburden was removed via shovel shaving. The first field season (1968) was dedicated to locating the remains of the Village, and excavating the first artifact concentration encountered (House 1). 


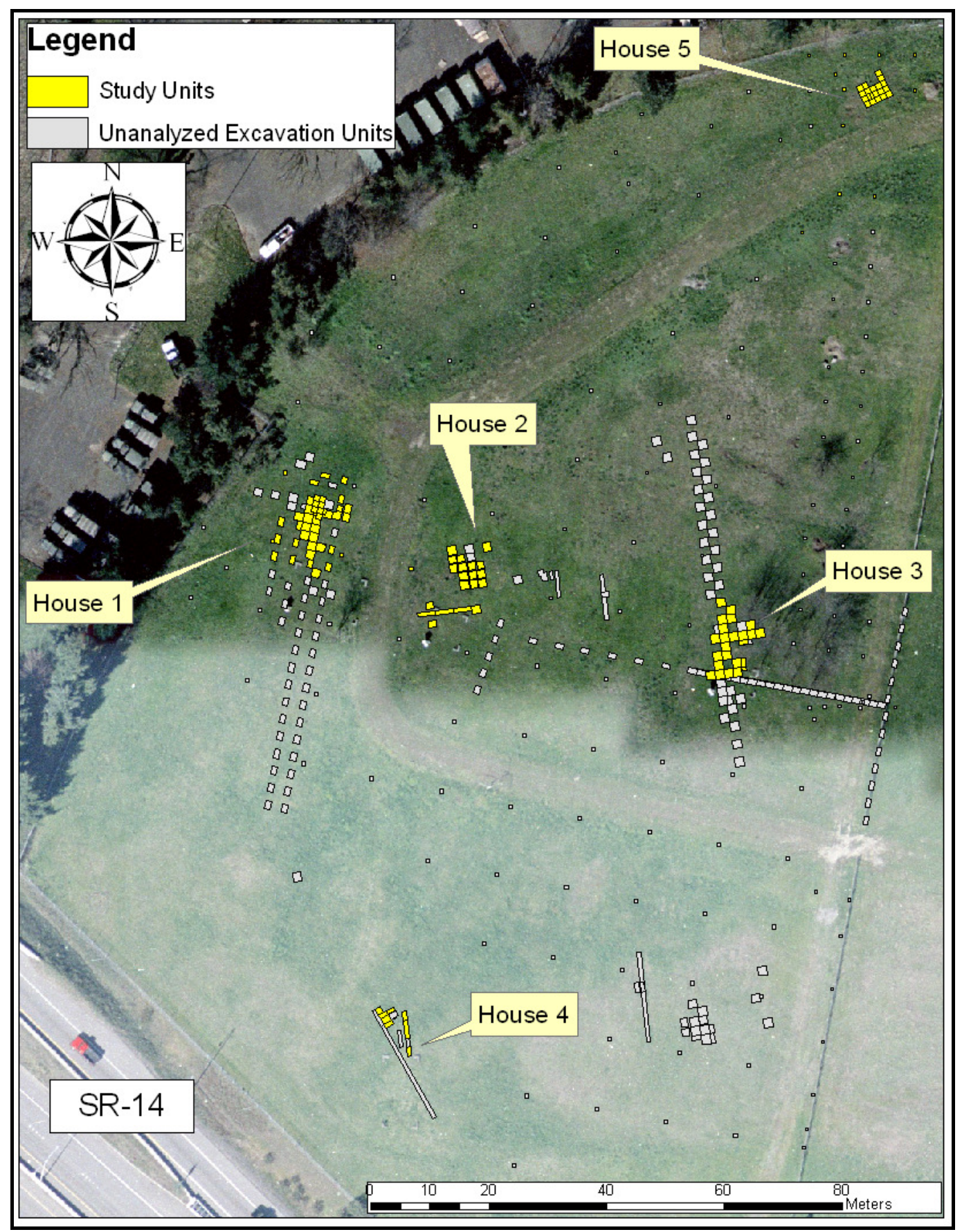

FIGURE 4. Aerial photomap of the western extent of the Village site, showing Houses 15 excavations (Wynia 2013) 
The next field season (1969), Larrabee and Kardas returned to the Village to explore the area to the east of the House 1 concentration. Their methods were similar to those from 1968, however the sod was removed mechanically to expose concentrations of artifacts which they then excavated by hand. Surface collection proceeded across the uncovered ground, and digging was directed toward areas of artifact concentrations (Kardas 1971). One divergence from the 1968 to the 1969 field season was in employing screening (no mention of the screen size) in selected areas, including a trash pit, the House 2 concentration, and the contents of a wood-lined pit (Kardas 1971). The excavation units from these two field seasons are shown in Figure 5.

\section{Hoffman and Ross, 1971}

J.J. Hoffman and Lester Ross excavated the remains of the Chief Factor's House and Kitchen buildings during the 1971 field season. They excavated all areas within or adjacent to the house and kitchen foundations using a total of 102 complete or partial, contiguous 10x10-foot square units. Hoffman and Ross removed the overburden, which varied in depth, and excavated the HBC-era deposits in 0.5-foot arbitrary levels. No mention is made in their final report of the Chief Factor's House excavations of whether, or to what extent, screening was employed (Hoffman and Ross 1973b).

\section{SAIP 2001, 2002 and 2003}

The House 1 assemblage was supplemented by artifacts recovered from additional testing in the Village through consecutive field schools in 2001-2003. The entirety of the House 5 assemblage is the result of these excavations, which used modern field methods. 
These units were excavated by hand, with shovels and trowels. All excavated soil matrix was screened through 1/4 and 1/8-inch mesh hardware cloth, and all encountered artifacts were recovered and bagged by excavation unit and level (Cromwell 2002). Larger-scale excavations were accomplished through the excavation of contiguous 1x1m units. All excavation was performed using arbitrary 10-cm levels. Advanced technology such as the use of total stations helped to control provenience information and artifact recovery in these later excavations (Gembala et al. 2004).

The methods of recovery are significant for their influence on the archaeological assemblages under study. While the use of screens or the size of units excavated influences the data that can be gleaned from archaeological assemblages, ultimately for the current study, the effect is minimal as this study uses vessel counts that are independent of sherd size to address the presence of matching sets of ceramics in the Village assemblages. The recovery of diverse size classes through various methodologies had little effect on the relative frequencies of any given assemblage.

All of the assemblages under study include various types of stoneware, as well as many varied earthenwares, including transferprinted white-bodied earthenware. The ceramics types of porcelain and ironstone, while present in the House 1 and 5 assemblages, were not included in the following analysis in order to remain consistent with Cromwell's data, in which these classes are not included (Cromwell 2006). Although the Village is overlain with deposits dating to the U.S. Army and Civilian 
Concentration Corps (CCC) periods, as well as modern deposits, only the levels containing HBC-era ceramics from these excavations were considered in this study.

\section{House 1}

A total of 870 sherds comprise the House 1 ceramic assemblage, recovered during two multi-phased excavations: those of Larrabee and Kardas in 1968 and those from the SAIP surveys in 2002 and 2003 (Figure 5). A total of 687 of these sherds are from Kardas and Larrabee's initial excavation, wherein they observed a "domestic concentration" that later became known as House 1 in the western extent of NPS property, in association with a compacted gray clay floor surface. Kardas reported the concentration measured 10-feet wide by 20 -feet long, with an artifact density three times greater than the surrounding areas (Larrabee and Kardas 1968; Kardas 1971). For this analysis the House 1 ceramic assemblage includes ceramic sherds recovered from the 13 units directly associated with the House 1 floor and artifact concentration, as well 11 additional excavation units from Larrabee and Kardas' original excavations, totaling 34 units (Figure 5).

The remaining 183 ceramic sherds were recovered from supplemental testing around House 1 during the 2002 and 2003 field seasons. In 2002, the SAIP survey excavated four contiguous $1 \times 1$-meter units to the immediate north of the House 1 floor artifact concentration. Subsequent testing in 2003 included three additional 1x1-meter and one 1x0.5-meter excavation units adjacent to those from 2002. 


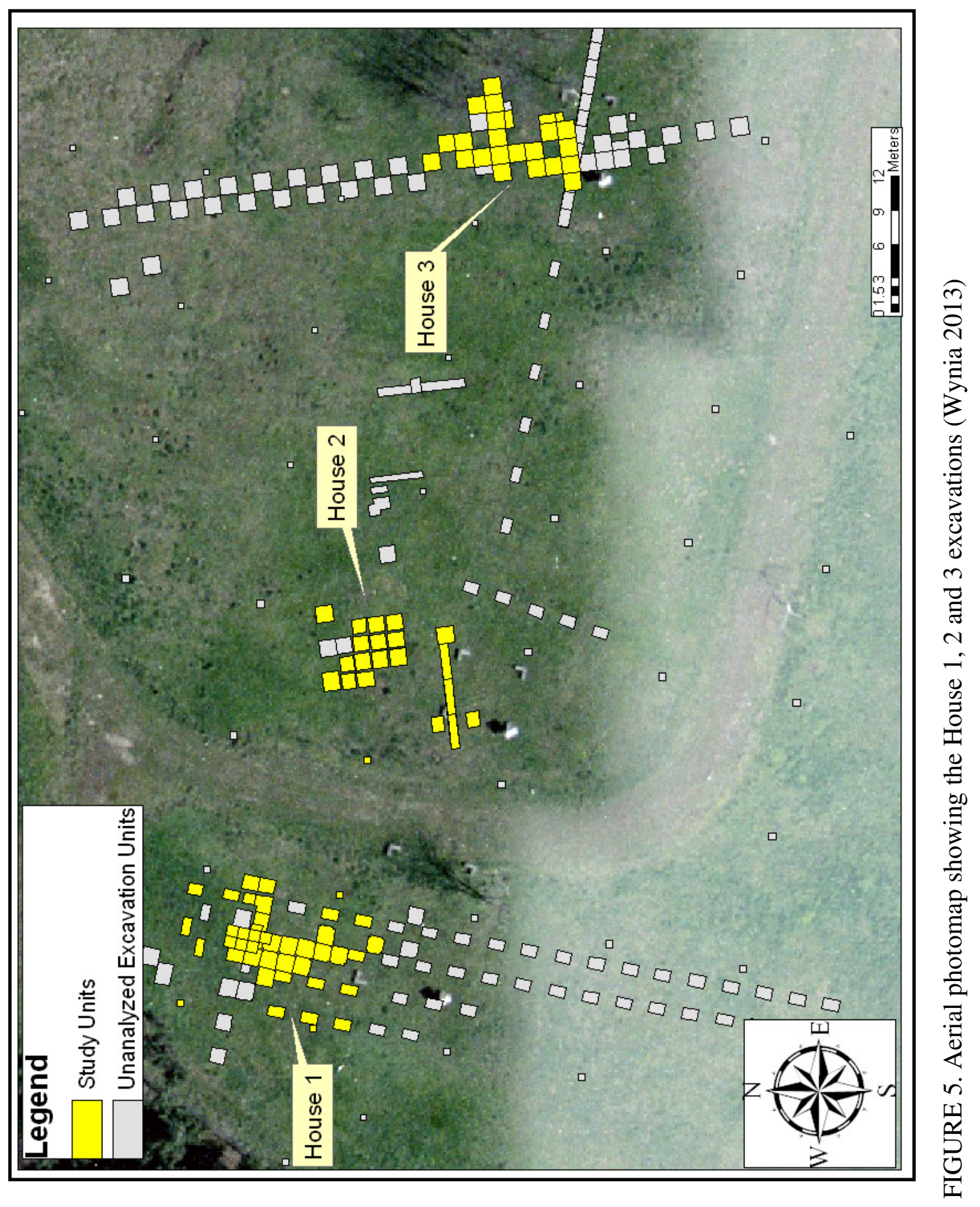




\section{House 5}

A total of 547 ceramic sherds were included in the assemblage analyzed from House 5, comprised of ceramics recovered during all three seasons of SAIP survey excavations (2001, 2002 and 2003). The initial SAIP survey in 2001 was divided into six distinct "Operations" in order to test the entirety of the NPS-administered Village Site (Cromwell 2002). Operation 4 consisted of $3950 \times 50 \mathrm{~cm}$ shovel test units and one 1x1meter excavation unit. House 5 was initially identified as a roughly square-shaped concentration of cobbles at the base of ST 30, and this unit was opened into a full 1x1-m excavation unit, EU 1.

A total of 69 sherds from the House 5 assemblage were recovered from 11 test units and EU 1, excavated in 2001 (Figure 6). The rock feature (Feature \#2001-04) was interpreted to be the remains of an HBC-era domestic hearth and subsequent excavations revealed a concentration of domestic artifacts associated with a hard-packed grey clay floor corresponding to the House 1 floor and artifact concentration observed by Kardas and Larrabee (Larrabee and Kardas 1969; Cromwell 2002; Gembala et al. 2004).

Excavations during the subsequent field seasons (2002 and 2003) focused on the House 5 domestic concentration. The House 5 study area was expanded to include 18 contiguous 1x1-meter excavation units. A total of 478 ceramic sherds recovered from these excavations, and test units in the vicinity are included in the House 5 ceramic assemblage in the current study. 


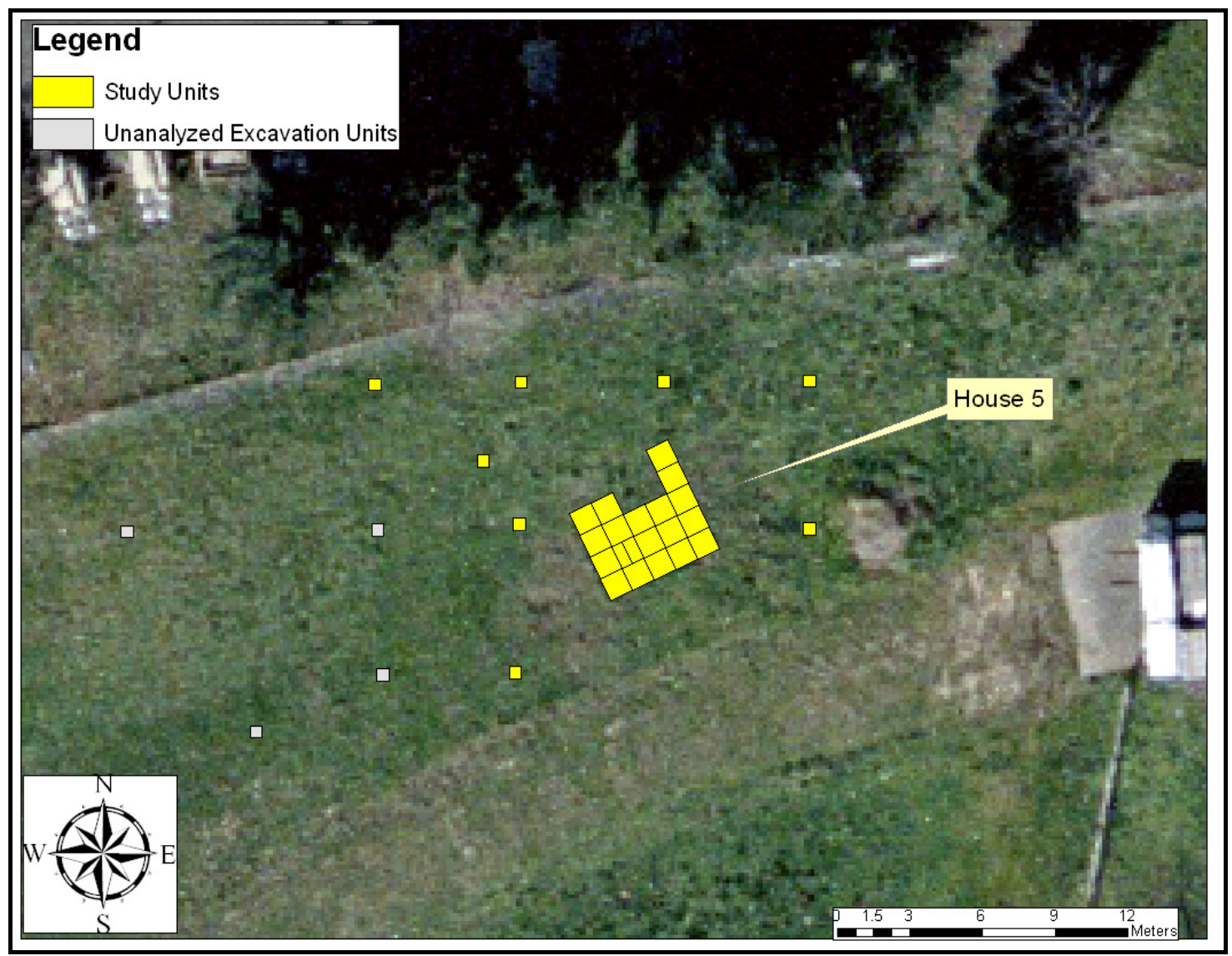

FIGURE 6. Aerial photomap showing the House 5 excavations (Wynia 2013).

\section{Houses 2, 3 and 4}

For the purposes of comparison, three previously analyzed ceramic assemblages from the Houses 2, 3 and 4 sites within the Village were included in the current analysis. These assemblages were recovered during the 1969 field season. The houses were identified by the characteristic packed, gray clay floors and dense concentrations of artifacts, as well as by associated features such as foundation planks, fire hearths and animal burials (Kardas 1969; Cromwell 2006). All three of these assemblages were previously analyzed by Robert Cromwell for his 2006 dissertation. Sherd counts for the 
House 2, 3 and 4 assemblages, taken from Cromwell's original analysis, are given below (Table 1).

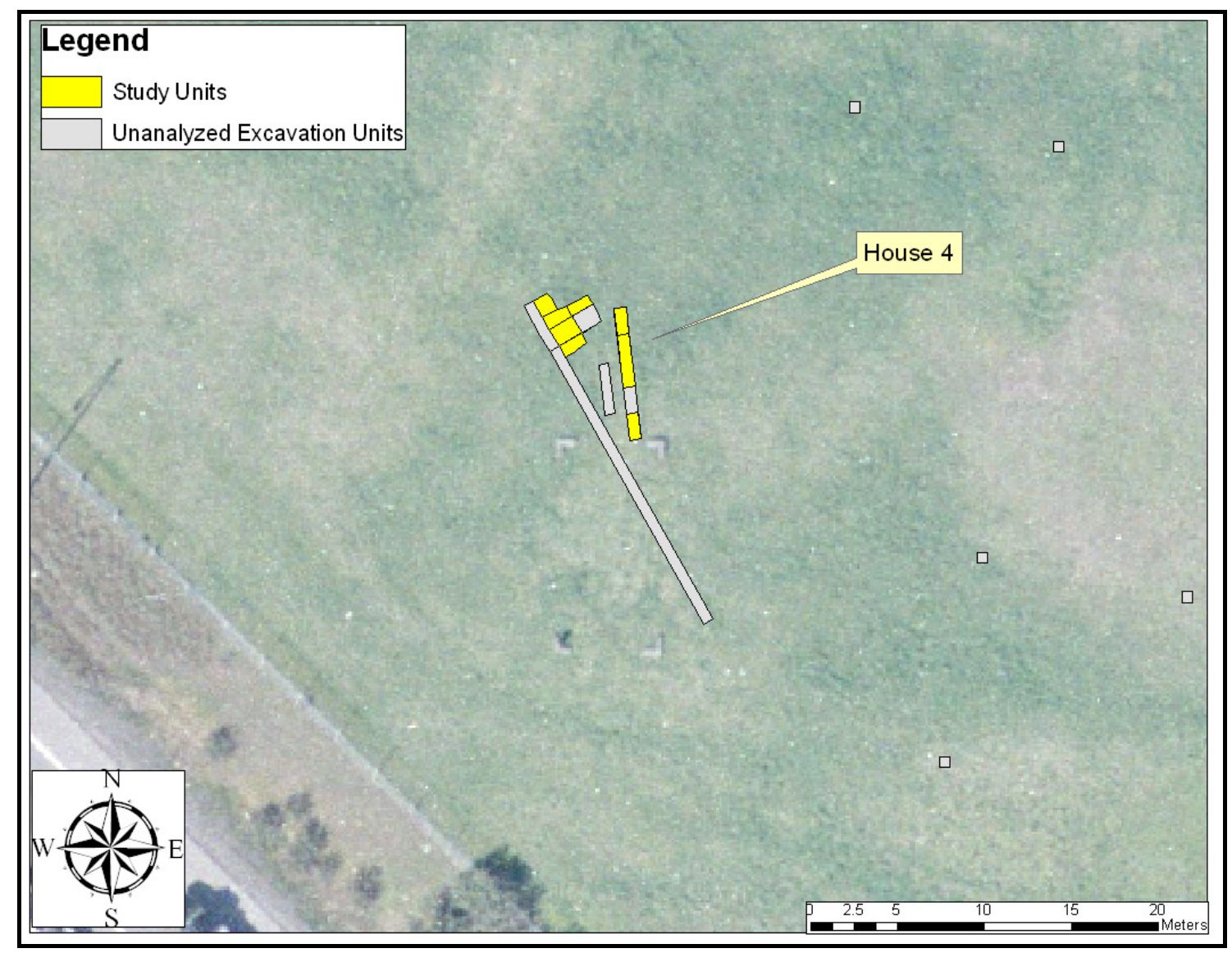

FIGURE 7. Aerial photomap showing the House 4 excavations (Wynia 2013)

\section{The Chief Factor's House and Kitchen (CFH)}

The final assemblage included in this study is that recovered from the Chief

Factor's House and Kitchen, referred to here as the CFH assemblage. The CFH assemblage was used to provide a means of comparison. As will be discussed in Chapter $\mathrm{V}$, the CFH was the social, political and economic focus of the fort, and was carefully 
constructed, furnished and appointed with articles that would communicate the importance of the building's occupants and their authority as representatives of the upper levels of the company hierarchy.

The first archaeological excavations of the CFH occurred in 1948 and 1950 during Louis Caywood's exploratory excavations for the National Park Service (Caywood 1955). Caywood revealed the remnants of the $\mathrm{CFH}$, as well as the separate kitchen building, recording features such as wooden footings, wall lines, the remains of a stone chimney, and two privy pits. The artifacts recovered from these preliminary investigations are not included in this study, as they have lost their provenience (Cromwell 2006). During the data recovery of the CFH, Hoffman and Ross excavated a total of 102 full or partial 10-foot squares, revealing the extent of the remains of the house and both the early and later kitchen buildings (Hoffman and Ross 1973b) (Figure 8).

A total of 2,370 fragments of various ceramicwares are included in the $\mathrm{CFH}$ assemblage used for the current study. Cromwell (2006) analyzed ceramics recovered from five excavation units that together are interpreted to be the passageway between the north wall of the $\mathrm{CFH}$ and the south wall of the first kitchen building. As Cromwell states,

These units were chosen based upon the thought that any broken ceramic vessels being used in either of these structures may have been disposed of in the alleyway, nearest to the passageway between the two buildings. This thought is confirmed by Hoffman and Ross's rudimentary spatial analysis of the frequency of fragments of ceramic 
vessels recovered per excavated unit, which showed the greatest concentration of recovered ceramic sherds originating from four of these five units (Cromwell 2006: 146).

The $\mathrm{CFH}$ assemblage was recovered from an area through which servants carried full dishes to the dining room from the kitchen, and empty dishes from the CFH back to the kitchen. It represents a more liminal space than the earthen floors of the Village houses, but the assemblages are comparable as this passageway was highly trafficked and therefore subject to many of the same formation processes as the Village house floors, namely trampling and the effects of cleaning or sweeping. The effects of site formation processes on the six assemblages under study are explored below.

TABLE 1

SHERD COUNTS AND MINIMUM NUMBER OF VESSEL (MNV) COUNTS FOR EACH OF THE VILLAGE ASSEMBLAGES AND THE CFH

\begin{tabular}{|c|c|c|}
\hline House \# & Sherd Count & MNV \\
\hline 1 & 870 & 136 \\
\hline 2 & 780 & 138 \\
\hline 3 & 862 & 128 \\
\hline 4 & 290 & 98 \\
\hline 5 & 547 & 113 \\
\hline CFH & 2,370 & 214 \\
\hline
\end{tabular}




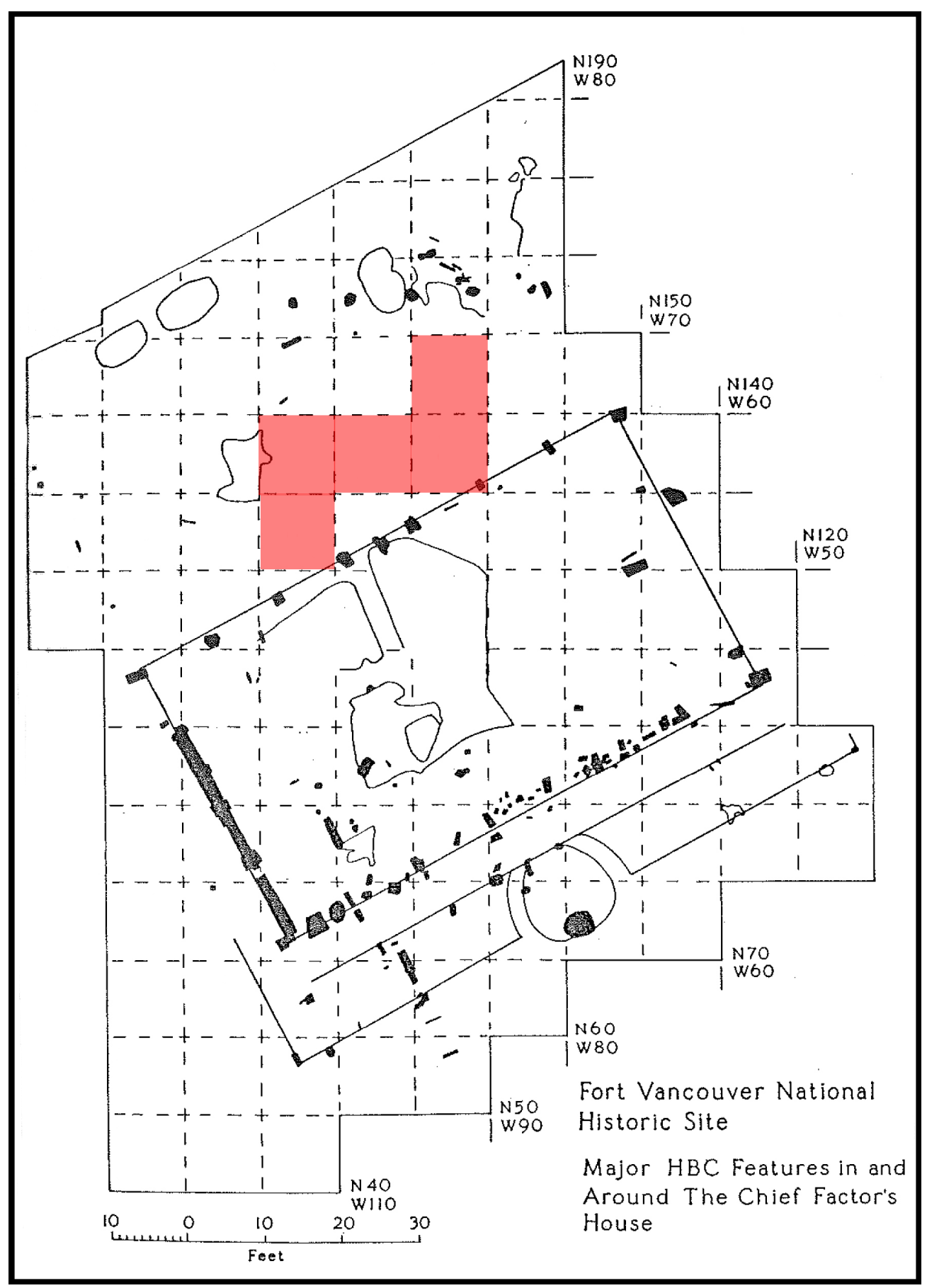

FIGURE 8. Chief Factor's House and Kitchen excavation units; ceramics recovered from the units in red were previously analyzed by Dr. Cromwell and are used in the current analysis (Hoffman and Ross 1972; Author 2013). 


\section{Site Formation Processes}

These six assemblages were compared in order to gain insight into the types and forms of ceramic vessels in use at households of varying socioeconomic status. However, site formation processes have direct effects on the comparability of assemblages, and archaeological assemblages reflect more than simply what was in use at each locus of occupation. The "identification of formation processes [...] must precede behavioral inferences" (Schiffer 1983: 675). For the current study there were three key components that may have altered the expected archaeological signatures of matching ceramic sets: depositional context, post depositional effects and archaeological excavation methods.

Culturally, the depositional contexts of ceramics from loci within both the Village and the Fort stockade itself were assumed to be, for the most part, directly comparable. It was assumed that in all of the loci under study, regardless of the socioeconomic status of the structures' inhabitants, ceramic sherds were deposited during the daily creation and serving of meals within their distinct contexts. Similarities in the use-life of ceramics in $19^{\text {th }}$-century households extend to the discard-life of these vessels as well.

Refuse disposal practices in the 19th century were learned behaviors subject to surveillance and regulation just as dining etiquette or other manners (Leone 2005). The rules governing where and how to dispose of refuse directly influenced the location of artifact concentrations. The assemblage from the Chief Factor's House was excavated from a space between two structures, where, Cromwell explains, "it was hypothesized that this deposit was created during the daily creation and serving of meals by the 
kitchens staff, who had to transport each serving from the kitchen, through the breezeway, and into the Chief Factor's House dining hall" (Cromwell 2006: 153). All six assemblages were recovered from areas of high artifact concentration: household floors in the Village, and the floor of a highly traveled corridor at the $\mathrm{CFH}$.

There are some issues of comparability between the assemblages related to post depositional processes such as trampling and exposure to weather, animals and other corrosive agents, which can have significant effects on the size and condition of ceramic sherds. The CFH assemblage, located within the stockade fort, was therefore not exposed to the increased foot traffic and other surface disturbances in the yard spaces around each household in the Village where the assemblages were exposed to greater disturbance after the structures were removed.

The historical effect of the U.S. Army is one of the most important postdepositional processes affecting the material culture in the Village. The U.S. Army took over the fort and Village sites in 1849, demolishing and cannibalizing the Village structures for building materials before sweeping any leftover unusable materials into the pond by 1859 (Hussey 1957: 271; Mullaley 2012). The extent of the ground disturbance within the Village can also be extrapolated from maps which depict at least six large buildings within the boundaries of the Village site by the early $20^{\text {th }}$ century (Figure 9). All accounts of Village excavations document disturbances into the HBC-era strata from the U.S. Army strata overlaying them. Many significant post-HBC era disturbances observed during excavation of all of the assemblages in question: features such as the 
CCC-era roadway looping through the Village site, and the wood-lined water lines placed by the U.S. Army in the early twentieth-century observed during excavations at the Chief Factor's House (Hoffman and Ross 1973b: 7-13). In an attempt to minimize the effects of these intrusions, the current study used strata from Village deposits that contain HBC-era artifacts, and addresses only the categories included in Dr. Cromwell's analysis of Houses 2-4 and the Chief Factor's House.

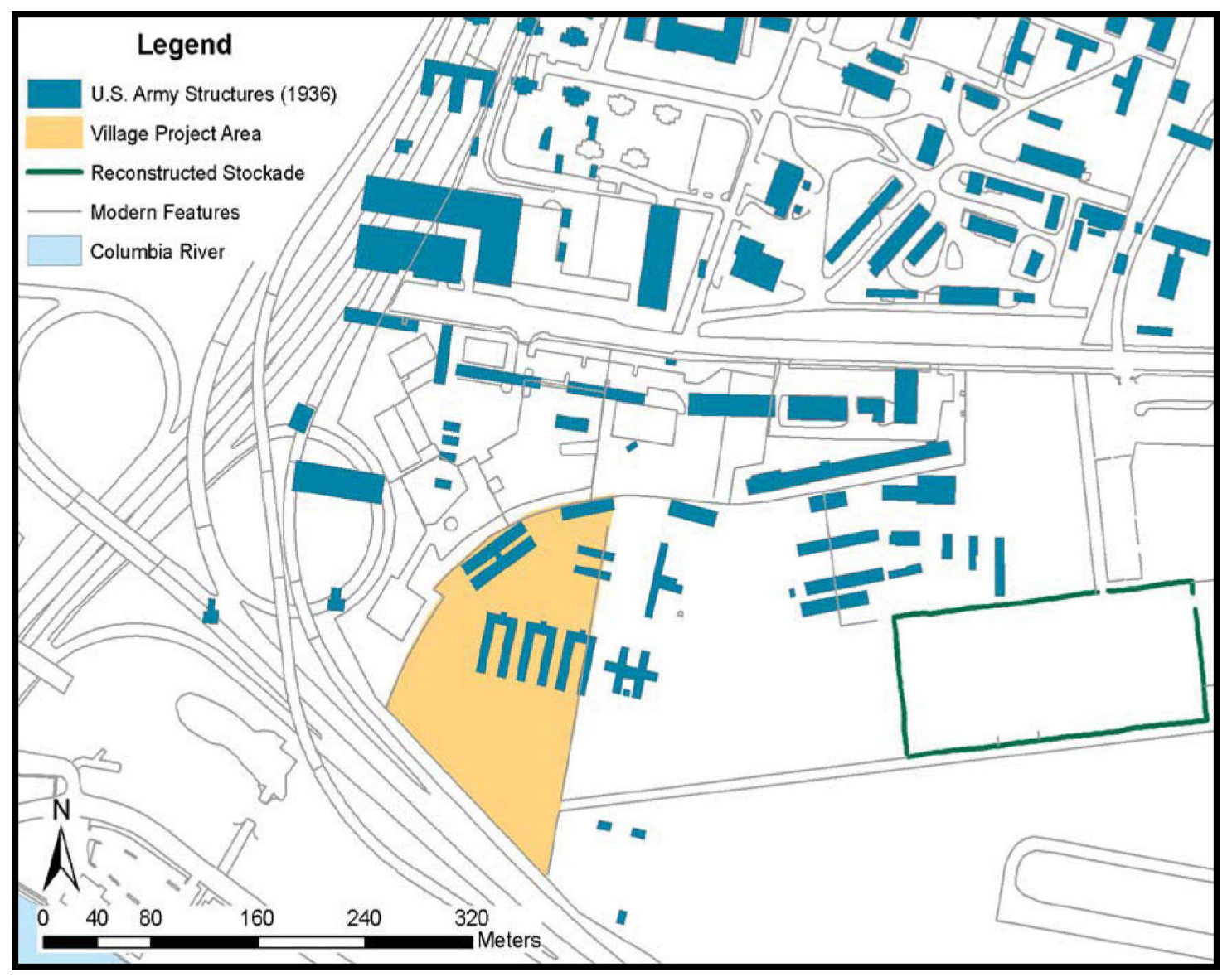

FIGURE 9. Plan view showing the location of early 20th century U.S. Army buildings at Vancouver Barracks, relative to the Village and the Fort Vancouver stockade. (Mullaley 2011). 
The CFH assemblage was also not impacted as heavily by the post-HBC occupation of the Fort site, such as the demolition of structures in the Village. While the Village houses were demolished, the stockade buildings, including the $\mathrm{CFH}$, were occupied until finally abandoned by 1865 , and burned in place in 1866 (Thomas and Hibbs 1984; Cromwell 2006). In order to control for these effects, only sherds with discernible stylistic decoration were used in diversity analysis, and sherds that were burnt, excessively scratched or with otherwise obscured decorative style were excluded. Size inhibited the analysis of ceramic form and function in cases where sherds were less than $10 \mathrm{~mm}$; however, as this is true of the smaller specimens from all six assemblages, it ultimately had little effect on their degree of usefulness for the present study.

Archaeology can itself be an important post-depositional disturbance, especially across the 60 years of archaeological excavations at Fort Vancouver. The CFH has been the focus of intense archaeological study since the 1940s, when Louis Caywood first identified the $\mathrm{CFH}$. The previous excavations removed many of the larger ceramics from this location, and therefore reduced the assemblage size recovered. Hoffman and Ross encountered Caywood's excavation trenches during the data recovery they performed on the CFH (1973b). The Village assemblages analyzed here are primarily the result of the initial excavations in the Village (Houses 1-4), beginning in the 1968-1969 field seasons, with some later units included in the case of House 1.

Finally, one of the biggest challenges posed by this research is the ability to compare archaeological assemblages excavated by archaeologists from different 
generations and to make the best interpretations possible from these assemblages (Cromwell 2006: 150). This study used previously excavated assemblages. The varying level of detail available in the field records, excavation reports, and artifact catalogs, as well as the vast differences in field methodology certainly affected the availability of data used in analyses.

The two multi-year excavation projects conducted within the NPS-administered portion of the Village were spaced thirty-five years apart and used two different field and preliminary laboratory methodologies (Mullaley 2011). As has been discussed earlier, 1968 and 1969 archaeologists employed large scale exploratory methods, to target dense concentrations of artifacts and features with hand-excavated trenches and excavation units. Artifacts recovered from these excavations were grouped and cataloged according to excavation unit levels that ranged from 15 to $51 \mathrm{~cm}$ (6 to 20in.) in thickness and screening excavated sediment was not consistently applied. The CFH excavations, in contrast, were completed entirely using trowels and hand shovels, and excavation proceeded stratigraphically in arbitrary 0.5-foot levels (Hoffman and Ross 1973b; Cromwell 2006). More recent excavations, including that of House 5, have relied on standardized field methods including the excavation of units by stratigraphic and arbitrary 10cm levels (Cromwell 2006: 31).

\section{Ceramic Analysis}

Ceramics have a high archaeological value, stemming from their pervasiveness, as well as from their durability and their diagnostic utility (Barker and Majewski 2006; 
Cromwell 2006). In addition to their value as temporal indicators, sherds of ceramic table and toiletwares represent ubiquitous products whose function remains largely unchanged even as they are prone to stylistic change, and changes in their availability can reflect changes in production, transportation and social importance. As such, ceramicwares have the potential to provide insight into a wide range of topics, including but not limited to: cultural change and colonization; the identities of groups and individuals; the social and economic status of consumers; the emergence of changing practices relating to the consumption of food and drink; patterns of trade and of local and regional variations in trade; and technological change and industrialization (Barker and Majewski 2006: 205). In the current study, ceramics are used as a material gauge of the degree to which Village households participated in the ideologies of Fort Vancouver in the mid-19th century.

Transferprinted, white-bodied earthenware is the most frequently recovered style of ceramics at Fort Vancouver, reflecting the revolution of developed technology and increased transportation capabilities in the Staffordshire region of England during the $18^{\text {th }}$ century, resulting in the overwhelming dominance of these ceramics, which were shipped around the world including the Pacific Northwest (Cromwell 2006). The ceramics at Fort Vancouver have a high degree of diagnostic utility, as the patterns imported to Fort Vancouver and other forts in the northwest have been documented extensively, thanks in large part to the relationship between the Spode/Copeland Company and the HBC that began in 1836 (Sussman 1979). Between 1823 and 1834 Robert Elliot was the sole provider of ceramic wares to the HBC, while John Blackburn provided the ceramics in 
1835 (Ross et al. 1975, 1979; Hamilton 1982: 52; Cromwell 2006). As previously discussed, the firm of Spode/Copeland first began supplying ceramics to the HBC in 1836. Becoming the sole ceramic provider to the $\mathrm{HBC}$ in 1837 , the firm retained a monopoly in supply until 1847, when Thomas Garrett separated from the firm and the name changed to W.T. Copeland (Hamilton 1982: 50; Cromwell 2006). Available records of Spode patterns imported to Fort Vancouver are critical to the analysis of ceramics at Fort Vancouver, as discussed below.

\section{Analysis Methods}

Analysis of the House 1 and 5 ceramic assemblages followed methods specifically developed for the Fort Vancouver National Historic Site laboratory, which were also followed in Cromwell's analysis (Wilson et al. 2003; Cromwell 2006). Every sherd was measured for size, using a metric-based size target. Sherds were then analyzed for specific ware type, i.e.: earthenware or stoneware. Decoration type, if any, was recorded as well as vessel shape (including vessel function, and anatomical position on vessel, i.e.: rim, base, foot etc.). Finally, all sherds were weighed and surface modifications such as crazing, burning and use wear were recorded.

In order to be consistent with Cromwell's analysis, the sherd-level analysis was transformed to object-level, using a minimum number of vessels (MNV) count. MNV counts describe the minimum number of original items that can account for the sherds present in archaeological assemblages (Voss and Allen 2010). A vessel count is a more accurate reflection of the actual number of vessels present in each assemblage, as it helps 
avoid the inflation of sherd counts from various breakage patterns, as the greater number of pieces into which a vessel is broken the more the vessel count might be artificially inflated (Staski 1990: 82). In order to minimize this effect, this author converted all six assemblages to MNV by comparing relevant variables such as vessel form, anatomical position on vessel, curvature and thickness of sherd bodies, as well as the decoration style, including pattern and color of transferprinting on each sherd, when applicable. The calculation of MNV counts was performed conservatively; if there was any possibility that two sherds could be from the same vessel, they were grouped together (Voss and Allen 2010). The value of this approach is discussed in Sussman (2000), wherein the author demonstrates the statistical inadequacy of sherd counts for basic archaeological analyses, including chi-square testing and correlation statistics, and states that "for any serious research purposes, sherd counts cannot be used as substitutes for object counts" (Sussman 2000: 103). 


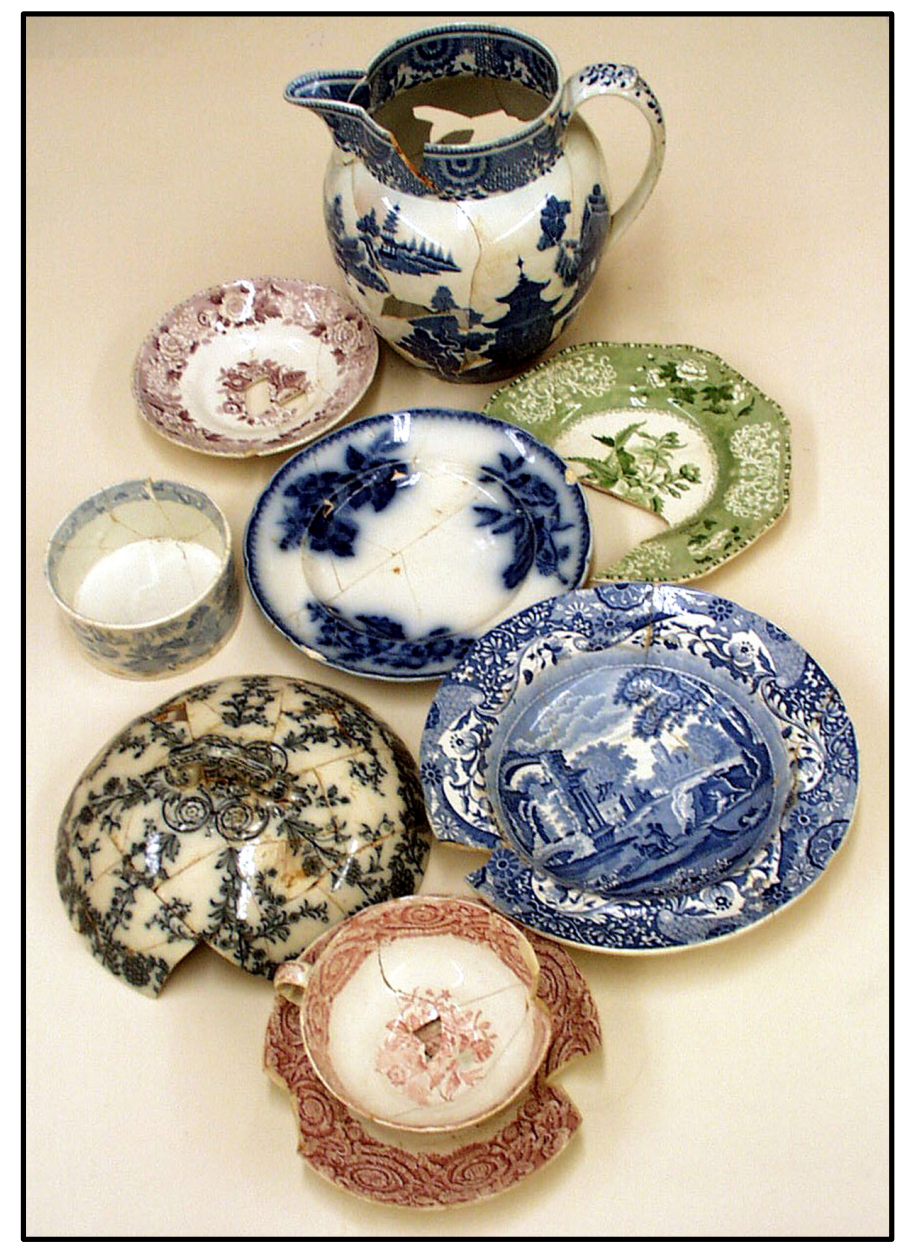

FIGURE 10. Examples of Spode ceramics representing various patterns and vessel forms, recovered archaeologically from excavations at Fort Vancouver National Historic Site (NPS Stock Image)

\section{Diversity Analysis}

Once the assemblages were rendered directly comparable through MNV analysis, diversity analysis began with the division of artifacts into classes, based on decoration style and vessel form. Decoration style was determined first by the color and composition of the ceramic fabric and then by the method of decoration and, in the case of transferprinted ceramics, the color and the specific transferprinted pattern represented on 
each sherd. As mentioned previously, the HBC's monopoly contract with Spode resulted in a proliferation of these patterns, which were primarily identified using Lynn Sussman's book Spode/Copeland Transfer-printed Patterns (1979), in which examples of Spode ceramicware patterns identified at Fort Vancouver and other Northwest fur trade posts are presented as they would appear on whole vessels.

Vessel form was determined by observing and comparing the relative thickness and curvature of the ceramic body, as well as the decoration style and shape of each sherd. Many sherds were too fragmentary to allow the identification of vessel type. In these cases, an attempt was made to classify these unknown sherds as either flatware (i.e.: dinner plates, saucers, soup plates, platters etc.) or hollowware (i.e.: cups, bowl, pitchers, jugs etc.).

Once the classes were finalized, diversity analysis was performed following the methods described in Kintigh (1989), using both richness and evenness. Comparisons of assemblages using only richness present a problem when the effects of sample size are considered, and even when combined with evenness, differences in sample size compromise the ability of assemblages to be compared directly (Kintigh 1989: 26). Larger assemblage size is not necessarily an indicator of greater richness; what needs to be considered is relative richness. This study utilized Keith Kintigh's Tools for Quantitative Analysis (TFQA) software package, and specifically the diversity module DIVERS, which calculates richness and evenness (H/Hmax) dimensions of diversity for a given data set and uses Monte-Carlo methods to derive expected diversity for a model 
distribution over a range of sample sizes, effectively allowing for analyses of diversity to control for the influence of sample size (Kintigh 1984, 1989, 2006).

In the current study, the assemblages were compared not only to each other, but to the model assemblage recovered from the $\mathrm{CFH}$. This assemblage was chosen as the model because the wealthiest inhabitants of the Fort lived and ate in this house, and as such it demonstrated the etiquette and consumer practices that workers were to emulate. Once the classes were defined and populated for the variables of decorative style (Table 4) and vessel form (Table 5), the six assemblages, including the model assemblage from the $\mathrm{CFH}$, were input into the DIVERS module of TFQA.

DIVERS automatically calculates richness and evenness values for the model assemblage at sample sizes ranging from 100 to 500, increasing at intervals of 20 from 100 to 200 , and at intervals of 50 from 200 to 500. DIVERS produced four graphic representations of the derived richness and evenness values: one each for richness of form, richness of style, evenness of form and evenness of style. The mean expected richness and evenness values for the $\mathrm{CFH}$ were given graphically in the form of a solid line, on which the values for each assemblage were overlaid for comparison (Figures 1215). In addition to the mean expected value for the CFH model, the software generated the upper and lower limits of a 95\% confidence interval (dotted lines), which was used as a tool to determine the significance of each assemblage's position relative to the CFH.

This analysis was first performed for each of the complete ceramic assemblages, which included stoneware and various earthenware types such as yellowware and 
lustreware. The same tests were then run for only the transferprint ceramics from each assemblage, as these comprise the majority of all six assemblages, are the most easily identified patterns, and were most readily available for purchase- both at Fort Vancouver and in general- in complete matching sets. The results of this analysis are given in Chapter VI (Figures 16-19). 


\section{CHAPTER V: LITERATURE REVIEW}

The following is an examination of the modes of production that were in play, and the mechanisms employed by the $\mathrm{HBC}$ and its Officers to reinforce the disparity between the classes employed at Fort Vancouver. Instead of adherence to free market capitalism, such as that in Annapolis, the fort was caught in a complex web of economic influences from various modes of production. As seen in Chapter III, the HBC embodied a colonial political economy, with mercantile and feudal land policies, while relying on the labor of those who worked to support the system of corporate capitalism in place at their forts. Instead of an ideology of individualism like that observed in Annapolis, the HBC sought to preserve loyalty to the ideals of the company through an ideology of paternalism that was built on a long history of the Hudson's Bay Company's institutional policy, and reinforced through landscape design, socioeconomic disparity and established daily habits, presented here (Leone et al. 1992).

\section{Routinization of Labor and Daily Life}

In order to extract as much productivity as possible, the HBC constantly policed the actions and behaviors of its Servants through many means, including the strictly enforced routine of the workday. According to Leone, "the ideology of time in capitalism cuts up daily activities into fragments which appear more rational and which thus become controllable" (Leone 1984: 26). The ways this was accomplished at Fort Vancouver are difficult to determine, however one important account from John Wilkes, an American expedition commander, shows the "machine-like regularity by which the lives of [the 
fort's] workers moved" (Schenk 1932: 37). While visiting the fort in 1841, Wilkes

remarked that:

At early dawn the bell is rung for the working parties, who soon after go to work: the sound of hammers, click of anvils, the rumbling of carts, with tinkling of bells render it difficult to sleep after this hour. The bell rings again at eight, for breakfast; at nine they resume their work, which continues until one; then an hour is allowed for dinner, after which they work till six, when the labours of the day close, at five o clock on Saturday afternoon the work is stopped, when the servants receive their weekly rations (sic, Wilkes 1856).

The tolling of bells has served as a mechanism to establish the daily habits of labor since medieval times. Their use at Fort Vancouver perhaps indicates the persistence of pre-capitalist signals and the ways they were re-appropriated as an auditory means of strengthening the divisions of the day into segments of time and appropriate behavior, to extract as much labor of the working class as possible, and to subtly reinforce the reliance of the Servants on the company to set standards of behavior and time-work discipline from above. Here the HBC, a private entity, adopted a mechanism of state control in order to naturalize the exploitation of workers through the segmentation of the workday. The bells signified a code to which each member of the Fort Vancouver labor hierarchy tacitly adhered and link the economic system at the fort to feudalism and mercantilism as well as corporate capitalism.

\section{Landscapes of Power}

The fort was a colonial community, a center of agriculture and commerce that was heavily influenced by European feudalism and mercantile capitalism in the midst of what 
was essentially, to European eyes, the wilderness. As such, the layout and design of the fort itself, its environs, including the garden and the buildings within it was ideologically informed, and served to naturalize the presence of the HBC in the Northwest.

As at many other colonial settlements, Fort Vancouver was constructed to emphasize its dominant economic position as founder and sponsor of the $\mathrm{HBC}$ on this particular landscape (Monks 1992: 44; Lightfoot 2006, Hamilton 2000). Descriptions of the physical fort reveal that it was a dominant feature of the local landscape "a symbol of authority and power to the local community...command[ing] power over the landscape" (Nelson 2007: 9). It was an edifice of defense against economic adversaries, both external in the form of other interests in the fur trade of the area, and internal in the form of those who would subvert the established hierarchy.

At Fort Vancouver the HBC also established and supported the authority of their Officers by using non-verbal symbols and the positions of structures to reinforce their leadership to all those who came to and worked at their forts (Monks 1992; Nelson 2007). The Chief Factor's House was the social and political focus of Fort Vancouver. As such, it was the largest and most ostentatious building at the fort, and is described in various accounts as the "big house" since it was two stories, with its main floor elevated several feet (Caywood 1955). It occupied the primary focal point from the main entrance of the stockade and served as a symbol of authority to all those who lived or did business within the fort (Morrison 1999). The physical appearance of the Chief Factor's house also served to reinforce the dominance of the highest company Officer at Fort Vancouver. The 
house was built after the French-Canadian model, surrounded by a piazza, small flower beds, grapes, and other vines, while the other buildings in the fort were largely utilitarian and unadorned. Perhaps the most obvious physical symbol of the dominance of the Chief Factor are the two cannons situated in front of the house, which were inoperable and served primarily as symbols of authority and markers of dominance (Schenk 1932; Hoffman and Ross 1973; Nelson 2007). The dominant and grandiose appearance of the $\mathrm{CFH}$ was meant to communicate authority and dominance of the Chief Factor as the occupier of the top of the hierarchy at the fort.

In addition to being an imposing edifice of colonial authority, the fort also represented an oasis of order in the midst of the wilderness, as described by 19th-century visitors to the Fort such as Narcissa Whitman, who exclaimed in her diary, "What a delightful place this is; what a contrast to the rough, barren sand plains, through which we had so recently passed" (Whitman 1982: 63). The HBC carefully cultivated the appearance of the fort, the buildings therein and its garden, creating a disparity between the wild land surrounding the fort, and the ordered environment within its influence, that naturalized the ways in which the European capitalists had exploited the landscape of North America throughout the previous centuries in order to amass financial and political gains (Carlos 1988, 1990; Hammond 1993). Examination of the English garden at the fort recalls Leone's study of the ways in which the layout of the city underscored the ideology of individualism that masked the realities of inequality throughout it (Leone 1984, 1987, 1988, 2005; Leone et al. 1989, 2005). Narcissa Whitman described a similar attention to 
detail in the layout of the gardens at the fort, remarking "here we find fruit of every description...and every kind of vegetable too numerous to be mentioned. Every part is very neat and tastefully arranged, with fine walks, lined on each side with strawberry vines" (Whitman 1982: 63).

The garden was a symbol of the power of the HBC and a specific locus where the order imposed by the $\mathrm{HBC}$ on the natural world functioned to disguise the arbitrariness of the imposed order of the social world, and this ideological confusion made the highly structured social world of the HBC appear to be unquestionable (Deetz 1977; Leone 1984; Dorset 2012). The HBC had long-standing policies of unequal access to food at the various hierarchical levels of the Company, a policy that served to conform to the rules of provision at the time, and to emphasize the separation of the classes (Loudon 1824; Burley 1997; Hamilton 2000). While significant symbolically, the garden also provided food for the Gentlemen of the fort only, a reminder that exotic foods from around the world were still not available to certain classes of employees, nor to the local inhabitants. The restriction also communicated and reinforced the hierarchical system to those who were employed within the company (Dorset 2012).

\section{Economic Isolation}

Economically, control of the labor force was carefully maintained through differing degrees of remuneration and reward in exchange for labor. The HBC has a long history of setting differential pay-scales. During retrenchment, for example, new systems of remuneration were put in place, including the opening of company shares to the 
Officer classes. By 1815, however, the London Committee feared that giving company shares to junior officers would provide them with too much information about company affairs and shareholders were then limited to "Chiefs or Officers of the First Rank' (Burley 1997; HBCA A.6/18). This is one important instance where the Officer class was subjected to the same rules of hierarchy as the Servants, as their remuneration was regulated from above by the Committee in London.

At Fort Vancouver, the lowest classes felt the effects of economic reinforcement of the labor hierarchy most keenly. The upper levels determined the system of wages and rewards for the Servant classes in correlation with their appropriate station, recalling a classically familial group in which the paternal figure set the standard for behavior and rewarded those who exemplified the ideals of that family. This system is favored in capitalist societies as it allows those at the top to set the remuneration and limit the advancement of those at the bottom (Burley 1997). The isolated location of Fort Vancouver also trapped workers into these relations, as it prevented them from simply quitting and seeking more equitable employment elsewhere. In Table 2, Cromwell (2006) has assembled the pay scale of Fort Vancouver/HBC employees. Here it is apparent that the various classes (Officers, Servants and Charges) differed significantly in their yearly salaries, with the Chief Factor earning almost 25 times as much per year as the lowest rank, the charges (Cromwell 2006; HBCA B.223/d/162; Morrison 1999). The differences in pay reflected the ideology of favoring Gentlemen: educated, white, European men who were given ample opportunity to advance in the ranks. Those at the bottom of the 
hierarchy were restricted by their lack of education as well as their ethnicity and earning potential (Table 2).

TABLE 2

GENERALIZED PAY SCALE OF FORT VANCOUVER/HBC EMPLOYEES, CA. 1829-1860, BY COMPANY CLASS AND JOB RANK (HBCA B.223/D/162; Morrison 1999; Cromwell 2006: 126)

\begin{tabular}{|c|c|c|c|c|}
\hline CLASS & CAPACITY & £/YEAR (LOW) & £/YEAR (HIGH) & MEAN £/YEAR \\
\hline $\begin{array}{c}\text { Commissioned } \\
\text { Officers }\end{array}$ & Chief Factor & 78.29 & 500 & 289.1 \\
\cline { 2 - 5 } & Chief Trader & 50 & 250 & 150 \\
\hline \multirow{3}{*}{ Servants } & Gentlemen & 30 & 150 & 90 \\
\cline { 2 - 5 } & Tradesmen & 20 & 50 & 35 \\
\cline { 2 - 5 } & Voyageurs & 17 & 22 & 19.5 \\
\cline { 2 - 5 } & Laborers & 16 & 17 & 16.5 \\
\hline
\end{tabular}

The prices employees were charged for luxury goods such as alcohol reinforced the hierarchy as well. For the Servant, liquor had to be purchased at a differential price, which served as a way to police employee behavior and reinforce their status. In some instances price differences were used to police the behavior of members of the higher classes as well. McLoughlin, writing to the Governor and Committee about a ship captain named Haynes writes, "in [Captain Haynes] account spirits is charged 18/pr gall, the price it is sold to servants. I do not know if I am correct in charging this price, but even if not I would still have done so to prevent too great a demand" (McLoughlin 1829). Here is a clear example of the ways in which employee behavior is corrected through economic restrictions, as McLoughlin limited the alcohol consumption of a ship's captain by charging him the same, higher, price as the Servant class. 
The practice of reinforcing divisions through economic means extended to transactions at the employee Sale Shop. The policy of applying differential tariffs to employee goods was laid out in the Standing Rules and Regulations in 1828 (Rupert's Land Northern Department Council 1828). Cromwell (2006) showed the rather appalling increases in the prices of goods sold to workers at the Sale Shop (Table 3).

TABLE 3

PERCENT INCREASE IN THE COST OF GOODS AT FORT VANCOUVER, BASED UPON SOCIAL CLASS AND ETHNICITY, CA.1829-1860 (Cromwell 2006: 128)

\begin{tabular}{|c|c|c|c|c|c|c|}
\hline & \multicolumn{3}{|c|}{ Imported Goods } & \multicolumn{3}{c|}{ Country-Made Goods } \\
\cline { 2 - 8 } & Summer & Winter & Annual & Summer & Winter & Annual \\
\hline \multirow{3}{*}{ Commissioned Officers } & Cost + & Cost + & & & & \\
\hline \multirow{2}{*}{ Servants } & $25 \%$ & $100 \%$ & & & & Cost \\
& & & Cost + & Cost + & Cost + & \\
& & & $50 \%$ & $12.5 \%$ & $50 \%$ & \\
\hline \multirow{2}{*}{ Owyhees } & & & Cost + & & & Cost + \\
& & & $200 \%$ & & & $200 \%$ \\
\hline
\end{tabular}

In analyzing data from the 1852 Sale Shop inventory, Cromwell notes that a "E.W. (earthenware) dinner Service complete" is listed at a price of 141 shillings, 9 pence, or converted to Pounds Sterling, $£ 7,1$ shilling, 9 pence (2006: 128; HBCA 223d205ss). Based upon the costs referenced in Table 3, with the summer tariff, an employee of the Commissioned Officer or Gentlemen classes could have purchased this dinner set (interpreted to consist of 12 dinner plates, 12 soup plates, 12 side plates, 12 bread and butter plates, 3 platters, 2 vegetable dishes, 2 gravy boats and 1 soup tureen or a total of 56 vessels) for approximately $£ 8,16$ shilling, 3 pence. A member of the Servants class, purchasing this same set, would have paid $£ 10,12$ shilling, 2 pence; for a 
Native Hawaiian laborer, this dinner set would have cost over $£ 14$ (Cromwell 2006: 129). The differences in pay scale and taxation rates underscored the differences between the classes and even the ethnicities within those classes and kept the people who made up those divisions within their appropriate place. It also likely restricted the ability of the lower classes to replicate the purchasing patterns observed in the higher classes.

\section{Victorian Etiquette at Fort Vancouver}

The symbols of authority connected to the Chief Factor's House did not stop at the door. In addition to housing the Chief Factor, Chief Trader and their families, the Chief Factor's House served as a visitor's center, and the public center of social, economic and political activity in the Columbia Department. The Chief Factor's House was also the dining hall for the Gentlemen class as well as all visitors to Fort Vancouver. The etiquette followed at the Chief Factor's table was not empty formality. Etiquette "is dynamic, it supports interest groups, and it had material consequences....the elite used goods and the rules associated with their use to maintain social distance and stratification" (Shackel 1993: 3). The extension of ideologies to dining etiquette is central to the current study.

The strict Victorian social etiquette that pervaded the 19th century is perhaps best seen in the standards of behavior governing dining in the Gentlemen's mess hall. The importance of dining as a social ritual in the Victorian world cannot be overstated. According to handbooks from the late 1800s, the dinner table was of utmost importance to the construction of social relations (Jameson 1987). Not much is written of the 
specifics of the Chief Factor's table, but what is available suggests that the strict etiquette that governed the table was an extension of the rules that governed every level of capitalist societies. Even at the dining table behavioral standards were imposed using a rigid system of hierarchy. The wives of the Officers, along with the Servant classes were excluded from the table altogether and rank, grade and seniority determined the daily seating arrangement. Dr. McLoughlin, the symbolic head of the Fort Vancouver family presided at the head of the table, with guests seated to his right, the highest officials to the left, and the remaining employees seated according to relative rank, privilege and station (Schenk 1932). This practice reinforced not only the separation of the working classes from the Gentlemen class, but distinctions within the Gentlemen.

In addition to reinforcing the distinctions between classes, the Chief Factor's dining table was also a locus of the segmentation mentioned earlier in connection to formal gardens. The table was set with "beautiful chinaware, glassware and more elaborate furnishings" (Hoffman and Ross 1973; McKie 1981: 31), in individual, matching transferprint place settings (Cromwell 2006). The plates are not described in first-hand accounts, except as "elegant queensware" (i.e.: Spode) (Farnham 1843: 133) or in more general descriptions of a "table set with blue" (Pittman 1837: 153). Narcissa Whitman gave a description of a meal at the Chief Factor's table wherein she describes a lavish, multi-course meal consisting of several courses. After every new dish, "we have a clean plate" (Whitman 1982: 68). While Whitman would have dined separately from the 
Gentlemen, as a visitor, it can be assumed that she received similar tableware and observed similar etiquette to that at the Chief Factor's table.

The appearance of so many distinct dishes is especially important to the current study when one considers the connection between ideology and ceramics that was posited in Chapter III. "The development of a new etiquette and material culture associated with formal and segmented dining and increasing concern for personal appearance and hygiene are some of the tools people used to create explicitly different groups" (Shackel 1993: 7). The archaeological evidence for these matched sets both in the CFH and in several households in the village will be presented in the following chapter. 


\section{CHAPTER VI: ARCHAEOLOGICAL RESULTS}

This chapter presents the results of the archaeological analysis of ceramics from Houses 1-5 in the Village, and that from the CFH site from within the Fort Vancouver stockade. It begins with a brief discussion of the analysis of the Village household assemblages, including that of Houses 1 and 5, which are summarized for the first time by this author. Following the discussion of MNV numbers in Chapter IV, all the numbers reported in the tables that follow are vessel numbers. Only data related to vessel form and decoration style are presented here. The chapter then gives a summary of the pertinent classes from Cromwell's (2006) analysis of the assemblages from Houses 2- 4, and from the CFH. Finally, the diversity analysis performed on all six assemblages is presented with interpretation. This analysis focused on identifying the presence of matched sets of ceramics as an indicator of participation in the segmenting ideology of capitalism. The importance of matched sets is discussed in Chapter III.

\section{House 1}

A total of 870 ceramic sherds, representing a minimum of 136 distinct vessels, comprise the House 1 ceramic assemblage. These vessels represent 10 ware types: nine varieties of earthenware, and stoneware (Table 4). The category of stoneware is made up of both gray and buff-bodied English stonewares, as well as brown-bodied Chinese stoneware. 
A total of 14 vessel forms (Table 5) comprise the House 1 ceramic assemblage. If the specific vessel form could not be determined, that vessel was classified as either flatware or hollowware.

TABLE 4

WARE TYPES IN ASSEMBALGES FROM HOUSES 1-5 (VILLAGE) AND THE CFH (FORT)

\begin{tabular}{|c|c|c|c|c|c|c|c|}
\hline & & & & House & & & \\
Ware & House 1 & House 2 & House 3 & 4 & House 5 & CFH & TOTAL \\
\hline Banded Whiteware & 9 & 7 & 1 & 9 & 2 & 2 & $\mathbf{3 0}$ \\
\hline Creamware & 0 & 11 & 1 & 0 & 0 & 3 & $\mathbf{1 5}$ \\
\hline Shell-edge Whiteware & 4 & 0 & 0 & 0 & 1 & 2 & $\mathbf{7}$ \\
\hline Yellowware & 6 & 0 & 0 & 0 & 2 & 0 & $\mathbf{8}$ \\
\hline Molded Whiteware & 1 & 2 & 0 & 1 & 1 & 2 & $\mathbf{7}$ \\
\hline Cottageware & 7 & 0 & 1 & 2 & 13 & 5 & $\mathbf{2 8}$ \\
\hline Lustreware & 9 & 2 & 1 & 2 & 1 & 6 & $\mathbf{2 1}$ \\
\hline Other Redware & 0 & 2 & 0 & 7 & 1 & 0 & $\mathbf{1 0}$ \\
\hline Mochaware & 4 & 0 & 1 & 0 & 4 & 0 & $\mathbf{9}$ \\
\hline Stoneware & 21 & 2 & 31 & 6 & 5 & 10 & $\mathbf{7 5}$ \\
\hline Undecorated Whiteware* & 10 & 15 & 2 & 8 & 12 & 11 & $\mathbf{5 8}$ \\
\hline Transferprinted Whiteware & 65 & 97 & 90 & 63 & 71 & 173 & $\mathbf{5 5 9}$ \\
\hline TOTAL & $\mathbf{1 3 6}$ & $\mathbf{1 3 8}$ & $\mathbf{1 2 8}$ & $\mathbf{9 8}$ & $\mathbf{1 1 3}$ & $\mathbf{2 1 4}$ & $\mathbf{8 2 7}$ \\
\hline
\end{tabular}

*Following Cromwell (2006), the undecorated white earthenware fragments, which represent a large percentage of each assemblage, are given their own category, although they may represent undecorated portions of transferprinted or other decorated wares. 
TABLE 5

VESSEL FORMS IN ASSEMBLAGES FROM HOUSES 1-5 (VILLAGE) AND THE CFH (FORT)

\begin{tabular}{|c|c|c|c|c|c|c|c|}
\hline Form & House 1 & House 2 & House 3 & House 4 & House 5 & CFH & Total \\
\hline Bowl & 10 & 13 & 0 & 12 & 6 & 1 & $\mathbf{4 2}$ \\
\hline Chamber Pot & 2 & 3 & 0 & 1 & 0 & 1 & $\mathbf{7}$ \\
\hline Dessert/Side Plate & 10 & 0 & 3 & 0 & 1 & 4 & $\mathbf{1 8}$ \\
\hline Flatware & 6 & 1 & 1 & 2 & 18 & 31 & $\mathbf{5 9}$ \\
\hline Hollowware & 36 & 7 & 33 & 13 & 26 & 35 & $\mathbf{1 5 0}$ \\
\hline Jug & 4 & 0 & 1 & 2 & 0 & 7 & $\mathbf{1 4}$ \\
\hline Mug & 1 & 0 & 1 & 1 & 0 & 1 & $\mathbf{4}$ \\
\hline Pitcher & 0 & 5 & 0 & 0 & 3 & 3 & $\mathbf{1 1}$ \\
\hline Plate & 17 & 19 & 11 & 18 & 20 & 26 & $\mathbf{1 1 1}$ \\
\hline Platter & 2 & 4 & 0 & 3 & 2 & 12 & $\mathbf{2 3}$ \\
\hline Saucer & 13 & 35 & 29 & 19 & 13 & 32 & $\mathbf{1 4 1}$ \\
\hline Soup Plate & 9 & 23 & 12 & 3 & 7 & 17 & $\mathbf{7 1}$ \\
\hline Teacup & 23 & 26 & 34 & 23 & 15 & 33 & $\mathbf{1 5 4}$ \\
\hline Tureen & 2 & 0 & 0 & 1 & 1 & 3 & $\mathbf{7}$ \\
\hline Wash Basin & 1 & 2 & 3 & 0 & 1 & 8 & $\mathbf{1 5}$ \\
\hline TOTAL & $\mathbf{1 3 6}$ & $\mathbf{1 3 8}$ & $\mathbf{1 2 8}$ & $\mathbf{9 8}$ & $\mathbf{1 1 3}$ & $\mathbf{2 1 4}$ & $\mathbf{8 2 7}$ \\
\hline
\end{tabular}

Transferprinted white earthenware ( $n=65$ vessels) accounts for $47.8 \%$ of the House 1 ceramic assemblage, representing 25 distinct transferprint patterns in seven colors (Table 6). A total of $83 \%$ of these patterns ( $n=54$ vessels) are attributed to the Spode company (as identified in Sussman 1979), reflecting the dominance of this ceramic brand's monopoly contract during the mid $-19^{\text {th }}$ century. Of the identifiable patterns, the most commonly recovered were Spode's Lily ( $n=11$ or $16.92 \%)$, Camilla $(n=7$ or $10.77 \%$ ) and Beverly ( $n=6$ or $9.23 \%$ ), which together account for $36.92 \%$ of the transferprint assemblage (Table 6). 
TABLE 6

TRANSFERPRINT PATTERNS INDENTIFIED IN ASSEMBLAGES FROM HOUSES 1-5 (VILLAGE) AND THE CFH (FORT), CONTINUED ON THE FOLLOWING PAGE

\begin{tabular}{|c|c|c|c|c|c|c|c|}
\hline & & & & & CFH & \\
\hline Pattern & House 1 & House 2 & House 3 & House 4 & House 5 & (Model) & TOTAL \\
\hline Aesop's Fables & 3 & 0 & 8 & 5 & 2 & 7 & $\mathbf{2 5}$ \\
\hline Alhambra & 0 & 1 & 0 & 6 & 0 & 5 & $\mathbf{1 2}$ \\
\hline Antique Vase & 1 & 0 & 1 & 3 & 2 & 7 & $\mathbf{1 4}$ \\
\hline Antoinette & 0 & 0 & 1 & 0 & 0 & 0 & $\mathbf{1}$ \\
\hline B700 & 0 & 0 & 0 & 0 & 0 & 3 & $\mathbf{3}$ \\
\hline B770 & 0 & 0 & 0 & 0 & 1 & 1 & $\mathbf{2}$ \\
\hline B772 & 0 & 15 & 0 & 5 & 0 & 6 & $\mathbf{2 6}$ \\
\hline B773 & 1 & 1 & 0 & 3 & 0 & 5 & $\mathbf{1 0}$ \\
\hline Bamboo \& Flower & 2 & 0 & 2 & 0 & 0 & 0 & $\mathbf{4}$ \\
\hline Beverly & 6 & 6 & 3 & 0 & 2 & 2 & $\mathbf{1 9}$ \\
\hline Blue Rose & 2 & 4 & 3 & 0 & 4 & 7 & $\mathbf{2 0}$ \\
\hline Botanical & 2 & 0 & 0 & 0 & 2 & 0 & $\mathbf{4}$ \\
\hline British Flowers & 1 & 2 & 3 & 0 & 1 & 8 & $\mathbf{1 5}$ \\
\hline Broseley & 0 & 5 & 4 & 0 & 4 & 6 & $\mathbf{1 9}$ \\
\hline Byron Groups & 3 & 2 & 2 & 2 & 1 & 6 & $\mathbf{1 6}$ \\
\hline Byron Views & 3 & 0 & 0 & 0 & 0 & 2 & $\mathbf{5}$ \\
\hline Camilla & 7 & 16 & 8 & 12 & 2 & 10 & $\mathbf{5 5}$ \\
\hline Chinese Flowers & 0 & 1 & 0 & 1 & 3 & 3 & $\mathbf{8}$ \\
\hline Chinese Gardens & 0 & 0 & 1 & 0 & 1 & 0 & $\mathbf{2}$ \\
\hline Chinese Plants & 0 & 0 & 0 & 0 & 3 & 0 & $\mathbf{3}$ \\
\hline Claremont & 0 & 0 & 0 & 0 & 5 & 0 & $\mathbf{5}$ \\
\hline Continental Views & 0 & 0 & 0 & 0 & 0 & 3 & $\mathbf{3}$ \\
\hline Fairy Villas & 0 & 0 & 0 & 0 & 1 & 0 & $\mathbf{1}$ \\
\hline Field Sports & 0 & 0 & 7 & 0 & 0 & 0 & $\mathbf{7}$ \\
\hline Florence & 0 & 0 & 1 & 0 & 0 & 0 & $\mathbf{1}$ \\
\hline Flower Vase & 0 & 0 & 0 & 0 & 0 & 3 & $\mathbf{3}$ \\
\hline French Radiating Sprigs & 0 & 0 & 2 & 0 & 0 & 1 & $\mathbf{3}$ \\
\hline Fruit \& Flowers & 2 & 4 & 1 & 0 & 2 & 6 & $\mathbf{1 5}$ \\
\hline Geranium & 0 & 0 & 0 & 0 & 0 & 2 & $\mathbf{2}$ \\
\hline Italian & 3 & 9 & 1 & 0 & 5 & 6 & $\mathbf{2 4}$ \\
\hline Lily & 9 & 6 & 11 & 4 & 5 & 14 & $\mathbf{4 9}$ \\
\hline Macaw/Pagoda & 2 & 13 & 6 & 8 & 2 & 6 & $\mathbf{3 7}$ \\
\hline Palmyra & 0 & 0 & 1 & 0 & 0 & 0 & $\mathbf{1}$ \\
\hline & & & & & & & \\
\hline
\end{tabular}


TABLE 6 Contiuned

\begin{tabular}{|c|c|c|c|c|c|c|c|}
\hline Pattern & & & & & CFH & \\
\hline Porsian Vase & 3 & 0 & 11 & 3 & 0 & 0 & $\mathbf{1 7}$ \\
\hline Portland Vase & 1 & 5 & 0 & 0 & 0 & 2 & $\mathbf{8}$ \\
\hline Raphaelesque & 0 & 1 & 3 & 0 & 0 & 5 & $\mathbf{9}$ \\
\hline Rose and Sprigs & 0 & 0 & 0 & 0 & 0 & 1 & $\mathbf{1}$ \\
\hline Ruins & 0 & 0 & 0 & 2 & 0 & 6 & $\mathbf{8}$ \\
\hline Rural Scenes & 0 & 0 & 0 & 0 & 0 & 1 & $\mathbf{1}$ \\
\hline Scroll & 0 & 0 & 0 & 1 & 0 & 0 & $\mathbf{1}$ \\
\hline Seasons & 1 & 0 & 0 & 1 & 6 & 6 & $\mathbf{1 4}$ \\
\hline Seaweed & 0 & 0 & 0 & 0 & 0 & 1 & $\mathbf{1}$ \\
\hline Sevres & 0 & 0 & 0 & 0 & 0 & 10 & $\mathbf{1 0}$ \\
\hline Shagreen & 0 & 0 & 0 & 0 & 5 & 2 & $\mathbf{7}$ \\
\hline Ship Border & 0 & 0 & 0 & 0 & 0 & 1 & $\mathbf{1}$ \\
\hline Sirius & 1 & 0 & 0 & 1 & 0 & 0 & $\mathbf{2}$ \\
\hline Statice & 0 & 0 & 0 & 0 & 1 & 0 & $\mathbf{1}$ \\
\hline Statue & 1 & 0 & 0 & 0 & 0 & 0 & $\mathbf{1}$ \\
\hline Temple & 0 & 0 & 0 & 0 & 1 & 3 & $\mathbf{4}$ \\
\hline Tower & 0 & 0 & 0 & 0 & 0 & 1 & $\mathbf{1}$ \\
\hline Tyrol Hunters & 0 & 0 & 0 & 0 & 0 & 1 & $\mathbf{1}$ \\
\hline Union & 3 & 0 & 2 & 0 & 5 & 0 & $\mathbf{1 0}$ \\
\hline Venustus & 1 & 0 & 0 & 0 & 0 & 0 & $\mathbf{1}$ \\
\hline Warwick Groups & 3 & 2 & 0 & 0 & 0 & 5 & $\mathbf{1 0}$ \\
\hline Waterloo & 0 & 0 & 0 & 0 & 0 & 1 & $\mathbf{1}$ \\
\hline Watteau & 1 & 0 & 7 & 3 & 1 & 6 & $\mathbf{1 8}$ \\
\hline Willow & 3 & 4 & 1 & 3 & 4 & 2 & $\mathbf{1 7}$ \\
\hline TOTAL & $\mathbf{6 5}$ & $\mathbf{9 7}$ & $\mathbf{9 0}$ & $\mathbf{6 3}$ & $\mathbf{7 1}$ & $\mathbf{1 7 3}$ & $\mathbf{5 5 9}$ \\
\hline
\end{tabular}




\section{House 5}

The 547 ceramic sherds that comprise the House 5 ceramic assemblage represent a minimum of 113 vessels. These vessels represent 11 different ware types, including 10 types of earthenware and at least three types of stoneware (Table 4).

A total of 12 vessel forms comprise the House 5 assemblage (Table 5).

Transferprinted white earthenwares account for $62.8 \%$ of the House 5 assemblage $(n=71$ vessels), and occur in 27 transferprint patterns in five colors (Table 6). As in the House 1 assemblage, Spode ceramics comprise the majority, $(n=61$ vessels or $85.9 \%$ of the transferprint assemblage). The most common patterns observed in the House 5 assemblage were Spode's Seasons and Lily as well as Minton’s Claremont patterns. These three patterns account for a total of $25.35 \%$ of the transferprint ceramics from House 5 ( $n=6$ vessels or $8.45 \%$ for each of these three patterns).

\section{Houses 2, 3 and 4}

For the full analysis of Houses 2, 3, and 4, as well as the Chief Factor's House, the reader is referred to Cromwell's 2006 doctoral dissertation. The characteristics of these assemblages that are most salient to the current study (vessel form and decoration style) are presented together here for direct comparison (Tables 4-6, above).

\section{House 2}

A minimum of 138 vessels comprise the House 2 assemblage, representing 11 vessel forms and eight decoration styles (Tables 4 and 5). Transferprinted white 
earthenwares account for $70.29 \%$ of the assemblage ( $n=97$ vessels), and a total of 18 distinct patterns in five colors were identified (Table 6). All of these patterns are attributable to the Spode Company. The most common patterns are Camilla $(n=16$ or $16.49 \%), B 772(n=15$ or $15.46 \%)$ and Macaw/Pagoda ( $n=13$ or $13.4 \%)$, which account for a total of $45.36 \%$ of the transferprint assemblage from House 2.

\section{House 3}

A minimum of 128 vessels comprise the House 3 assemblage, representing eight decoration styles and 10 vessel forms (Tables 4 and5). A total of 90 transferprinted white earthenwares vessels are included (70.31\% of the assemblage), representing 24 distinct patterns in seven colors (Table 6). Of these patterns, 21 (87.5\% of the transferprinted vessels) are attributable to the Spode Company. The most commonly recovered patterns are Persian Vase by William Davenport Co. and Spode's Lily pattern, each with 11 vessels accounting for $12.22 \%$ of the transferprint assemblage, and Spode's Field Sports ( $n=7$ or $7.78 \%$ of the identifiable transferprint patterns). Together these three patterns account for $32.22 \%$ of the transferprint assemblage from House 3.

\section{House 4}

House 4 is the smallest assemblage included in the current study, with a minimum of 98 vessels representing eight decoration styles and 12 vessel forms (Tables 4 and 5). Transferprinted white earthenwares ( $n=63$ vessels) account for $64.29 \%$ of the assemblage; a total of 17 distinct patterns in five colors were identified (Table 6). Of 
these patterns, $15(88.24 \%)$ are attributable to the Spode Company. The most commonly recovered patterns are Spode's Camilla ( $n=12$ vessels or $19.05 \%)$, Macaw/Pagoda $(n=8$ vessels or $12.7 \%$ ) and Alhambra ( $\mathrm{n}=6$ vessels or $9.52 \%)$, accounting for a combined total of $41.27 \%$.

\section{Chief Factor's House and Kitchen (CFH)}

The data for the CFH assemblage was taken from Cromwell (2006). This assemblage is comprised of 214 vessels representing nine decoration styles and 15 vessel forms (Tables 4 and 5). Transferprinted white earthenwares account for $80.84 \%$ of the assemblage ( $n=173$ vessels), the highest percentage of any of the assemblages in the

current study. The transferprint vessels within the $\mathrm{CFH}$ assemblage represent 40 distinct patterns in eight colors of which all but one pattern (Tyrol Hunters, William Davenport and Co.) can be attributed to the Spode Company (Table 6). The most commonly recovered patterns are Spode's Lily ( $\mathrm{n}=14$ vessels or $8.09 \%$ ), followed by Sevres and Camilla ( $\mathrm{n}=10$ vessels or $5.78 \%$ each), accounting for a combined total of $13.87 \%$.

\section{Diversity Analysis}

All six assemblages are dominated by blue transferprinted white earthenwares, specifically those attributable to the Spode Company. Beyond this, however, simple comparison of the assemblages obscures important differences, due in large part to the differences in sample size. The diversity module (DIVERS) of the TFQA software was used to facilitate comparison by generating a model for the comparison of relative richness and evenness for a given attribute (vessel form and decoration style), which 
accounts for the varying sample sizes of the assemblages under study (Kintigh 1989: 27). This section presents the results of these diversity analyses.

The CFH assemblage from within the stockade represents a carefully controlled locus of ceramic use, and served as a model against which the five Village assemblages were compared. It represented complete participation in the capitalist mode of production at Fort Vancouver, and is inferred to reflect not only what ceramicwares were used at the Chief Factor's table and presented to the Officers and visitors to the fort who dined there, but also the communication of an appropriately arranged mid- $19^{\text {th }}$ century upper class table. It is inferred from documentary sources that matching sets of ceramics were in use at this table (Chapter V), which are an indication of the segmentation of dining that accompanied the adaptation of capitalist values, and was codified through Victorian etiquette.

The DIVERS module of the TFQA software generated a model against which specific data, such as the richness and evenness values calculated for each assemblage and attribute can be compared using an expected richness or evenness value calculated for a given sample size. According to Kintigh, this model provides a means of simulating the creation of an assemblage for a given sample size based on two assumptions, the first of which is that "for a given typology of artifacts and a given cultural situation there is a culturally determined underlying frequency distribution” (Kintigh 1989: 27). In the current study, the cultural determinant would be the degree to which each household participated, actively or passively in the capitalist ideology that created docile workers 
through the segmentation and codification of daily life, and extended this segmentation to the purchase of matching sets of ceramics. The second assumption is that "a simulated archaeological assemblage can be created through a process of random selection of items of the different classes" as explained in Chapter IV and seen below (Kintigh 1989: 27).

The DIVERS modules assigned richness and evenness values to the variable under study (decoration style or vessel from) for each Village assemblage and overlaid these values on the graph of the $\mathrm{CFH}$ model and confidence interval in order to observe variations (Figures 12-19). The appearance of values lying on or above the upper confidence interval limit or on or below the lower limit for the $\mathrm{CFH}$ model indicate a statistically distinct assemblage from the $\mathrm{CFH}$, as $95 \%$ of the simulated assemblages would be expected to fall within this interval.

Tests were run for the richness and evenness of the decoration style (ware type) of all ceramics in the Village assemblages (Figures 12 and 13), followed by richness and evenness of vessel form for the Village assemblages (Figures 14 and 15). The tests were then refined for the detection of matched sets using only the transferprint ceramics from each assemblage, as these were the most common ware types recovered with the most distinct and identifiable patterns, and the most potential to reveal patterns about matching ceramic sets. The results were then compared to the expectations (Chapter IV) and the results are given below. 


\section{All Ceramics}

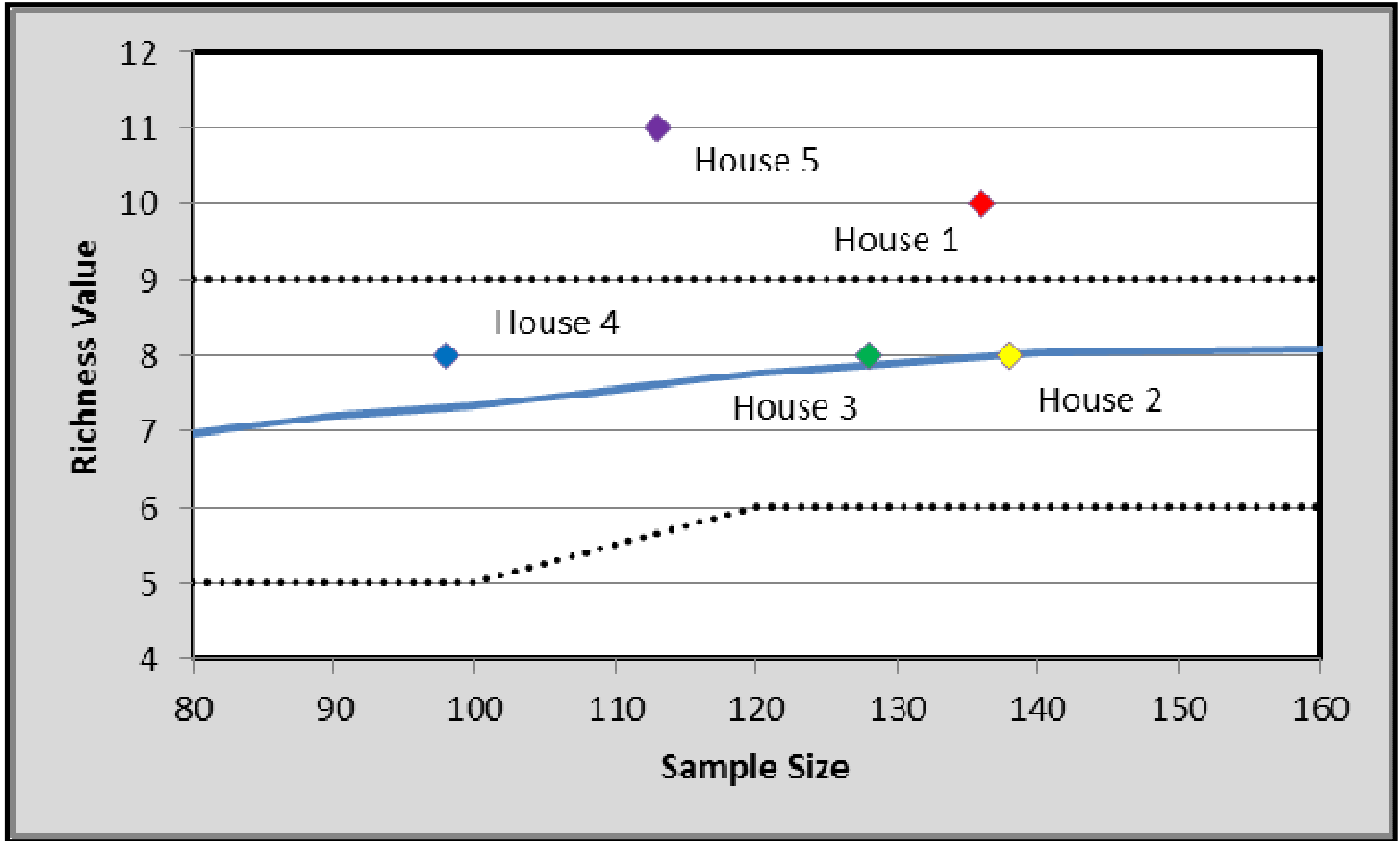

FIGURE 11. Scatter plot of the richness values for ware type mapped onto those expected for the $\mathrm{CFH}$

TABLE 7

RICHNESS VALUES FOR WARE TYPE OF VILLAGE HOUSES

\begin{tabular}{|c|c|}
\hline House \# & Richness \\
\hline House 1 & 10 \\
\hline House 2 & 8 \\
\hline House 3 & 8 \\
\hline House 4 & 8 \\
\hline House 5 & 11 \\
\hline
\end{tabular}

\section{Ware Type, Richness}

It was expected that the presence of matching sets of ceramics would be indicated

by low richness values, as sets are rendered in a single decoration style. Further, it was 
expected that the presence of matched sets would result in richness values that were comparable to or lower than that calculated for the $\mathrm{CFH}$ (8 classes of decoration style). Houses 2, 3 and 4 (richness value $=8$ ) fall on or just above the mean; although they are richer in decoration style (more categories are present) they are the most comparable to the model. The House 1 and 5 assemblages have much higher richness values that fall above the upper limit of the $95 \%$ confidence interval, in direct opposition to the expected outcome (Table 7, Figure 12). Overall, the richness of decoration style for the complete ceramic assemblages was higher than expected, although several households were comparable to the expected mean value calculated for the model. In general the Village assemblages were comprised of a greater number of ware types than that from the $\mathrm{CFH}$.

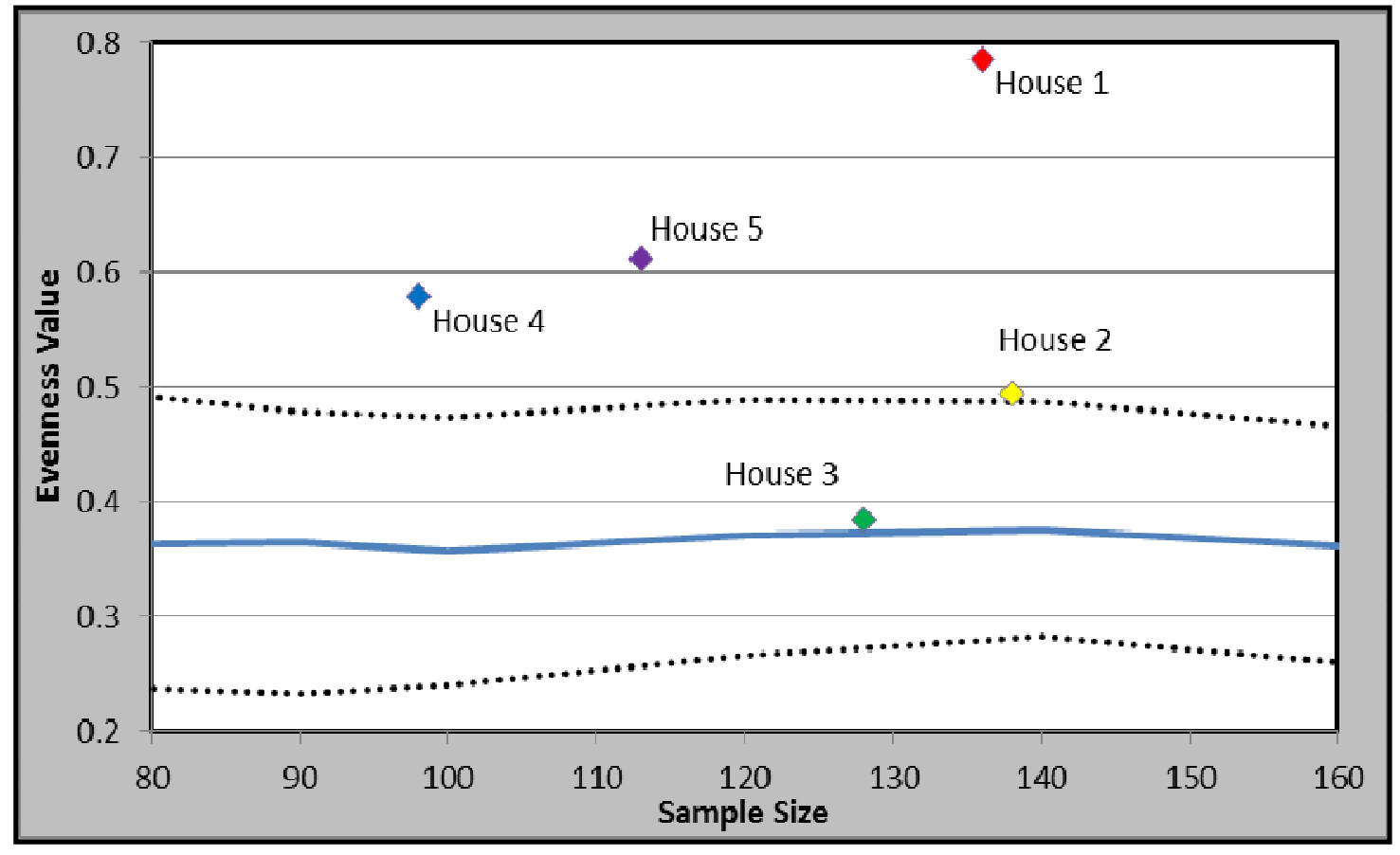

FIGURE 12. Scatter plot of evenness values for ware type, mapped onto those expected for the $\mathrm{CFH}$ 
TABLE 8

EVENNESS VALUES FOR WARE TYPE

\begin{tabular}{|c|c|}
\hline House \# & Evenness Value \\
\hline House 1 & 0.7858 \\
\hline House 2 & 0.4949 \\
\hline House 3 & 0.3849 \\
\hline House 4 & 0.5794 \\
\hline House 5 & 0.6123 \\
\hline
\end{tabular}

\section{Ware Type, Evenness}

It was expected that the presence of matching sets of ceramics would be indicated by low evenness values for decoration style, as sets are rendered in a single matching pattern. It was also expected that the Village assemblages would have evenness values that were comparable to or below that calculated for the $\mathrm{CFH}$. All five village households surpassed the CFH in evenness of style, with four assemblages falling above not only the mean for the model assemblage, but three of them (Houses 1,4 and 5) falling well above the upper limits of the 95\% confidence interval (Figure 13). Houses 2 and 3 fall within the interval, but above the mean expected value, making them less statistically distinct from the model than the other three. The high evenness values for the village households indicate that the ceramics from these assemblages are evenly distributed over the classes of vessel forms present, rather than unevenly distributed over only a few classes, as was expected (Table 8). Overall, the results of evenness analysis for all ceramics were much higher than expected. 


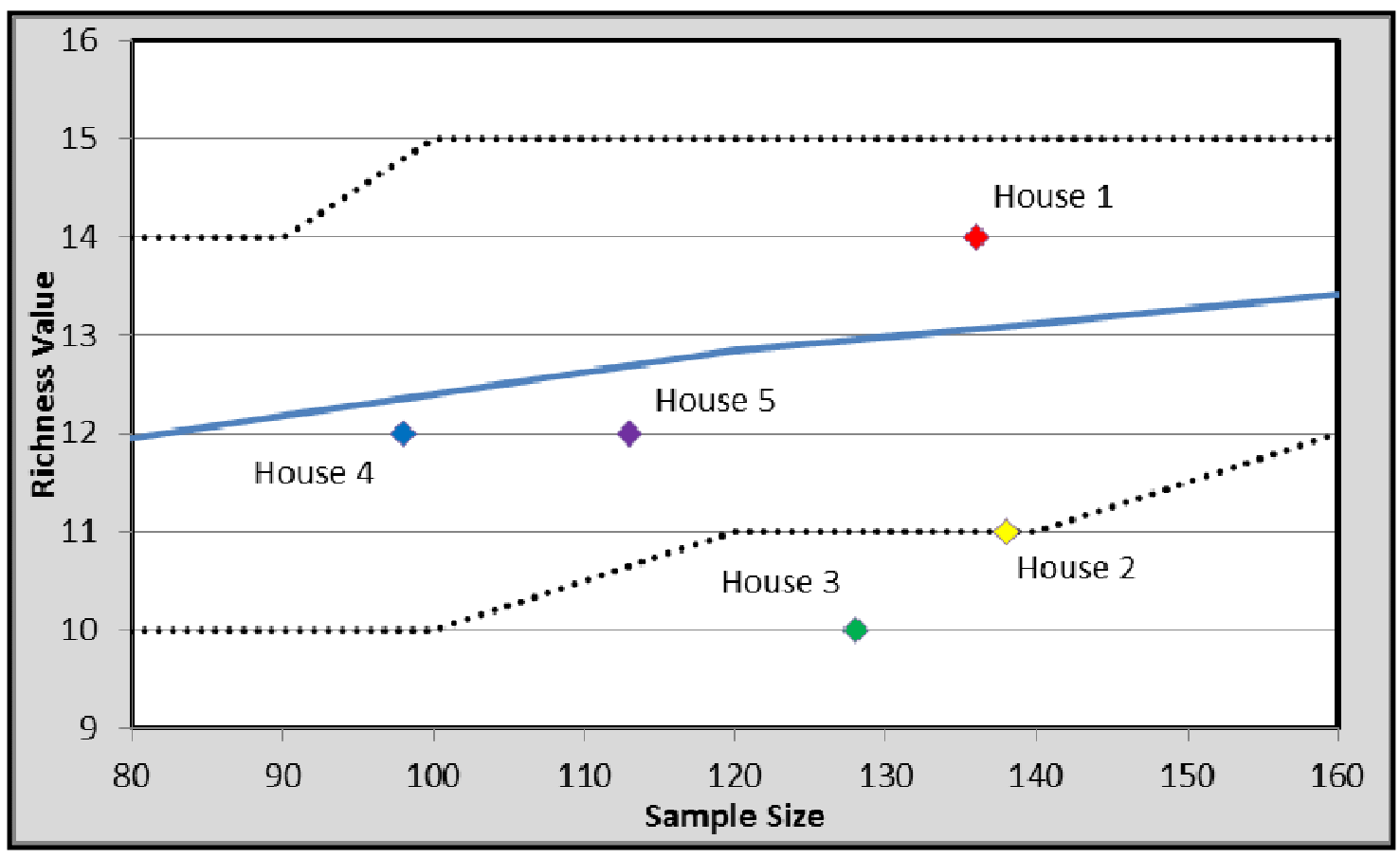

FIGURE 13. Scatter plot of richness values for vessel form, mapped onto those expected for the $\mathrm{CFH}$

TABLE 9

\section{RICHNESS VALUES FOR VESSEL FORM}

\begin{tabular}{|c|c|}
\hline House \# & Richness Value \\
\hline House 1 & 14 \\
\hline House 2 & 11 \\
\hline House 3 & 10 \\
\hline House 4 & 12 \\
\hline House 5 & 12 \\
\hline
\end{tabular}

\section{Vessel Form, Richness}

The presence of matched sets in the Village assemblages was expected to generate a high richness value for vessel form, as matching sets of ceramics are comprised of many vessel forms. Further, it was expected that the richness values for the Village households would be comparable to or higher than the mean expected mean value, falling 
in the upper portion of the confidence interval. Only the House 1 richness value matched these expectations, falling above the mean calculated model value, but within the confidence interval (Figure 14). The remaining assemblages contradicted these expectations, either falling in the lower portion of the confidence interval (Houses 2, 4 and 5 , richness $=11$ or 12 ) or below the interval entirely (House 3 , richness $=10$ ). The House 3 assemblage is statistically dissimilar to the $\mathrm{CFH}$ in richness of vessel form, while the House 2, 4 and 5 assemblages are similar to the model, but do not have the high richness values that were expected.

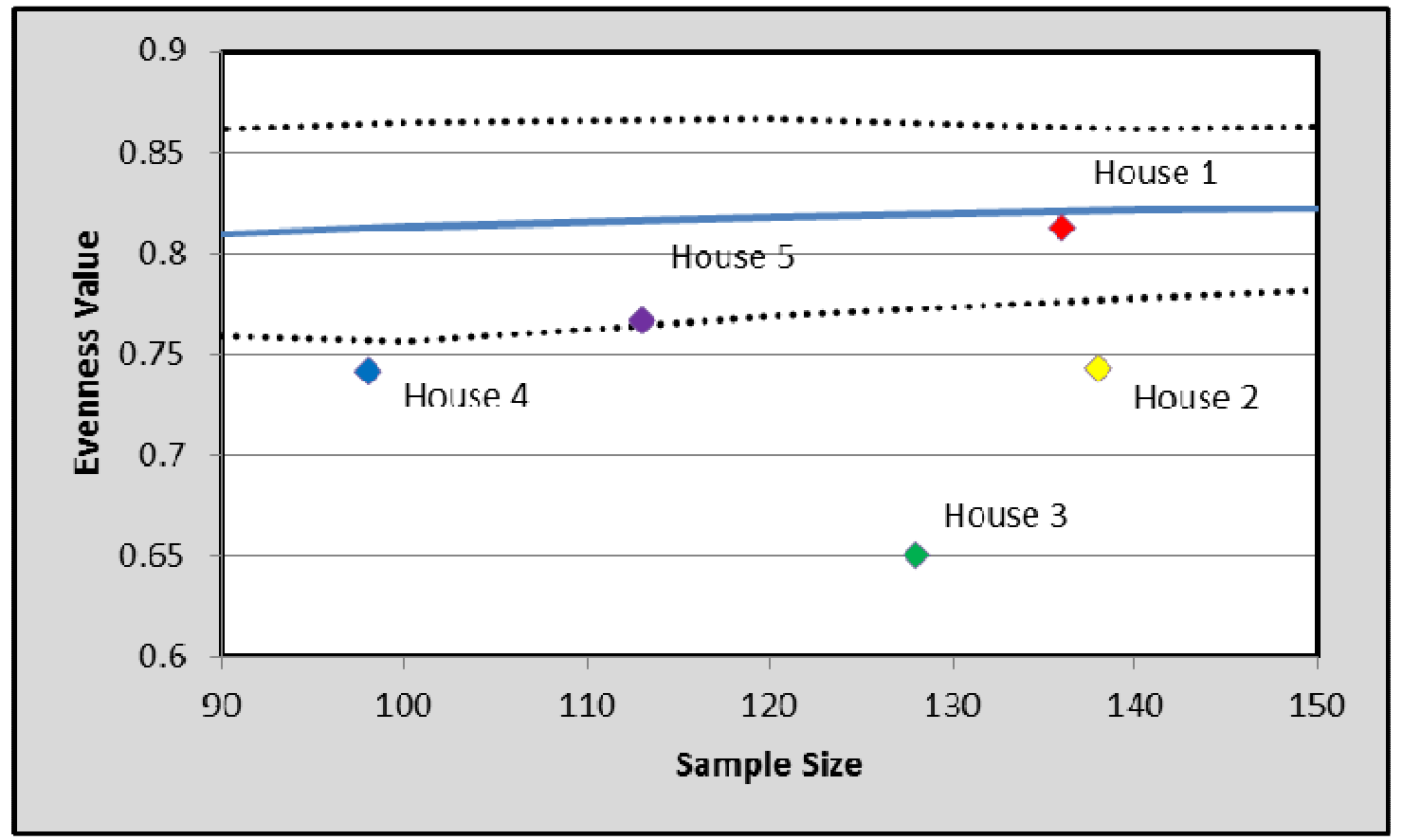

FIGURE 14. Scatter plot of evenness values for vessel form, mapped onto those expected for the $\mathrm{CFH}$ 
TABLE 10

EVENNESS VALUES FOR VESSEL FORM

\begin{tabular}{|c|c|}
\hline House \# & Evenness Value \\
\hline House 1 & 0.8124 \\
\hline House 2 & 0.7426 \\
\hline House 3 & 0.6501 \\
\hline House 4 & 0.7412 \\
\hline House 5 & 0.7664 \\
\hline
\end{tabular}

\section{Vessel Form, Evenness}

The expectation for evenness of vessel form was that the Village assemblages would fall above that for the model, as the presence of matched sets would be inherently more evenly distributed than a random assortment of vessel types. Only the House 1 assemblage met this expectation, falling close to the expected mean value for the $\mathrm{CFH}$ (Figure 15). Three of the assemblages (Houses 2, 3 and 4) fall below the lower limits of the confidence interval, meaning they are statistically distinct from the model and the vessels from these assemblages are not evenly distributed across the categories present. The House 5 assemblage falls on the lower limit of the confidence interval, indicating that although it is closer to the expected value than Houses 2, 3 and 4, it is still statistically dissimilar to the $\mathrm{CFH}$ assemblage.

\section{Transferprint only}

It is documented that transferprinted sets were sold at the Fort Vancouver Sale Shop (HBCA 1826, 1833, 1834, 1839, 1840, 1845, 1852; Cromwell 2006).

Transferprinted ceramics are the most readily identifiable ware type that was sold in 
matching sets. Running the tests on only these ceramics excluded ware types such as utilitarian stoneware storage bottles and crocks, which did not adhere to the same standards of presentation as the table and toiletwares. It also eliminated less expensive ware types such as undecorated whiteware, bandedware and cottageware, resulting in assemblages that were more comparable so that trends in the ceramic use in the Village as it relates to that at the $\mathrm{CFH}$ are more visible.

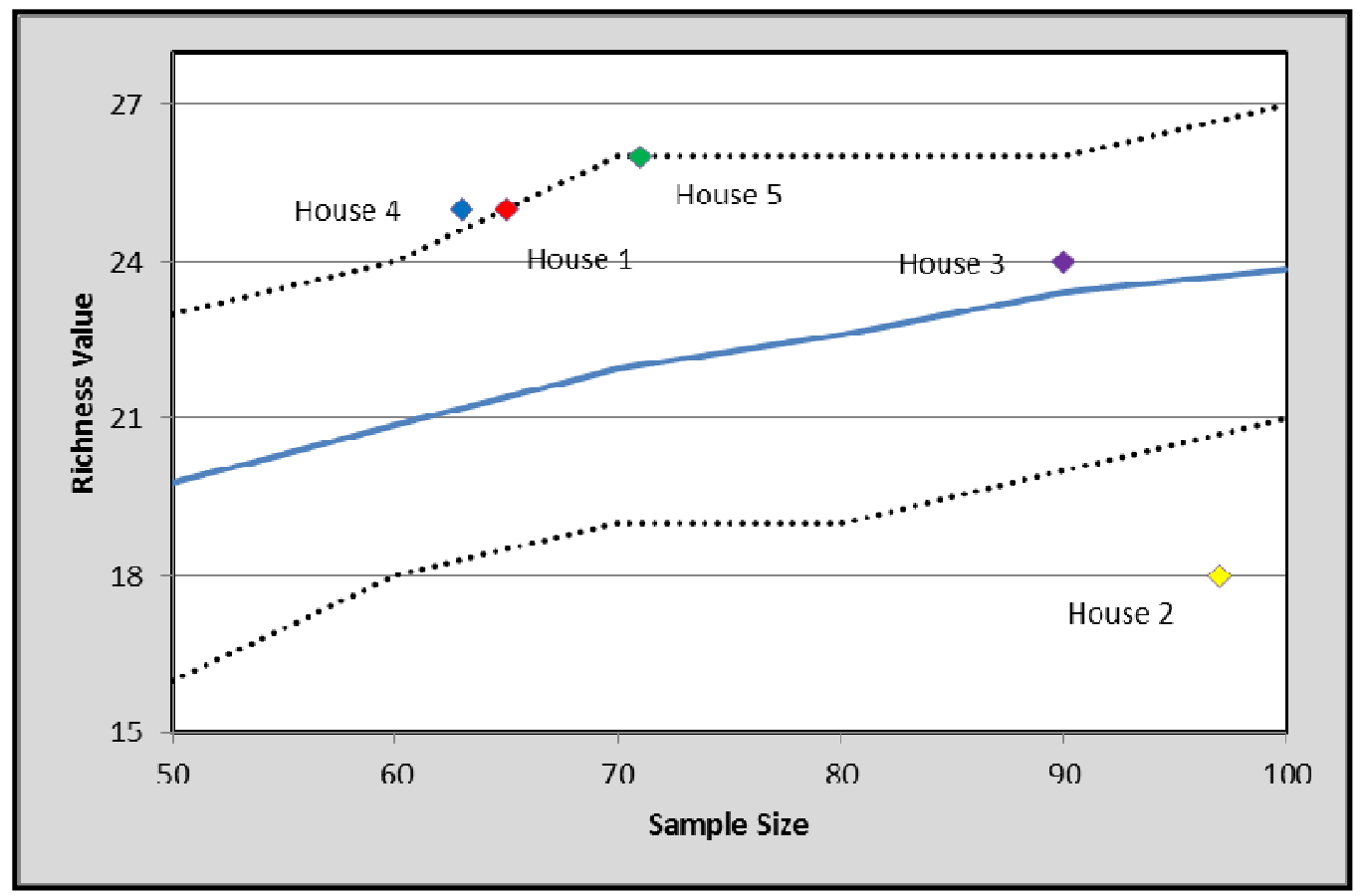

FIGURE 15. Scatter plot of richness values for transferprint pattern, mapped onto those expected for the $\mathrm{CFH}$ 
TABLE 11

\section{RICHNESS VALUES FOR TRANFERPRINT PATTERN}

\begin{tabular}{|c|c|}
\hline House \# & Richness \\
\hline House 1 & 25 \\
\hline House 2 & 18 \\
\hline House 3 & 24 \\
\hline House 4 & 25 \\
\hline House 5 & 26 \\
\hline
\end{tabular}

\section{Transferprint Pattern, Richness}

If, as was hypothesized, matching sets were present in the Village assemblages, the expectation was that the richness values for transferprint ceramic patterns would be statistically similar to the model, and would fall on or below the mean expected value, that is, within the lower half of the $95 \%$ confidence interval for the $\mathrm{CFH}$. Most of the houses have richness values that fall well above the mean, and in three cases (Houses 1 and 5, on the upper limit of the confidence interval, and House 4, above this limit) are statistically dissimilar to the CFH model (Figure 16). House 3 is statistically similar to the model, falling within the confidence interval, but in the upper half of the interval, above the mean expected value. While the House 2 assemblage falls below the mean, it is also below the lower limit of the $95 \%$ confidence interval, indicating that it is significantly less rich than the model predicts. All five households have high richness values for transferprint pattern; even House 2 is comprised of 18 identifiable transferprint patterns. This is in direct opposition to the expectation that assemblages dominated by matching sets of ceramics would therefore be comprised of a small number of patterns. 


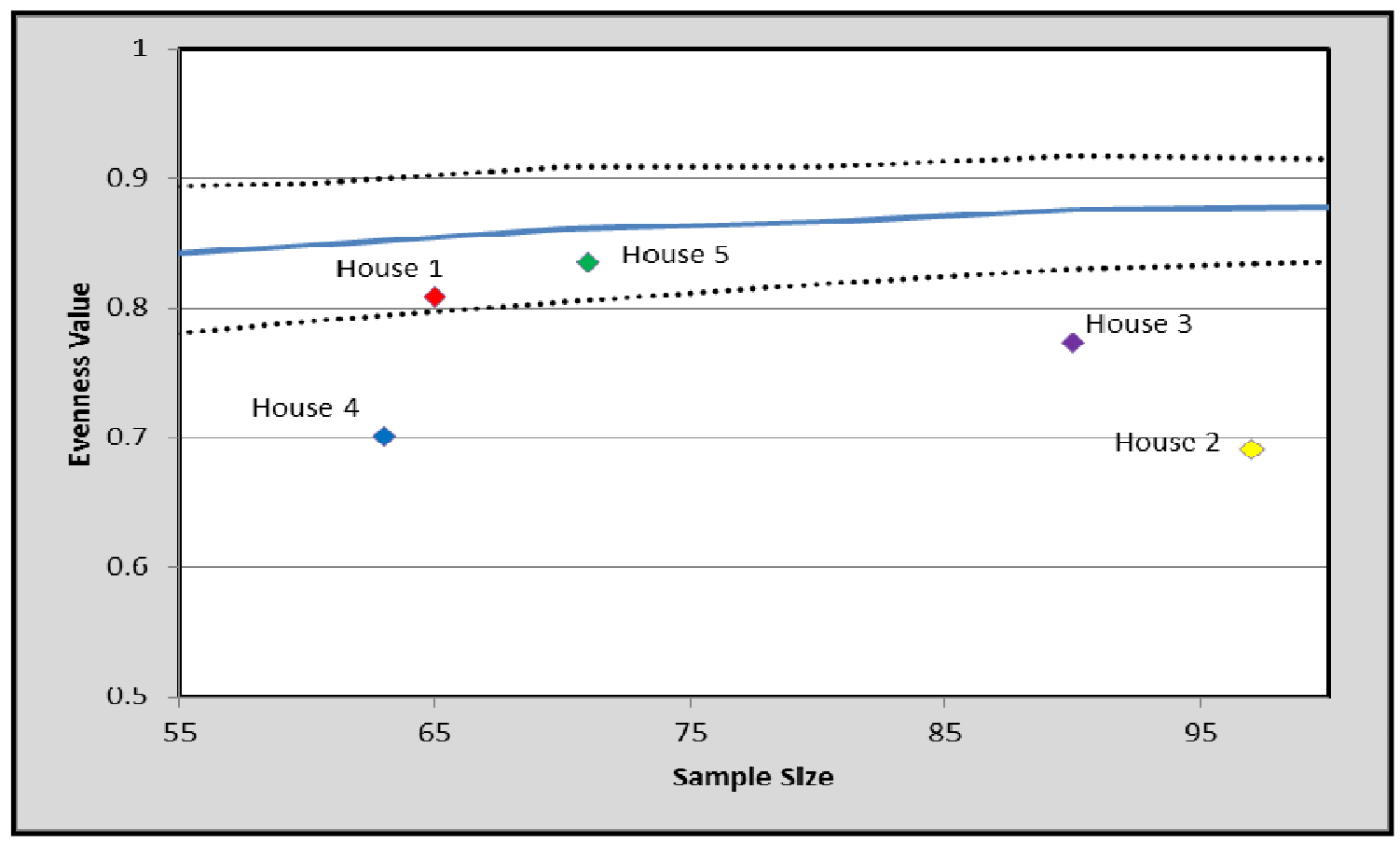

FIGURE 16. Scatter plot of evenness values for transferprint pattern, mapped onto those expected for the $\mathrm{CFH}$

TABLE 12

\section{EVENNESS VALUES FOR TRANSFERPRINT PATTERN}

\begin{tabular}{|c|c|}
\hline House \# & Evenness Values \\
\hline House 1 & 0.8086 \\
\hline House 2 & 0.6910 \\
\hline House 3 & 0.7732 \\
\hline House 4 & 0.7010 \\
\hline House 5 & 0.8351 \\
\hline
\end{tabular}

\section{Transferprint Pattern, Evenness}

The hypothesis that matching sets are present in the Village assemblages led to the expectation that the transferprint patterns in the Village assemblages would be unevenly distributed- skewed toward one or more patterns representing a matching set. 
Further, evenness values for the Village assemblages were expected to be statistically similar to the model, falling on or below the mean expected value, within the lower half of the $95 \%$ confidence interval for the $\mathrm{CFH}$. House 1 and 5 meet this expectation, while the other houses have evenness values that fall well below the confidence interval (Figure 17). Houses 2, 3, and 4 are statistically dissimilar to the CFH model, suggesting that they are more heavily dominated by matching sets of transferprint ceramics. The transferprint patterns in these assemblages are much less evenly distributed than the expected mean value for the model.

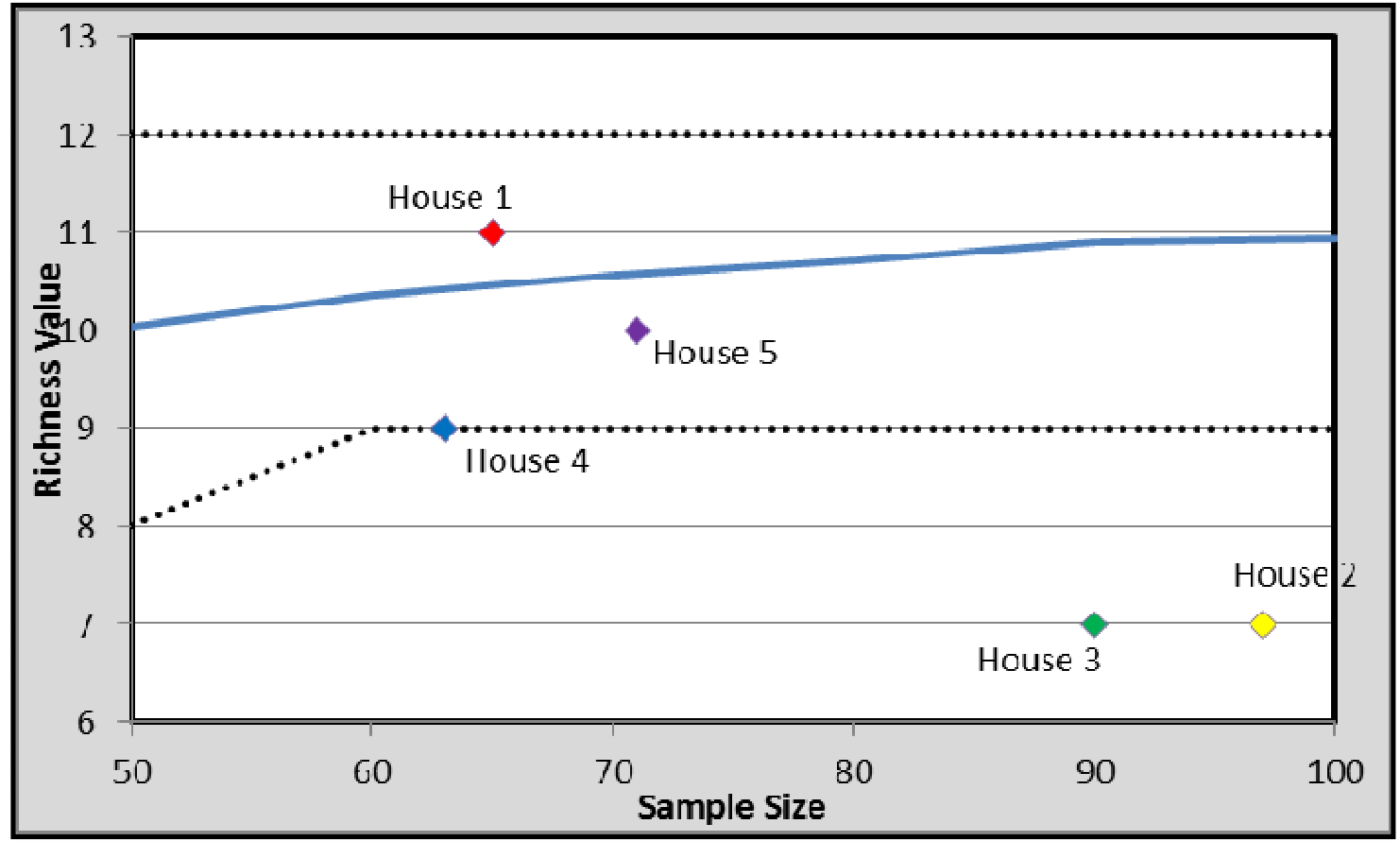

FIGURE17. Scatter plot of richness values for transferprint vessel form, mapped onto those expected for the $\mathrm{CFH}$ 
TABLE 13

RICHNESS VALUES FOR TRANSFERPRINT VESSEL FORM

\begin{tabular}{|c|c|}
\hline House \# & Richness \\
\hline House 1 & 11 \\
\hline House 2 & 7 \\
\hline House 3 & 7 \\
\hline House 4 & 9 \\
\hline House 5 & 10 \\
\hline
\end{tabular}

\section{Transferprint Vessel Form, Richness}

It was expected that matching sets of ceramics in the Village houses would be indicated by assemblages that are rich in vessel form as matching sets of transferprint ceramics are characterized by a high number of vessel forms. Further, it was expected that the richness values for the Village transferprint assemblages would fall within the upper portion of the confidence interval, indicating assemblages that were as rich as or richer than the $\mathrm{CFH}$. These expectations were only met by House 1 (Figure 18). House 5 is within the confidence interval, but below the calculated value for the model, while the House 2, 3 and 4 assemblages fall on or below the lower limits of the interval, indicating they are statistically dissimilar, and extremely less rich, than the model.

TABLE 14

EVENNESS VALUES FOR TRANSFERPRINT VESSEL FORM

\begin{tabular}{|c|c|}
\hline House \# & Evenness Value \\
\hline House 1 & 0.8512 \\
\hline House 2 & 0.6894 \\
\hline House 3 & 0.656 \\
\hline House 4 & 0.7178 \\
\hline House 5 & 0.8553 \\
\hline
\end{tabular}




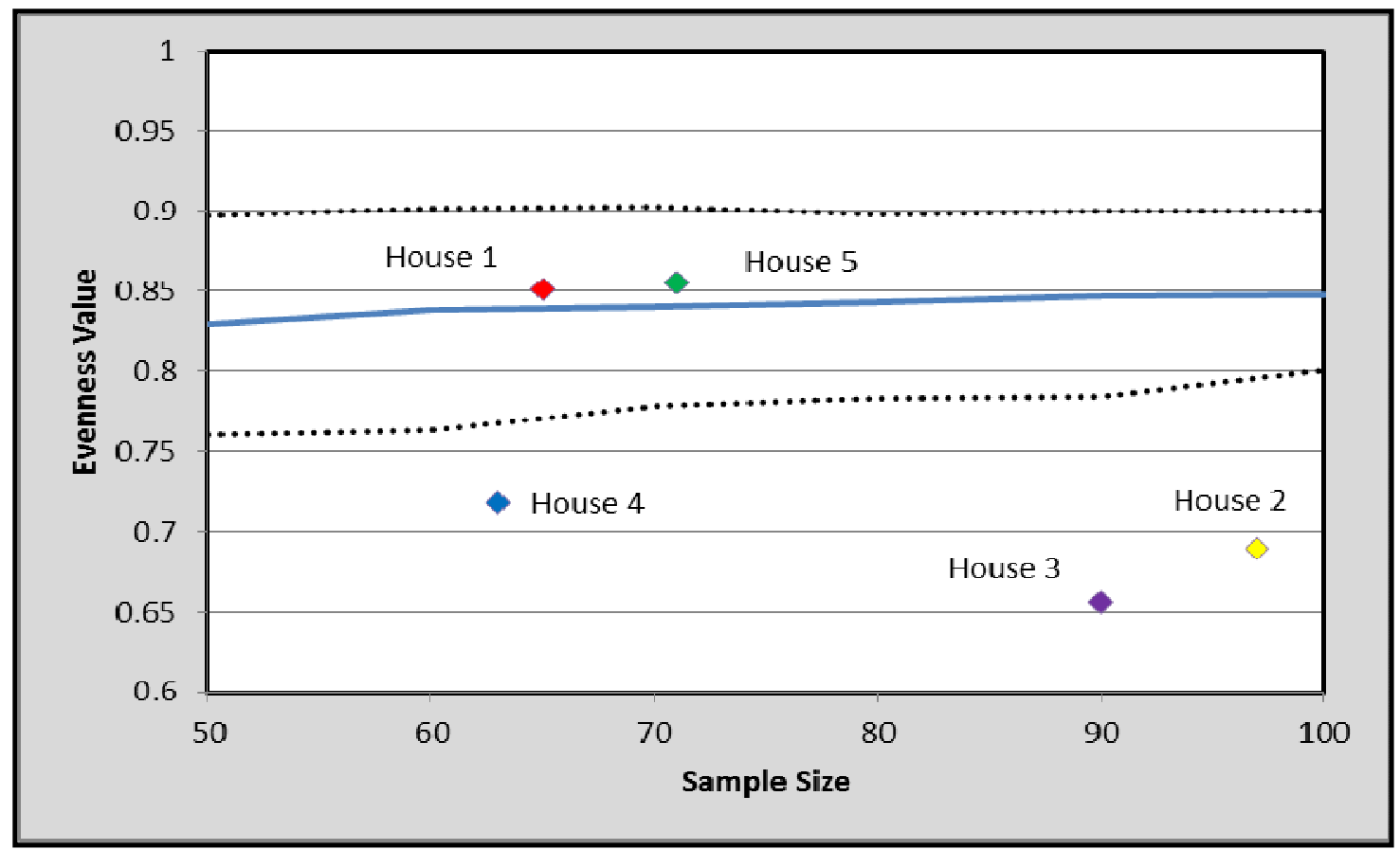

FIGURE 18. Scatter plot of evenness values for transferprint vessel form, mapped onto those expected for the $\mathrm{CFH}$

\section{Transferprint Vessel Form, Evenness}

It was hypothesized that the presence of matching sets of transferprint ceramics would be indicated by a high evenness of vessel form, as sets are comprised of many place settings made up of multiple matching pieces. Further, it was expected that the Village households would display evenness values that fell near or above the expected mean value, but still within the $95 \%$ confidence interval. None of the five Village assemblages conformed to these expectations. Houses 1 and 5 are the most evenly distributed assemblages, with evenness values at the lower limit of the confidence interval (Figure 19). Houses 2, 3 and 4 all fall well below this interval, and are therefore 
statistically distinct from the model and far less evenly distributed over the classes present. Overall the expectations about matching sets of transferprint ceramics, as indicated by evenness of vessel form, were not met.

\section{Summary of Results}

The results of this analysis indicate that it is unlikely that the Village households are comprised of complete sets of dishes in matching transferprint patterns. In almost every case, the richness and evenness values generated for the Village assemblages were not consistent with the expectations. Instead of the dominance of a few patterns as was expected for richness and evenness of decoration style, the Village assemblages appear to be comprised of many patterns (as many as 26 different transferprint patterns to an assemblage), and are fairly evenly distributed (high evenness values) over those patterns.

For vessel form, the Village assemblages are all comprised of vessels of varying forms (as many as 14 types), which matches expectations for assemblages comprised of matching sets, however the vessel forms are relatively unevenly distributed over these forms. This is in contrast to the expected even distributions, hypothesized to indicate a comparable number of each vessel form, as would be present in a matched set. The Village assemblages are dominated by categories that indicate more versatile vessel forms such as plates, saucers and teacups (Table 5). A discussion of the implications of these results follows in Chapter VII. 


\section{CHAPTER VII: DISCUSSION}

This chapter presents an interpretation of the results from both documentary research into the ideologies of Fort Vancouver and the archaeological analysis of ceramics recovered from various loci within the Fort and the Village sites. There is a contradiction between the results of these lines of inquiry, as documentary sources confirmed that in the mid- $19^{\text {th }}$-century Fort Vancouver and the Village displayed the effects of the ideologies of segmentation and division that accompanied the capitalist mode of production observed in Annapolis and New England (Chapter V).

Archaeological analysis of the ceramics recovered from these sites however showed only minimal indication of matching sets of ceramics, the expected archaeological signature of these ideologies (Chapter VI). The following is an exploration of this contradiction with an eye to the issues of comparability at the heart of this study, and the suitability of a Marxist analytical framework for the analysis of Village ceramic assemblages.

The methodology used in this study was derived from that performed on ceramics from Leone's work on the Archaeology in Annapolis project. Archaeologists in Annapolis use archaeological interpretation to explore how objects of everyday life, such as tablewares, have been significant mechanisms in reproducing the complex social rules that accompany capitalist society in the colonial town (Shackel et al. 1998; Leone 2005). Specifically, the presence of matching sets of ceramics was used as an analytical tool to explore the degree to which capitalist principles, as espoused through ideology, were accepted by residents and workers at Fort Vancouver, just as Leone et al. (1987) 
hypothesized that. It was expected that the results of the current study would mirror those from Annapolis, where the presence of matching ceramic sets was interpreted to indicate the capitalist ideology that encouraged increasing segmentation and standardization in daily life. The results of the analysis of the Village ceramic assemblages did not meet these expectations. The following is an exploration of the factors, ranging from differences in ideology to issues of assemblage comparability, which affected the results of the current study.

\section{Capitalism across Time and Space}

One of the fundamental limitations of a Marxist analytical framework lies in its tendency to treat capitalism as a monolithic institution that functions in the same predictable way independent of the time and location under study, instead of as a global phenomenon with local manifestations. While on the macro level capitalists in all ages and settings share a common project or goal: that of maximizing profit in order to maintain their position at the top of the system, on the micro level the tools for achieving these objectives, and the ways in which the capitalist polices and ideologies manifest in the material record, differed greatly across time and space. Marx's writings are geared toward urban Europe in the early industrial era, one manifestation of the global capitalist system, which is distinct from the ways that the evolution of a capitalist mode of production manifested itself in the colonial city of Annapolis. The examination of ceramics from the Village, a multi-ethnic, frontier settlement in the northwest yielded even more distinct results. The manifestations of capitalism, as measured in the current 
study of ceramics from Fort Vancouver and the Village were less comparable to those in either of these locations than previously hypothesized.

On the surface, Fort Vancouver, the only center for European metropolitan and industrial life in the vast Columbia Department, shared many attributes with a developing urban center like Annapolis, including a strict class hierarchy and the relations of production that define capitalist systems. The modes of production are subtly different however, as the specifics of capitalism varied in these two distinct locales. The mid- $19^{\text {th }}$ century fort was a colonial outpost of mercantile and corporate capitalism on the edge of a vast economic holding and Annapolis was an established city increasingly operating under free-market capitalism. Whereas in a free market structure the distribution and costs of goods and services, along with the structure and hierarchy between capital and consumer goods, are coordinated by supply and demand, the economic system at Fort Vancouver was controlled by external regulation by the HBC and was tinged with vestiges of feudal land tenure policies and the imperial interests of mercantilism. While in Annapolis, the products of capitalism were a part of the local economy in which the city's inhabitants participated, goods produced, processed or distributed at Fort Vancouver were exported for use on overseas markets, with only small amounts distributed to the Servant class as remuneration, or available for purchase at the Sale Shop. As seen in Chapter V, prices were set by the company, and differed greatly depending on who was buying.

The major project of all who lived and worked at Fort Vancouver was to maintain not only their specific social position within the hierarchy, but the very existence of the 
hierarchy, i.e. the continuation and success of the Company's operations. While in Annapolis the project of the capitalists was in direct opposition to that of the working class, at Fort Vancouver the success of every individual who worked for or was under the control of the company was dependent on the same project: that of company success. It is therefore not surprising that the ideologies in play at the two locations were distinct as well. Annapolis, an established city with regional and national power, wealth, highly specialized workers and many industries, was carefully planned, thought out, and created (Leone 2005: 22). The household assemblages analyzed by Leone etc. were the result of activities that occurred entirely within the conditions of capitalism that were specific to this location. The differences in the modes of production in the two locations, and by extension the ideologies and the importance of etiquette in sustaining them in both Annapolis and Fort Vancouver are central to the results of the current study, which relied on the translation of analytical tools from one capitalist location to another.

\section{Ideology at Fort Vancouver}

In Annapolis, the ideology of possessive individualism was carefully cultivated within the more complete free-market economy and maintained to mesh perfectly with the revolutionary rhetoric of the time. If "a worker believes that he is an individual with rights and opportunities, believes that hard work and talent will produce equity because he is guaranteed equal access by law or nature, then that person sees himself as having free will or as an active agent of his own life" (Leone 2005: 25). This belief in agency was part of the larger notion of false consciousness, the process by which the exploitative 
daily conditions of capitalism were obscured. This ideology allowed the population to see themselves as individuals, which led to a belief in personal merit, opportunity and private property. It also functioned to deny the realities of inequality, poverty and slavery, helping to naturalize them and mask their origin as social products of capitalism (Leone 1999; McGuire 1999).

An ideology of individualism worked to police free Annapolitans living as individuals and market consumers in an established city. However, in order for ideology to function in a newly established frontier setting such as Fort Vancouver, the notion of individualism was subtly downplayed in favor of an ideology that addressed the company's responsibility to its workers and encouraged them to view the hierarchy as natural. The $\mathrm{HBC}$ was a mercantile enterprise that fostered an ideology of paternalism as a way to discipline worker behavior and to naturalize and morally justify a system of exploitation. The history of the HBC, as presented in Chapter II, demonstrates that throughout the $17^{\text {th }}-19^{\text {th }}$ centuries, it evolved into a conservative, capitalist organization. The ideology of work and labor organization at Fort Vancouver while designed to perpetuate the economic system of mercantile capitalism was based on the feudal notion of paternalistic benevolence (Bloch 1961; Burley 1997; Hamilton 2000). The hierarchical structure of the Company easily maps onto that of a family, with the Governor and committee at the head. At Fort Vancouver, the Chief Factor John McLoughlin, often called the "father of Oregon", assumed the role of patriarch, standing in for the head of the frontier HBC family (Burley 1997). McLoughlin assumed absolute financial and 
operational authority on the ground at the fort, as a father would assume these roles in a $19^{\text {th }}$-century household. He effectively functioned as a stand-in for the company itself, representing a source of livelihood, including wages, food provisions and shelter, much as a feudal lord would have functioned for those who occupied his land.

The elite of the HBC were paternalists who possessed a social outlook based on the assumption that those at the top, as the owners of property, had both the right and the responsibility to rule and guide everyone else, whose sole obligation was to obey (Burley 1997: 19). The paternalistic ideology permeating life at Fort Vancouver required that the divisions among personnel be carefully and constantly maintained, rather than obscured as in Annapolis. In this way, the ideology of paternalism could be seen as a holdover of feudalism, in which landowners offer protection to those who work their land in return for their loyalty and labor. Like the under-age members of a family, Servants at Fort Vancouver were entirely dependent on the company for their livelihood, and even, in the case of the Hawaiian workers, for their return home (Barman and Watson 2006). Wages were set from above, and the rules were strictly enforced. Disobedience was unacceptable to the upper levels of the hierarchy. It was a worker's duty, as it would be a family member's responsibility, to perform his tasks diligently and thoroughly for the good of the company (Burley 1997). The upper levels of the HBC hierarchy expected loyalty, dedication and unquestioning obedience from their Servants.

While the division between Officers and Servants was reinforced spatially as well as socially and economically, a middle class of sorts was present at the fort. The largely 
European or Euro-American Officers, clerks, apprentice clerks, shipmasters and surgeons at Fort Vancouver lived in the Bachelor Quarters within the stockade, distinct from either the $\mathrm{CFH}$ or the Village. With regards to dining behavior however, the middle class is largely absent from the world of the fort, as the Officers all ate at the Chief Factor's table, obscuring their dining behavior. The ceramics of this class of Officers, recovered from the privies of the Bachelor Quarters were analyzed by Cromwell (2006), but omitted from the current study due to issues of comparability. These assemblages were recovered from privies and not household or corridor middens and those living in the Bachelor Quarters had less need to purchase their own tablewares than the inhabitants of the Village or those outfitting the Chief Factor's table. Cromwell's results indicate that these assemblages were roughly comparable in composition to those from the $\mathrm{CFH}$, and the Village, as all three classes purchased the same ceramics from the same shop.

Matching sets of ceramics were an effective indicator of capitalist ideology in Annapolis, where Deetz' segmentation and separation were plainly in evidence. These ideals were also in evidence at Fort Vancouver however they served a different purpose. In Annapolis, segmentation and division were the symptoms of an ideology that fostered individualism, while at the same time they created and maintained an interchangeable workforce. At Fort Vancouver, these ideals were downplayed in order to unite the HBC's employees in an ideology of paternal allegiance. The basics of the segmentation were intact: the division of the workday, the division of the population into classes and the 
division of these classes into labor groups; however these divisions were designed to place everyone into a distinct role that mapped onto the $\mathrm{HBC}$ family structure.

The colonial-military social structure of Fort Vancouver emphasized difference in order to reinforce status. This is in direct contrast to the structure of Annapolis, which was populated by discrete households of individuals, all equal under the law. The concern at Fort Vancouver was naturalizing the authority and power of the HBC, and its upperlevel representatives, while in Annapolis, ideology sought to make individuals feel that they were in charge of their own destiny. These differences are manifested materially in the absence of clear evidence of matching ceramic sets from the Village. The ideology and the markers that indicate it are distinct in the two locations. The particular ideology in place therefore is the most fundamental difference in the two locations, and the strength of the etiquette surrounding dining that was employed to sustain the ideologies also had a direct effect on the assemblages under study.

\section{Etiquette and Ideology}

The development of a new etiquette and material culture associated with formal and segmented dining and increasing concern for personal appearance and hygiene were some of the tools used to create and sustain explicitly different groups in Annapolis (Shackel 1993: 7). Maintenance of capitalist ideology relied on the rules of Victorian etiquette that governed both public and private life in the urban east. Leone (2005) discusses at length the ways in which etiquette in Annapolis was used as a technique to sustain the ideology of individualism that was used to mask the inequalities of capitalism, 
framing eating as a discipline that taught at home and observed widely, signaling a person's readiness to self-inspect and therefore readiness to observe rules of society. Once the concept and specifics of etiquette had been internalized, a person was equally ready to observe the rules of capitalism: punctuality, willingness to subject to working for wages, and being responsible to market pressures. It was etiquette that produced both workers and consumers, and left signatures in the archaeological record (Leone 2005: 57).

As has been described earlier, Fort Vancouver represented an oasis of “civilization" in the wilderness (Whitman 1982). Despite this facade of civilization however, the Fort was located on the frontier of the known world. The elites of Fort Vancouver attempted to recreate and reinforce Victorian ideals and etiquette, as evidenced by the accounts of finery and elegance at the Fort in general, and at the Chief Factor's table specifically (Wilkes 1856; Whitman 1982). However, the subtleties of formal etiquette that were developed and refined in the urban east were likely not as strictly enforced at Fort Vancouver as they had been in Annapolis through techniques like seeing/watching, reading/talking and eating/etiquette (Leone 2005: 35). Annapolis was in transition from the earlier, colonial Georgian order to the later and more complex Victorian ideals that proscribed the use of specific ceramics, and indoctrinated the city's citizens to the segmentation and division that defined a capitalist mindset. Fort Vancouver operated as a colonial settlement under a demi-feudal system of land tenure that was less dependent on etiquette as a mechanism of control. 
While etiquette was a part of life at Fort Vancouver, it was intended for the elite, the Officers, Gentlemen and visitors, whose dining habits were regimented at the Chief Factor's table. The inhabitants of the Village, who prepared and ate meals in their own households, were less concerned with experiencing their reality as individuals in possession of their own destinies as the citizens of Annapolis. Leone and Shackel's analysis of ceramic use in Annapolis used Foucault's ideas of personal discipline (Shackel 1993), and technologies of the self (Leone 2005) to explain the ways in which discipline standardized behavior and the use of material goods related to dining and hygiene practices (Foucault 1973, 1979; Leone 2005), however in a frontier setting such as Fort Vancouver, it stands to reason that the lower classes were more concerned with survival than with the constraints of formal etiquette. While an Officer could have purchased a complete, matching set of ceramic tableware for approximately $2 \%$ of his annual salary, the same set would have cost almost $60 \%$ of a Hawaiian laborer's yearly salary, a prohibitive investment for the members of this lowest class (Cromwell 2006; HBCA 223d205ss). Another consideration is the fact that the CFH assemblage was comprised of several matched sets of dishes, while it is unlikely that Village households would have been comprised of more than one set. In short, economic restrictions would have been more influential on the behavior of Villagers than the desire to adhere to Victorian etiquette or the emulation of the upper class.

The data for vessel form are heavily skewed to three classes of vessels: plates, cups and saucers (Table 14). These classes represent the most functionally diverse vessel 
types, which could be procured as a partial set, while costing significantly less than a full set. Used together, these items could function as a proper tea service for superficial adherence to the rules of Victorian etiquette and propriety. Separately, the pieces could also function as bowls for soups and other watery foods, or as serving pieces for the smaller meals that might have been prepared within the Village houses. Cromwell discussed the use of slop bowls, regularly used for tea slops, as a vessel from which to eat soup-based foods, as evidenced by the usewear observed on their inner bases (Cromwell 2006: 290).

Rather than adhere to a strict etiquette, people in the Village lived with a degree of freedom due to the physical separation between the stockade and the Village and the diminished power of surveillance as a training method. The use of plates, cups and saucers reflects the relaxation of etiquette on the frontier and out of the gaze of capitalists. People in the Village experienced life far differently than those who lived within the stockade. Every aspect of their working existence was cultivated to reinforce the differences between them and the Officers. It stands to reason that the workers in the Village would amass, use and discard material culture differently than those people within the fort, and not adhere specifically to the etiquette of segmentation that required individual place settings.

\section{Household Composition}

In addition to the distinctions between the formal etiquette in Annapolis and that at Fort Vancouver, the differences in household composition likely had profound 
influences on the use of ceramics in the Village, as determined by the results of the current study. These differences reflect another fundamental limitation of a Marxist framework for the current analysis: the failure to adequately account for the effects of individual action or agency. Marx predicted that market forces would distill social relations into two competing classes: the proletariat and the bourgeoisie, while other social relations, i.e.: religion, nationality, race etc. would fade into the background or disappear altogether. Within a multi-ethnic locus such as the Village, social relations were far more complex. The results of the diversity analysis (Chapter VI), which treated all households from the Servant class as comparable, are contradictory to those expected, which calls into question the truth of the assumptions about their comparability. It is important to consider the salience of non-class identities and the effects they are sure to have had on material culture from this location.

Although there were houses in the Village that were occupied only by men, it is documented that many households were primarily comprised of male European or EuroAmerican fur traders, their Native American or Métis wives, and their children. The women in the Village were primarily elites from Chinook villages in the area, and were therefore able to maintain connections to their families and lifeways from their villages of origin. Numerous anecdotes testify that the Chinook women at the fort retained some of their native cultural practices however various archeologists (Kardas 1971; Ross et al. 1975; Chance and Chance 1976; Ross 1976; Pollard 1990; Stone 2010) have concluded that the extent to which they did so is unclear. 
Tribal society on the Northwest Coast was stratified into the two main classes: free people and slaves, although there were gradations within the free class based on wealth or access to resources (Ames and Maschner 1999). While the class structure of the fort mirrors this division with a single major division between Officers and Servants, the social and economic structure at Fort Vancouver would have been foreign to the Chinook and other tribal members who came to live there, who committed labor to the fur trade. Largely abandoning their traditional subsistence activities, they became specialized laborers in "a putting-out system, in which the entrepreneurs advanced both production goods and consumption goods against commodities to be delivered in the future" (Wolf 1982: 194). Whereas free peoples living in a native village were not beholden to their leaders, those at the fort were tied to the world of capitalism and were expected to behave in appropriate ways, which included following the etiquette required of all Servants of the company regardless of ethnicity. It is documented that when women from dozens of Native American tribal affiliations entered the fur trade, they were encouraged to become English in their manners. Taking on European dress and using the ornate English ceramics were some of the visual cues that distinguished "civilized behavior" in native and Metis women in the fur trade, and signaled her acceptance of the Euro-American ideals of civility and Victorian etiquette (Van Kirk 1980; Burley 1989, 1992).

The Red River Settlement in Manitoba has been studied extensively with an eye to the unique structural concerns of ethnicity among the Metis who lived there (Wolf 1982; Burley et al 1992; Ens 1996). Economically, this settlement was similar to the 
Village: established as a provisioning enterprise, and composed primarily of Scottish traders, their native wives and Metis children, the Red River people lived in a stable settlement, drawing advances from the company (Wolf 1982). Social position and material culture were intrinsically linked in this locus: owning and using ceramics, and Spode transferprint in particular, were critical elements in meeting the requirements of etiquette. As Burley et al (1992: 118) state, "The tea service, the cupboard of fine china, the full, matched place settings associated with proper dining and similar practices give meaning to ceramics beyond simple function". Ceramicwares at Red River were not a practical acquisition, but rather served the social or symbolic function of communicating a Metis woman's "civilized" appearance and knowledge of etiquette that symbolized modernity and social position (Burley et al. 1992). The Red River assemblages were therefore reflections of an ideology of acculturation and emulation that was fostered to bring Metis more firmly under the company control.

Cromwell (2006:24) considered it "unrealistic" to correlate the Village house assemblages with the ethnicity of the occupants because most of the goods were purchased from the HBC sale shop, which sold only European-manufactured products. It is likely that the social value of the ceramics for sale at the employee Sale Shop within the stockade would have had some measure of influence over their acquisition. Speaking of households in the Willamette Valley, Cromwell asserts that the acquisition of ceramics can be seen as "an attempt by these and Native American women to reinforce their social standing in an ever-'whitening' society, and perhaps train the next generation to become 
socialized in the etiquette proper of becoming a wife of an HBC Gentlemen, or recently immigrated American" (Pollard 1990; Cromwell 2006: 303). The social value of ceramics was at least partly independent of their functional or stylistic value, and may have obscured their usefulness as objects for the dissemination of paternalistic ideology.

Even with the equalizing influence of capitalist ideology and social pressure, Native women in the Village coming from their native villages would have had little or no familiarity with or understanding of Victorian etiquette and ideals or the influence they would have had over the purchase and use of English ceramics within their households. The role of surveillance is therefore diminished in their distinct dwellings, as Shackel notes, "surveillance is only successful on the level of everyday intercourse if material goods and codes of meaning are understood by the appropriate players" (Shackel 1993: 18). The mechanism of surveillance is not effective when those who are under surveillance are participating only partially in the codification of ideology through material culture, as was likely the case in the Village.

\section{Resistance}

Leone and the other archaeologists in Annapolis used the concept of ideology to understand how a large group that was homogenous when viewed from outside but was internally diverse, handled the threats of living alongside capitalism (Warner 1998; Mullins 1999; Leone 2005: 192). They documented that the ethnic composition of the household under study had a profound effect on the archaeological manifestations of that household, as African-Americans strove to be included in the American ideology of 
personal freedom and liberty, yet outside the state-sponsored exploitation that accompanied it (Leone 2005: 192). People of African descent were aware of, and resistant to the mechanisms of capitalism, using American material culture in unique ways. The archaeological signatures of resistance to pervasive capitalist ideology took the form of spirit bundles and caches of objects recovered from African-American loci, such as within their households and within the kitchens and servant rooms of European households. The presence of these items showed that the ideology that was so pervasive in the rest of the city was not as inevitable, natural, God-given or superior as it was touted to be (Leone 2005), a fact that has bearings on the current study, which uses the notion of ideology as its foundation.

As mentioned in Chapter III, excavations in the Village have largely been unsuccessful in locating the archaeological signatures of ethnicity. While Kardas (1971) and others failed to discover markers of the documented ethnic diversity within the Village, there can be no doubt that ethnicity had an impact on the archaeological assemblages under study, as the Village inhabitants represent a diverse population of Native Americans, Metis, Hawaiians and Europeans. Among the Native inhabitants, socio-economic disparities are documented: many of the women were from the elite class among their own people and as such brought their slaves to live with them at the Village. The diverse backgrounds of the Village inhabitants certainly influenced the ways in which they acquired, used and discarded material culture, and may have skewed the data presented here. The absence of complete matched sets of ceramics and the dominance of 
plates, bowls and cups may be an indication that the dominant model of behavior was being at least partially subverted. While there are high numbers of transferprint vessels and vessel forms within the Village assemblages, these items represent a considerable expenditure for these working class households and may represent distinct patterns of use.

The archaeological assemblages from Village households are distinct from those recovered from either English or African households in Annapolis. They do not adhere to the expected model of accumulation: that of purchasing a complete set of matching dishes, however neither do they display the extreme repurposing of ceramic sherds seen in the African-American spirit bundles. The pattern of ceramic accumulation and use is unique to Fort Vancouver, where the archaeological signatures of resistance to paternalism are as yet unknown. More research is needed to identify these signatures and what they reveal about resistance within the classes at Fort Vancouver, including the analysis of other artifact types such as tobacco pipes, vessel glass and personal items such as buckles and buttons. As it is, it is difficult to parse the ceramic assemblages of the Village along ethnic lines, as the only ceramics available for purchase were European in origin, a fact that obscured much of the diversity within the Village.

\section{Analytical Issues}

Finally, there are several analytical issues that must be addressed when discussing the results of ceramic analysis for the current study. The issue of post-depositional processes was touched on in Chapter IV and it is worth repeating the large role that these 
processes may have played in influencing the comparability of the assemblages under study. While extrapolation of behavior from archaeological materials is often revealing, it is important to remember that the collections of objects that comprise the archaeological assemblages under study do not necessarily give an accurate reflection of behavior at the time the assemblages were deposited. Many factors have influenced these assemblages after their deposition.

The current study relied on many fundamental expectations and assumptions about the assemblages under study and what they represent. At the heart of this study is the comparability of the assemblages in question, a discussion of which must touch on the issues of sample size, analytical consistency, and post depositional processes. The issue of sample size has been addressed in previous chapters, and directly in the analysis techniques which minimize the effect of sample size. Regardless an issue may be whether the larger $\mathrm{CFH}$ assemblage can be used as an effective foil for the Village assemblages. The existence of multiple large sets of dishes within the $\mathrm{CFH}$ was assumed, as this household more than any other was responsible for strict adherence to the rules of etiquette and personal discipline. However, it is unlikely that the inhabitants of Village households were able to purchase comparable amounts of transferprinted ceramicwares in matching sets. Village inhabitants were entirely responsible for the purchase of their own tablewares, while those using the dishes in the $\mathrm{CFH}$ were not in charge of their ordering or purchase, which likely had a profound influence on the resulting assemblages. For instance, the amount of banded whiteware, cottageware, stoneware and other inexpensive 
wares in these households is significantly higher than in the CFH, showing the Servants' reliance on, desire for or choice of these less expensive ware types (Table 4).

Analytical methodology is another important effect, and a major expectation of this study concerned the methodologies for analyzing the assemblages. The comparability of material culture from Fort Vancouver and that from Annapolis has been addressed. It was also assumed that the analytical methods used by Cromwell (2006) could be effectively replicated in order to minimize the effects of inter-observer error. As seen in Chapter VI, there are many instances where Houses 1 and 5 appear to be clustered (Figures 12, 16-19), and distinct from the other houses. While this may be an accurate reflection of their relative participation in capitalist practices at the fort and in the Village, the discrepancy may be a reflection of inter-observer error. The House 1 and 5 assemblages were analyzed for the current study, while those from Houses 2-4 and the Chief Factor's House and Kitchen were analyzed by Cromwell in 2006. Every attempt was made to minimize error between the analysts, including utilizing the same basic methodology for sherd-level ceramic analyses (Cromwell 2006; Wilson et al. 2003), and the conversion of all six assemblages from sherds to vessels in all six assemblages by one analyst for the current study. Despite these precautions however certain aspects of ceramic analysis are open to differences in interpretation which may have influenced the results. Ware type (identified through observation of fabric type, and decoration style) is a relatively standard attribute. However vessel form, identified primarily though 
observation of the sherd's thickness and curvature, is less precise, and is open to some interpretations.

Also influencing these results are the differences in occupation between the Village houses and the $\mathrm{CFH}$. In addition to housing the senior officers and their families, the Chief Factor's House served as a common dining hall for the Gentlemen of the Fort, as a visitors' center, as a social and economic center for the Hudson's Bay company activities in the Department of the Columbia, and even as a public center of political activity in the Oregon Country (Hoffman and Ross 1973b:1; Cromwell 2006; Stone 2010). The Gentlemen of the fort all took their daily meals in the $\mathrm{CFH}$; it functioned as more of a dining hall than a dwelling, and the table was set accordingly. The Village assemblages would have been outfitted much differently. Each household assemblage is the result of the occupants of a single domestic dwelling, home to Voyageurs and their family as well as other working class groups. Voyageurs did not live in the Village yearround. For nine months of the year these employees were assigned to fur brigade expeditions throughout the Northwest. They returned during the summer when the animal pelts were thin, and were sometimes housed by coworkers or camped in open areas (Hussey 1957: 6; Cromwell 2006: 56; Mullaley 2011). Village house deposits therefore should not be conceptualized as the result of a single household, as they likely represent multiple occupants, deposited over many years (Mullaley 2011: i).

It is difficult to say how long specific occupations lasted, but it stands to reason that, in addition to the distance between the Village and the Fort, the relatively ephemeral 
occupation of the Village households would have exposed their residents to less ideological manipulation than either those at the top of the hierarchy, whose position was more permanent, or those in Annapolis, who lived in permanent, private dwellings for generations.

\section{Conclusion}

This study sought to locate the people of the Village within the larger field of force generated by systems of power exercised over social labor (Wolf 1982). Although documentary research revealed that the HBC used ideology to ensure its continued operations in the northwest, examination of the material culture from the Village site failed to locate the expected archaeological signatures of this ideology. The dissemination of ideology did not wholly permeate the complex web of ethnic and socioeconomic identities in which the Villagers, who were caught. Village inhabitants purchased, used, and discarded ceramics in unique ways that were likely tempered by the influence of other modes of production beyond simple capitalism and it is likely that they resisted complete incorporation into the prevailing influences of Victorian ideology, segmentation and standardization. A Marxist perspective was important in order to examine material culture within the context of capitalist inequities and relations of power, but ultimately a Marxist perspective is limited in its ability to determine the patterns of individual and group behavior. In order to learn the truth of life in the Village, its material culture needs to be examined through an analytical lens which takes into account the salience of other social relations and identities beyond the market. Ultimately this study has highlighted 
the shortcomings of relying solely on the documentary record, which was focused on the upper classes at and foreign visitors to Fort Vancouver, and omits the perspective of the largely illiterate Village inhabitants. It is difficult to determine the patterns of both individual and group behavior in a location impacted by so many diverse influences, the salience of which must be accounted for in future work on the material culture from this unique location. 


\section{REFERENCES}

Althusser, Louis

1971 Ideology and Ideological State Apparatuses. In Lenin and Philosophy, and Other

Essays. Ben Brewster, translator, pp. 127-186. Monthly Review Press, New York, NY.

Ames, Kenneth M. and Herbert D.G. Maschner

1999 Peoples of the Northwest Coast: Their Archaeology and Prehistory. Thames and Hudson Ltd: London.

Ballantyne, Robert Michael

1857 Hudson's Bay: or Everyday Life in the Wilds of North America, during Six Years' Residence in the Territories of the Hon. Hudson's Bay Company. T. Nelson and Sons, London, UK.

Barker, David and Teresita Majewski

2006 Ceramic Studies in Historical Archaeology. In The Cambridge Companion to Historical Archaeology, Dan Hicks and Mary C. Beaudry editors, pp. 205-231.

Cambridge University Press, New York, NY.

Barman, Jean and Bruce McIntyre Watson

2006 Leaving Paradise: Indigenous Hawaiians in the Pacific Northwest1787-1898.

University of Hawaii Press, Honolulu, HI.

Binford, Lewis

1962 Archaeology as Anthropology. American Antiquity 28: 217-25.

Bloch, Marc

1961 Feudal Society Vol. 2: Social Classes and Political Organization.Routledge and Kenan Paul Ltd: London.

Bryce, George

1968 The Remarkable History of the Hudson's Bay Company: Including that of The

French Traders of North-Western Canada and of the North-West, XY and Astor Fur

Companies. Burt Franklin, New York, NY.

Burley, David V.

1989 Function, Meaning and Context: Ambiguities in Ceramic Use by the Hivernant of the Northwestern Plains. Historical Archaeology 23(1): 97-106.

Burley, David V. Gayel A. Horsfall and John D. Brandon 
1992 Structural Considerations of Métis Ethnicity. An Archaeological, Architectural, and Historic Study. University of South Dakota Press, Vermillion, SD.

Burley, Edith I.

1997 Servants of the Honourable Company: Work, Discipline and Conflict in the Hudson's Bay Company, 1770-1879. Oxford University Press, Toronto, ON.

Carlos, Ann

1981 The Causes and Origins of the North American Fur Trade Rivalry: 1804-1810.

The Journal of Economic History 41(4): 777-794.

Carlos, Ann and Elizabeth Hoffman

1986 The North American Fur Trade: Bargaining to a Joint Profit Maximum under

Incomplete Information. The Journal of Economic History 46(4): 967-986.

Carlos, Ann and Stephen Nicholas

1988 Giants of an Earlier Capitalism: The Chartered Trading Companies as Modern

Multinationals. The Business History Review 62 (3): 398-419.

1990 Agency Problems in Early Chartered Companies: The Case of the Hudson's Bay Company. The Journal of Economic History 50(4): 853-875.

Caywood, Louis R.

1955 Final Report: Fort Vancouver Excavations. National Park Service, San Francisco, CA.

Chance, David H. and Jennifer V. Chance

1976 Kanaka Village/Vancouver Barracks, 1974. Office of Public Archaeology, University of Washington, Seattle, WA.

Chapman, Judith Sanders

1993 French Prairie Ceramics: The Harriet D. Munnick Archaeological Collection circa 1820-1860, a Catalog and Comparative Guide. Anthropology Northwest, No 8, Department of Anthropology, Oregon State University, Corvallis, OR.

Childe, V. Gordon

1944 Archaeological Ages as Technological Stages. The Journal of the Royal Anthropological Institute of Great Britain and Ireland 74(1/2): 7-24.

1946 Archaeology and Anthropology. Southwestern Journal of Anthropology 2(3): 243-251. 
Cromwell, Robert J.

2002 Results of an Archaeological Survey of the Fort Vancouver Village Site, 2001.

National Park Service. On file at Fort Vancouver National Historic Site, Vancouver, WA.

2006 "Where Ornament and Function are so Agreeably Combined": Consumer Choice Studies of English Ceramic Wares at Hudson's Bay Company Fort Vancouver. Doctoral dissertation, Department of Anthropology, State University of New York at Syracuse, Syracuse, NY.

Deetz, James

1977 In Small Things Forgotten. Doubleday, Garden City, NJ.

Diamond, Stanley

1974 In Search of the Primitive: a Critique of Civilization. Transaction Books, New York, NY.

Dorset, Elaine C.

2012 A Historical and Archaeological Study of the Nineteenth Century Hudson's Bay Company Garden at Fort Vancouver: Focusing on Archaeological Field Methods and Microbotanical Analysis. Master's thesis, Department of Anthropology, Portland State University, Portland, OR.

Engels, Friederich and Eleanor Burke Leacock

1972 The Origin of the Family, Private Property and the State. International Publishers, New York, NY.

Ens, Gerhard J.

1996 Homeland to Hinterland: The Changing Worlds of the Red River Metis in the Nineteenth Century. University of Toronto Press, Toronto, ON.

Farnham, Thomas J.

1843 Travels in the Great Western Prairies: The Anahuac and Rocky Mountains and in the Oregon Territory. Greely and McElrath, New York, NY.

Foucault, Michel

1973 The Order of Things: An Archaeology of the Human Sciences. Vintage Books, New York, NY.

1979 Discipline and Punish. Vintage Books, New York, NY. 
Gay, Theressa

1936 Life and Letters of Mrs. Jason Lee, First Wife of Rev. Jason Lee of the Oregon Mission. Metropolitan Press, Portland, OR.

Gembala, Danielle D.M., Robert J. Cromwell and Douglas C. Wilson 2004 Results of the Systemwide Archaeological Inventory Project Excavations in the HBC Village Site (45CL300) Fort Vancouver National Historic Site 2001-2003. National Park Service, Vancouver, WA.

Galbraith, John S.

1957 The Hudson's Bay Company as an Imperial Factor. University of California Press, Berkeley, CA.

Goldring, Philip

1979 Papers on the Labour System of the Hudson's Bay Company, 1821-1900, Volume I. Parks Canada Manuscript Report No. 362.

1980 Papers on the Labour System of the Hudson's Bay Company, 1821-1900. Volume II. Parks Canada Manuscript Report No. 412.

Hamilton, Jennifer F.A.

1982 Ceramics Destined for York Factory: An Examination of Hudson's Bay Company Archival Sources. Ceramics in Canada. Parks Canada Material History Bulletin, No. 16.

Hamilton, Scott

2000 Dynamics of Social Complexity in Early Nineteenth-Century British Fur-Trade

Posts. International Journal of Historical Archaeology 4(3): 217-270.

Hammond, Lorne

1993 Marketing Wildlife: The Hudson's Bay Company and the Pacific Northwest, 1821-1849. Forest and Conservation History 37(1): 14-25.

Hoffman, J.J. and Lester A. Ross

1972a Fort Vancouver Excavations- I. Report to National Park Service, Fort Vancouver National Historic Site, Vancouver, WA.

1972b Fort Vancouver Excavations- II. Report to National Park Service, Fort Vancouver National Historic Site, Vancouver, WA.

1973a Fort Vancouver Excavations- III, 1845 Harness Shop. Report to National Park Service, Fort Vancouver National Historic Site, Vancouver, WA. 
1973b Fort Vancouver Excavations- IV, Chief Factor's House. Report to National Park Service, Fort Vancouver National Historic Site, Vancouver, WA.

1973c Fort Vancouver Excavations- V, Flagstaff and Belfry. Report to National Park Service, Fort Vancouver National Historic Site, Vancouver, WA.

1974a Fort Vancouver Excavations- VI, Sales Shop and Powder Magazine. Report to National Park Service, Fort Vancouver National Historic Site, Vancouver, WA.

1974b Fort Vancouver Excavations- VII, Northwest Bastion and Stockade System.

Report to National Park Service, Fort Vancouver National Historic Site, Vancouver, WA.

1974c Fort Vancouver Excavations- VIII, Fur Store. Report to National Park Service, Fort Vancouver National Historic Site, Vancouver, WA.

1975 Fort Vancouver Excavations- IX, Indian Trade Store. Report to National Park Service, Fort Vancouver National Historic Site, Vancouver, WA.

Hudson's Bay Company Archives (HBCA)

1670 Text of Royal Charter. Accessed online at

http://www.hbcheritage.ca/hbcheritage/collections/archival/charter/charter.asp.

1815 London Committee to Robert Semple, May 31st, 1815, 312-314. A.6/18. Hudson's Bay Company Archives, Winnipeg. On file at Fort Vancouver National Historic Site, Vancouver, WA.

1845 Columbia Outfit 1845. HBCA B.223/d/162. Hudson's Bay Company Archives, Winnipeg. On file at Fort Vancouver National Historic Site, Vancouver, WA.

1852 Invoice of Sundry Goods property of the Honourable Hudson's Bay Company Supplied Vancouver Sale Shop from Vancouver Depot, on Account of Outfit 1852 Viz. B.223/d/205 fo. 4-17. Hudson's Bay Company Archives, Winnipeg. On file at Fort Vancouver National Historic Site, Vancouver, WA.

Hussey, John A. 1957 The History of Fort Vancouver and its Physical Structure. Washington State Historical Society. Abbot, Kerns and Bell Co., Portland, OR.

Jameson, Robert 
1987 Purity and Power at the Victorian Dinner Party. In The Archaeology of Contextual Meanings. Ian Hodder, editor, pp. 55-67. University of Cambridge Press, Cambridge, UK.

Kardas, Susan

19701969 Excavations at Kanaka Village Site, Fort Vancouver, Washington. Report to National Park Service, Report to National Park Service, San Francisco, CA.

1971 "The People Bought this and the Clatsop Became Rich": A View of Nineteenth Century Fur Trade Relationships on the Lower Columbia between Chinookan Speakers, Whites and Kanakas. Doctoral dissertation, Department of Anthropology, Bryn Mawr College, Philadelphia, PA.

Kintigh, Keith

1984 Measuring Archaeological Diversity by Comparison with Simulated Assemblages. American Antiquity 49(10): 44-54.

1989 Sample Size, Significance and Measures of Diversity. In Quantifying Diversity in Archaeology, Robert D. Leonard and George T. Jones, editors, pp. 25-36. Cambridge University Press, Cambridge, UK.

2006 Tools for Quantitative Archaeology: Programs in Quantitative Analysis in Archaeology. Self-Published.

Larrabee, Edward McM. And Susan Kardas

1968 Exploratory Excavations for the Kanaka Village Fort Vancouver National Historic Site, Vancouver, Washington. Vancouver, WA.

Leacock, Eleanor Burke

1981 The Myth of Male Dominance: Collected Articles on Women Cross-Culturally. Monthly Review Press, New York, NY.

Leone, Mark P.

1977 Contemporary Archaeology: A Guide to Theory and Contributions. Southern Illinois University Press, Carbondale, IL.

1981 Archaeology's Relationship to the Present and the Past. Academic Press, New York, NY.

1982 Some Opinions about Recovering Mind. American Antiquity 47(4): 742-760. 
1984 Interpreting Ideology in Historical Archaeology: Using the Rules of Perspective in the William Paca Garden in Annapolis, Maryland. In Ideology, Power and Prehistory, Daniel Miller and Christopher Tilley, editors, pp. 25-36. Cambridge University Press, Cambridge, UK.

1987 Rule by Ostentation: The Relationship between Space and Sight in EighteenthCentury Landscape Architecture in the Chesapeake Region of Maryland. In Method and Theory for Activity Area Research: An Ethnoarchaeological Approach, ed. Susan Kent, 604-633. New York: Columbia University Press.

1988 The Georgian Order as the Order of Merchant Capitalism in Annapolis, Maryland. In Recovery of Meaning: Historical Archaeology in the Eastern United States, ed. M.P. Leone and Parker B. Potter Jr., 235-261. Washington D.C.: Smithsonian Institution Press.

1994 The Archaeology of Ideology: Archaeological Work in Annapolis since 1981. In Historical Archaeology of the Chesapeake, Paul A. Shackel and Barbara J. Little, editors, pp. 219-230. Smithsonian Institution Press, Washington, DC.

1999 Ceramics from Annapolis, Maryland: A Measure of Time Routines and Work Discipline. In Historic Archaeologies of Capitalism, Mark P. Leone and Parker B, Potter Jr., editors, pp. 195-216. Kluwer Academic/Plenum Publishers, New York, NY. 2005 The Archaeology of Liberty in an American Capital: Excavations in Annapolis. University of California Press, Berkeley, CA.

Leone, Mark P., Julie P. Ernstein, Elizabeth Kryder-Reid and Paul A. Shackel 1989 Power Gardens of Annapolis. Archaeology 42 (2): 34-37, 74-75.

Leone, Mark P., James M. Harmon, and Jessica L. Neuwirth

2005 Perspective and Surveillance in Eighteenth-Century Maryland Gardens, Including William Paca's on Wye Island. Historical Archaeology 39(4): 131-150.

Leone, Mark P., Elizabeth Kryder-Reid and Janice Bailey-Goldschmidt 1992 The Rationalization of Sound in Mid-18th Century Annapolis, Maryland. In The Art and Mystery of Historical Archaeology: Essays in Honor of James Deetz. Anne Elizabeth Yentsch and Mary C. Beaudry editors, pp. 229-245. CRC Press, Boca Raton, FL.

Leone, Mark P., Parker B. Potter, Jr. and Paul Shackel 1987 Toward a Critical Archaeology. Current Anthropology 28(3): 283-302.

Lightfoot, Kent 
2006 Missions, Furs, Gold and Manifest Destiny: Rethinking an Archaeology of Colonialism for Western North America. In Historical Archaeology. Martin Hall and Stephen W. Siliman editors, pp. 272-292.

Loudon, John Claudius

1824 An Encyclopedia of Gardening: Comprising the Theory and Practice of Horticulture, Floriculture, Arboriculture, and Landscape-gardening, Including all the Latest Improvements; a General History of Gardening in all Countries; and a Statistical View of its Present State; with Suggestions for its Future Progress in the British Isles, Vol. 1. London: Longman, Hurst, Rees, Orme, Brown and Green, London, UK.

MacKay, Douglas

1938 The Honourable Company: a History of the Hudson's Bay Company. Tudor Publishing Company, New York, NY.

Mackie, Richard Somerset

1997 Trading Beyond the Mountains: The Fur Trade on the Pacific, 1793-1843.

University of British Columbia Press, Vancouver, BC.

Marx, Karl

1970 Wage, Labor and Capital. Progress Publishers, Moscow, Russia.

1867 Capital: Critique of Political Economy. Volume I, Book One: The Process of Production of Capital. Samuel Moore, Edward B Aveling, translator. Reprinted 1970, Progress Publishers, Moscow, Russia.

Marx, Karl and Frederich Engels

1848 The Communist Manifesto. Reprinted in 1964, Monthly Review Press, New York, NY.

McGuire, Randall H.

1988 Dialogues with the Dead. In Recovery of Meaning: Historical Archaeology in the Eastern United States. Smithsonian Institution Press, Washington, D.C.

1992 A Marxist Archaeology. Academic Press, Inc., San Diego, CA.

1993 Archaeology and Marxism. Archaeological Method and Theory 5: 101-157.

2006 Marxism and Capitalism in Historical Archaeology. In The Cambridge Companion to Historical Archaeology, pp. 123-142.Cambridge University Press, Boston, MA

McKie, James Melvin 
1981 Selected Structures of the Hudson's Bay Company: a Functional Assessment. Master's thesis, University of Idaho, Boise, ID.

McLoughlin, John

1943 The Letters of John McLoughlin Written at Fort Vancouver 1829-1832. Burt Brown Baker, editor, Portland, OR.

Miller, George

1980 Classification and Economic Scaling of $19^{\text {th }}$ Century Ceramics. Historic

Archaeology 14:1-41.

1991 A revised Set of CC Index Values for Classification and Economic Scaling of English Ceramics from 1787 to 1880. Historical Archaeology 25(1): 1-25.

Monks, Gregory G.

1992 Architectural Symbolism and Non-Verbal Communication at Upper Fort Garry. Historical Archaeology 26: 199-222.

Morrison, Dorothy Nafus

1999 Outpost: John McLoughlin and the Far Northwest. Oregon Historical Society Press, Portland, OR.

Mullaley, Meredith J.

2011 Rebuilding the Architectural History of the Fort Vancouver Village. Master's thesis, Department of Anthropology, Portland State University, Portland, OR.

Nash. Manning

1979 Modernization as a Problem: An Anthropological View. Central Issues in Anthropology 1(1): 69-77.

Nelson, Peter

2007 Power and Place: the Dynamics of Non-Verbal Communication in the Human Landscape at Fort Vancouver. Undergraduate thesis, Department of Anthropology, University of Washington, Vancouver, WA.

Patterson, Thomas C.

2003 Marx's Ghost: Conversations with Archaeologists. Berg Publishing, Oxford, UK.

Paynter, Robert

1988 Steps to an Archaeology of Capitalism: Material Change and Class Analysis. In

Recovery of Meaning: Historical Archaeology in the Eastern United States. pp. 407-433.

Smithsonian Institution Press, Washington, D.C

Pearson, Michael Parker 
1984 Social Change, Ideology and the Archaeological Record. In Marxist Perspectives in Archaeology, Matthew Spriggs editor, pp. 59-72. Cambridge University Press.

Cambridge, UK.

Pittman, Anna Maria

1837 Letter to her Sisters and Brothers. In Life and Letters of Mrs. Jason Lee, Theressa Gay author, pp. 150-155. Metropolitan Press Publishers. Portland, OR.

Pollard, Juliet T.

1990 The Making of the Métis in the Pacific Northwest, Fur Trade Children: Race, Class and Gender. Doctoral dissertation, Department of Social and Educational Studies, University of British Columbia at Vancouver, BC.

Rich, E.E.

1959 The History of the Hudson's Bay Company: 1670-1870, II. The Hudson's Bay Record Society, London, UK.

Ross, Lester A.

1976 Fort Vancouver 1829-1860: A Historical Archaeological Investigation of the Goods Imported and Manufactured by the Hudson's Bay Company. National Park Service, Washington DC.

Ross, Lester

1976 Fort Vancouver Archaeological Report 1829-1860. National Park Service, Fort Vancouver National Historic Site, Vancouver, WA.

Ross, Lester A., Bryn H. Thomas, Charles H. Hibbs and Caroline D. Carley 1975 Fort Vancouver Excavations- X, Southeast Fort Area. Report to National Park Service, Fort Vancouver National Historic Site, Vancouver, WA.

Rupert's Land Northern Department Council

1828 Minutes of Council, Northern Department of Rupert's Land 1821-1831. R.

Harvey Fleming and E.E. Rich, editors. Reprinted 1940. Champlain Society, Toronto, ON.

Schenk, John Frederick

1932 The Hudson's Bay Company in Oregon, 1821-1860. Master's thesis, University of Oregon, Eugene, OR.

Schiffer, Michael B. 
1983 Toward the Identification of Formation Processes. American Antiquity. 48(4):675706.

Shackel, Paul A.

1993 Personal Discipline and Material Culture: An Archaeology of Annapolis, Maryland 1695-1870. University of Tennessee Press, Knoxville, TN.

1994 Town Plans and Everyday Material Culture: An Archaeology of Social Relations in Colonial Maryland's Capital Cities. In Historical Archaeology of the Chesapeake. Paul A. Shackel and Barbara J. Little editors, pp. 85-96. Smithsonian Institution Press, Washington, DC and London, UK.

Stone, Helen Delight

2010 Culture Contact and Gender in the Hudson's Bay Company of the Lower Columbia River, 1824-1860. PhD. Dissertation, Department of Archaeology and Ancient History, University of Leicester, Leicester, UK.

Sussman, Lynne

1978 A Preliminary Catalogue of Non-Copeland Patterns Associated with the Hudson's Bay Company. Parks Canada, Manuscript Report No. 430, Quebec.

1979 Spode/Copeland Transfer-printed Patterns Found at Twenty Hudson's Bay Company Sites. Canadian Historic Sites: Papers in Archaeology and History. No.22, Quebec.

2000 Objects vs. Sherds: A Statistical Evaluation. Studies in Material Culture Research, The Society for Historical Archaeology 2000: 96-103.

Thomas, Bryn and Charles Hibbs Jr.

1984 Report of Investigations of Excavations at Kanaka Village/Vancouver Barracks, Washington, 1980/1981. Washington State Department of Transportation, Seattle. On file at Fort Vancouver National Historic Site, Vancouver, WA.

Trigger, Bruce $\mathrm{G}$.

1993 Marxism in Contemporary Western Archaeology. Archaeological Method and Theory 5: 159-200.

2006 A History of Archaeological Thought. Cambridge University Press, Cambridge, UK. 
Voss, Barbara and Rebecca Allen

2010 Guide to Ceramic MNV Calculation Qualitative and Quantitative Analysis.

Technical Briefs in Historic Archaeology 5: 1-9.

Williams, Glyndwr

1970 The Hudson's Bay Company and Its Critics in the Early Eighteenth Century. Transactions of the Royal Historical Society, Fifth Series, Vol. 20: 149-171.

Wilkes, Charles

1856 Narrative of the United States Exploring Expedition during the Years 1838, 1839, 1840, 1841, 1842. 5 vols. G. P. Putnam and Company, New York, NY.

Whitman, Narcissa Prentiss

1982 My Journal, 1836. Lawrence Dodd, editor, Ye Galleon Press, Fairfield, WA.

Wilson, Douglas, Robert Cromwell, Danielle Gembala, Theresa Langford, and Debra Semrau

2003 Archaeology Lab Manual. On File at Fort Vancouver National Historic Site.

http://www.nps.gov/fova/historyculture/upload/Archaeology\%20Lab\%20Manual\%20200 3.pdf

Wolf, Eric

1982 Europe and the People without History. University of California Press, Berkeley, CA.

Wolf, Eric and Sidel Siverman 2001 Pathways of Power: Building an Anthropology of the Modern World. University of California Press, Berkeley, CA. 